Elsevier Editorial System(tm) for

Palaeogeography, Palaeoclimatology, Palaeoecology

Manuscript Draft

Manuscript Number: PALAEO9713R2

Title: LOESS CORRELATIONS - BETWEEN MYTH AND REALITY

Article Type: SI: 13_Eurasian Loess records

Keywords: : correlations, loess-paleosol sequences, Northern Hemisphere, Pleistocene

Corresponding Author: Professor Slobodan B Markovic, Ph.D.

Corresponding Author's Institution: Faculty of Sciences, University of Novi Sad

First Author: Slobodan Markovic

Order of Authors: Slobodan Markovic; Thomas Stevens; Jef Vandenberghe; Shiling Yang; Dan Veres; Joseph Mason; Gabor Ujvari; Alida Timar-Gabor; Christian Zeeden; Zhengtang Guo; Qingzhen Hao; Igor Obreht; Ulrich Hambach; Haibin Wu; MIlivoj B Gavrilov; Christian Rolf; Nemanja Tomic; Frank Lehmkuhl

Abstract: Loess correlations are one of the most common research topics in global loess research. In spite of significant progress in the development from speculative to quantitative research methods, even in some recent investigations application of loess correlations is still in many aspects too speculative. The aim of this overview is to provide an adequate frame for evaluation of accuracy of the loess correlations applied on different temporal and spatial scales. This opens up possibilities for detailed temporal and spatial environmental reconstructions across the huge loess provinces of the Eurasia and Northern America. In this study, we additionally evaluated the potential development of appropriate sub-millennial scale loess correlations, as well as essentially important chronological approaches for establishing valid correlations of different loess records, such as current improvements in tephrochronology, 14C and luminescence dating techniques. 


\section{COMMENTS TO EDITOR AND REVIEWERS}

\section{Dear Paul,}

Thanks a lot for your support! I agree that both reviewers are quite critical of the paper. We are grateful for their constructive comments. Following these suggestions we invested a lot of time and energy to significantly improve the manuscript. However, our impression is that both reviewers did not understand the main messages of this review article. This is why we did not completely accept all reviewer comments. We offered an explanation for the three main problems mentioned in your summary after reviewer's comments and we have tried to clarify the manuscript so the key messages are better presented.

1. Our co-authors Joseph Mason and Thomas Stevens corrected the English of the revised manuscript. I am still not happy with the English and have made numerous corrections.

2. Please see our detailed comments to the comments of both reviewers. We have accepted and changed the majority of suggested changes. However, for some of the suggestions we kept to our previous statements or partly modified our initial explanations, simply because some of the comments are not correct. In all of these cases we provided detailed explanations. All of these answers, changes, explanations and improvements are indicated in red colored letters after each comment of the reviewers. Additionally, we have also provided the previously submitted manuscript with track changes.

3. We agree that both reviewers have some reservations about the apparent lack of a new understanding and new data. The aim of our study was not the overview of all papers related to loess correlation problems. This opinion pushed reviewers to express in some cases unnecessary and unfounded criticism. The main purpose of our manuscript is a critical evaluation of loess correlations related to different temporal and spatial scales. These observations are new and can be very helpful for younger researchers to avoid many potential problems in their further investigations. 
Reviewer 1 has several times mentioned the Europocentric character of this review article. Northern American loess has been less intensively discussed

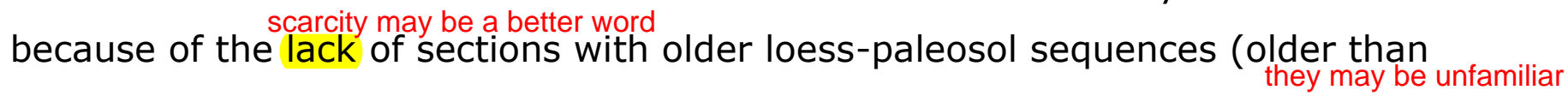
last glacial/interglacial cycle) and complicated nomenclatures of loess to you but they are no

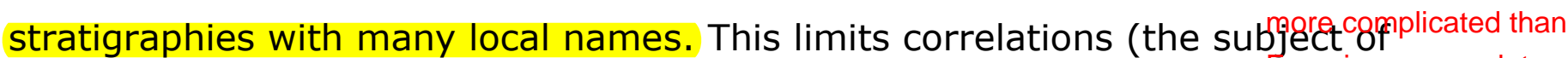
the submission). Further, if we analyze the quantity of loess papers, werofane! see that the absolute majority of papers are related to investigations of Asian and European loess provinces, contrasting with a much smaller amount of

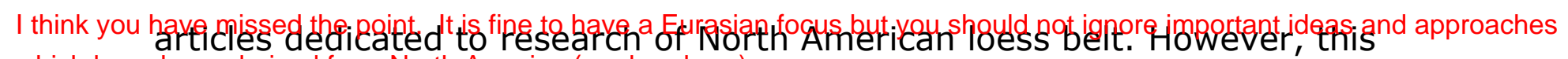
which have been derived from North America (or elsewhere).

statement does not diminish the great potential of Northern American loess for successful forthcoming research, nor the importance of the research previously undertaken on these archives. Additionally, we evaluated potential methodological improvements for providing more accurate loess correlations. In this case, we proposed a focus towards highly resolved loess sections (able to represent sub-millennial environmental and climatic dynamics) in forthcoming studies. Both reviewers suggested excluding the complete luminescence dating chapter. We decided to include a new section about a more intensive use of advanced radiocarbon methods and also to include a significantly redefined chapter related to luminescence dating that focusses on age extension of the technique for middle Pleistocene loess correlations (for details please see following answers to specific points of reviewers). We also mentioned great potential of tephrochronology as well as evidence of relative this is still variable: remove the basic description of techniques and focus on developments/improvements paleointensity of Earth's magnetic field preserved in loess records to improve validity of loess correlations. Application of these proposed stratigraphic tools as a new standard in future loess research has great potential for avoiding existing limitations recognized in current correlations between different loess records. This proposed, more robust methodological approach will also have a great stratigraphic significance in forthcoming studies providing a more accurate background for valid correlations of loess and other important paleoclimatic records.

We would highly appreciate if an additional reviewer could give an opinion about the quality of this improved version of our manuscript. In spite of 
substantially justified criticism of the reviewers, we strongly believe in the generally high importance of this review article, as a potential milestone paper. I have decided to review the paper carefully myself - I have no position or reputation to preserve!

Additionally, this review article is completely independent from the Editorial for our P3 loess special issue. The team of guest editors: Joe Mason, Shiling Yang and myself have to prepare an Editorial for this special issue. This Editorial will highlight the main topics of this thematic collection of papers as well as emphasize the importance of the individual contributions presented in the special issue.

Novi Sad, June 7, 2017

Best regards

On behalf of co-authors team

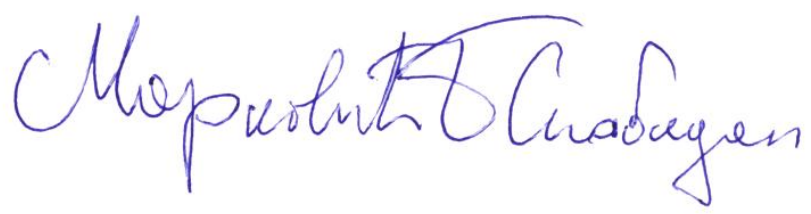

Slobodan B. Marković 
Reviewer \#1

Specific comments are as follows, key to line numbers:

--29-30-31: "...application of loess correlations is still overestimated..." and "...adequate evaluation of accuracy of the loess correlations application...": rephrase, please. I do not understand what is being said here. These are good examples of things the English speaking authors need to fix. We have improved the problematic part of the text. Lines 30-31;

I have suggested a further clarification of this sentence (which is

--33: "Northern Hemispheric continents": you mean North America and too long and Eurasia? Northern Hemispheric continents is replaced with Eurasia and confusing) Northern America; Line 34

--54: "close to major river systems": most of them ARE near major river systems - close to is replaced with most of them are near; Line 54

--57: what does "inter-profile" mean? We deleted inter-; Line 57

--60: you need to state what MIS means - We added Marine Isotope Stages;

Line 60

--65: what are "existing chronostratigraphic models"? We deleted chrono; Line 65

--68-69: this statement could be debated; lake sediments are also widespread terrestrial paleoclimate archives, as are glacial deposits, as are soils. Rephrase as "one of the most widespread..." Thanks. We rephrased this as one of the most widespread; Line 68

--76: what is "stratigraphic" in parentheses after "paleoclimatic" as if it means the same thing? It does not. It was a mistake that we deleted (statigraphic); Lines $79-80$

--77-79: this is a completely Eurocentric review of early loess research, ignoring all the contributions from North American researchers. Early (1930's, 1940 's, 1950's, 1960's) contributions on loess research were made in North America by Simonson, Torp, Péwé, Frye, Ruhe and many others-why are these not cited? Thanks. We cited articles of Shimek, 1902, 1909; Thorp and Smith, 1952; Simonson and Hutton, 1954 and Ruhe 1956, 1969; Lines 82-83 
--90: you may not cite a paper until it is at least in press - We deleted this unaccepted reference; Line 94

--96-101: again, Eurocentric, with no credit given to North American researchers - We have to say that the approach of Kukla and co-workers is at least one the most important moments in global loess research history. Thus, this is not an Europocentric statement and we did not ignore the contribution of North American scholars;

--102: why "re-opening"? We changed the sentence... "The development of magnetostratigraphic techniques opened the loess community in China to collaboration with international scholars and completely shifted global scientific interest towards the Chinese multiple loess-paleosol couplets..."; Lines 106109

--109-111: this is not correct. In Siberia (as in Alaska), higher MS is found in This unaltered loess and lower MS is found in paleosols. See Chlachula (2003), significantly weakens your QSR, and other papers of his. For Alaska, see papers by Beget and co-workers attempt and (1989, in Nature and 1990, in Geology) - Of course, we know about the claim to provide a

"inverse" magnetic signal observed in Siberian and Alaskan LPS. However, this Erovide a problem is out of the scope of our review paper. Currently, the application of magnetostratigraphic approach to Siberian and Alaskan LPS is much more limited than in the case of temperate Eurasian and Middle North American loess belt. Lines 118-120

review. Not only Alaska and Siberia but parts of China show this pattern. --112: same comment as above: you CANNOT correlate over long distances in(see Liu et al. Eurasia because Siberia shows MS trends that are exactly opposite that of Europe and China. We do not agree with this statement of the reviewer Aust J Soil Res. 2001). You are because a huge Central Asian loess belt exists between Europe and China, as excluding large and well as Iranian loess provinces. The Central Asian and Iranian LPS have similarimportant pedostratigraphic and magnetostratigrapic properties.

loess areas.

--113-114: delete the word "absolute" from your vocabulary; the word you want here is "numerical." Also luminescence is not a "radiometric" technique because it is not based on the measurement of a daughter isotope to a parent isotope to get an age. Thanks. We changed it to numerical isotope; Line 125 --121: "physic-chemical" is not a word. The entire sentence has been rephrased; Line 131-132 
- -126: the estimate of $10 \%$ of the land surface covered by loess did not come from Smalley et al. (2011), so this is an incorrect citation. I suspect the original estimate probably came from Pesci (1968, Encyclopedia of Geomorphology, edited by Rhodes Fairbridge). Note that Ken Pye (1987, Aeolian Dust and Dust Deposits, who strangely is not cited anywhere in this paper) points out that the figure for primary loess is probably

Change it to $5-10 \%$ to accommodate the value given in your other citation (Pye). closer to 5\%. We cited Pye, 1987 and replaced Smalley et al., 2011 with Pecsi, 1990, according to Pecsi, 1990 loess and loess-like deposits cover $10 \%$ of the land surface; Line 137

--127-128: what are "geomorphological units"? Landforms? We replaced geomorphological units with landforms; Line 138

--145-146: please define what is meant by "typical loess. We define typical loess as "Typical loess is in situ accumulated aeolian dust transformed by

I have commented below that this is an unhelpful definition unless you post depositional influences (Sprafke and Obreht, 2016)"; Lines 155-159 --147-148: I have no idea what this means: please rephrase This sentence is rephrased; Lines 157-159

--149: what is meant by "lithostratigraphic correlations" in the context of loess? What properties of loess are the basis of such correlations? Litostrathigraphic changes over every loess profile are a base for proper interprofile correlation. The most important are successions of fossil soils and loess layers;

--158, 165: misspelled words - We improved it; Lines 168-175

--166: "even grain size variations": this is written as if it were a surprise that paleosols in loess have grain size variations. One of the main expressions of paleosols in loess in most environments is that soils develop textural Bt horizons, clay-enriched zones, that have higher clay abundances than the parent loess. Why is this being stated as an unexpected observation? Thanks we completely agree with this statement. We deleted the word even; Line 177 --171-172: rephrase: vegetation cover as an influence on soil moisture is NOT the main control of vegetation on how soil morphology develops. The effect of vegetation is much more complex and varies tremendously with geography: under boreal forest, Spodosols can develop; under mixed deciduous forest, 
Alfisols develop; under grassland, Mollisols develop; under desert scrub, Aridisols develop. We agree with the observation that vegetation cover is not the main control of vegetation on how soil morphology develops. However, in the sentence "For instance, TOPOGRAPHY and vegetation cover may drastically influence soil moisture conditions and thus lead to highly diversified soil morphology." we used the word TOPOGRAPHY to mention the crucial role of local relief conditions. Thus, we do not see reason to change this sentence; --172: rephrase: this is a value judgment as to whether this is the "most illustrative" example of soil variability - We deleted most; Line 183 --180: "similar" to what? Similarity between LPS formed during MIS 4-3-2 in Serbian section Ruma and NE Tibetan Plateau and nearby regions in central Asia;

--183-185: please rephrase: I have no idea what is being said here - We rephrased it; Lines 193-196

--186-188: if there was only a slight grain size difference, how did you know what was glacial and what was interglacial? All other properties such as lithostratigraphy, sediment color, magnetic susceptibility indicate this statement;

--191: this is not correct for at least some parts of Europe. Antoine and Rousseau take pains to show that the Nussloch section had discontinuous loessEurope' to deposition because of the presence of paleosols that they interpret as "tundra gleys". Thanks. We added an example from Western Europe loess province and cited Antoine et al. 2001 and 2013; Line 204

--193: I suspect the authors mean Bettis et al., 2003, not 2013. If so, then it is not correct that Bettis et al. said this. Thanks. We replaced 2013 with 2003;

You need to add 'western the sentence othwerwise it appears that Antoine's paper deals with $\mathrm{N}$ America. Line 204-205 You have missed the point: The reviewer says that Bettis did NOT say this. You need a different --210: pollen assemblages are considered a "lithostratigraphic correlation" property? This is the first I have ever heard of this. Furthermore, pollen is The problem here is not rarely preserved in loess, so was is this said to be a property used "often"? W agree with this statement, we deleted pollen assemblages; Line 222

--211: please define what you mean by "thresholds" here. - Environmental threshold represents critical value when some environmental factor 'pollen' but 'litho-': MS or isotopes are also not lithostratigraphi c properties. significantly changes its influence to general environmental conditions; 
--214: please define what you mean by "marginal conditions" here. We rephrased this sentence; Lines 223-226

--215: "wiggle matching of proxies" is a phrase that has no place in science... that refers to a very unfortunate tendency for a very subjective interpretation of time-series data and is an embarrassment to the scientific community. Please delete this. Thanks. We did it; Lines 226-227

--218: why is this obvious? For example, after each fluvial action previous vegetation is disturbed and these conditions favor the development of new better adopted vegetation cover;

--219-221: I don't understand what is being said here at all. - We rephrased these sentences; Lines 230-236

--221-225: please rephrase all this: this makes no sense. - We rephrased it; Lines 237-242

--226-228: this needs rephrasing, too: I don't understand what is being said here. - We rephrased it; Lines 237-242

--232-244: how about citing some studies on methods of identifying loess sources? There are many excellent studies of identifying loess sources in the Chinese Loess Plateau and none of them are even briefly alluded to here: Chen et al. (2007, Geochimica et Cosmochimica Acta); Sun (2002, Earth and Planetary Science Letters), etc., etc. There has also been a fair amount of work on loess sources in North America, too. Thanks, we cited papers of Sun et al., 2002; Chen et al., 2007 and Muchs et al, 2008; Lines 244-245

--246-247: this is a self-obvious statement that can be deleted. We did it.

--247: what does "age information is scale dependent" mean? We rephrased it to ... may be supported when they have the same age; Line 259-260

--251: what does "terrestrially defined" mean? We changed it to defined based alternative on investigation of terrestrial environmental records; Lines 261-262

--254: link between what? We changed link with correlation point; Line 265 --260-267: all of this has been said earlier in the paper - We deleted ... although current research has provided significant progress in inter-profile correlation and direct comparison of different palaeoclimatic records; Line 279 --283-287: the Great Plains region is not representative of all of North America's loess. East of the Missouri River, the Holocene was characterized 
primarily by soil development with little or no additional loess deposition, just as is the case in Europe. Thanks we included this statement; Line 300-301 --321-324: I don't believe this statement is correct. Chinese loess goes back into the Miocene and I don't think "middle Eurasian" loess goes back that far. The middle Asian loess is not as old as Chinese loess, however it at least covers the complete Quaternary and in some places late Pliocene. Thus, the thickness and completeness of middle Asian loess is not questionable.

--325: this is written in sort of a self-congratulatory manner, so I would rephrase this. We deleted oldest; Line 333

--331-333: magnetic susceptibility does not DATE anything; this figure shows, at best, a possible correlation. Thanks;

--337-340: this is an outrageous claim, to say that the Serbian/Chinese loess records in this figure are "stronger" than the marine record. These records that are presented are not even (apparently) independently dated: where are the ages? Please recall also that in the obsession in the loess community with MS, we need to keep in mind that this property is measuring a distinct minority of your sentence loess minerals. Our text does not have any relation to obsession, we just indicate the remarkable similarity between these two distant loess magnetic records;

--349-351: the Danube Basin does not have a distinctive dry season whereas there is a very distinctive dry winter season in China. How can you say the needs to be modified accordingly (i.e. mention that it is an loess records are responding to similar dry seasons? Please see the paper by Hrnjak et al. 2014 published in Theoretical and Applied Climatology journal. This paper analyzed aridity in the northern Serbian province of Vojvodina and indicates frequent appearance of dry season especially during the summer months;

--357-358: you need to cite references for this statement - We cited Marković et al., 2012a, 2015; Line 363, 371

--361-362: how can you know this without ages? Funny statement; The reviewer can read some other papers about this topic

--378-373: "orbital tuning" is circular reasoning - We do not understand this comment;

--389-392: what this says is that orbital tuning is an invalid approach - Of 
course orbital tuning is not an invalid approach. We just indicated differences on some calculated time series;

--406: what does "...a resampled set of phase-randomized surrogates" mean? meaning is stil We deleted ... significance versus the result from a resampled set of phaseunclear randomized surrogates; Line 415

--433: you mean Figure 7 here Thanks;

--440: "methodological approach" is redundant - We replaced methodological approach with relative geochronology; Line 447-450

--442: replace "absolute" with "numerical" - Thanks we did it; Line 452 --444-445: this statement contradicts the previous statement - Thanks, we rephrased it; Line 453

--450-451: this statement is incorrect. Multiple amino acids have been measured by gas chromatographic methods for more than 40 years. Thanks, we excluded words related to method novelty; Line 457

--452-455: the main use of amino acid racemization in loess studies is CORRELATION from one loess section to another - Yes, but we can also observe the gradients in AAR rates in wider regions due to differences in mean annual air temperatures for example. If we take in consideration we can nicely also correlate different sections inside this region;

--472-473: you have things turned around here: the first question to ask is this: is there any reason they OUGHT to be correlated? Are there common climate controls or forcings on both records? If so, what are they? Climate is base for correlation

--493: you mean Figure 8 here. Thanks; Line 501

--508: where did this come from? Cite references. We cited Seelos et al.,

The reviewer is really asking WHICH climate patterns/ features are likely to link the two areas, e.g. NAO...

2009; Line 520

--510-513: This statement is not true. It was known long before ELSA that Europe was dusty during the last glacial period. Thanks you are right, however ELSA record proves evidence of submillenial dust variability in Central Europe --517: what are C24 and C23? C24 and C23 are cold events recorded in the North Atlantic region after the last interglacial (MIS 5e) period (McManus et al.çlearly. 1994); Lines 525-526

--522-524: how do you know that they are "accurate"? We do not understand The reviewer is asking whether both records are independently and numerically dated?
You have missed the point: your sentence should include this new point
çlearly. 
this question;

--525: why is this appearing here now? You were talking about ELSA. Yes; explanation to --553: formation of a Bt horizon IS a post-depositional process. Thanks! We changed it. Lines 562

--568: see earlier comment about "wiggle matching" - Thanks we did the same like in the previous case; Line 589-590

--585-590: what is the correct spelling of this locality in China? - Correct is Mangshan not Mangshang;

--586-587: Roberts et al., 2003 and Muhs et al., 2013 are not in the references list - We added these references to the reference list;

The paragraph is a single

--588: why does this paragraph end here? What is the significance of this? We also added Asian loess sequences; Line 607 sentence and

does not make a clear

--596-599: so which is it? 3 times or 8 times? The values are different in loess point.

and in paleosol sequences

--636, section 6.2.1.: I am not sure this section is needed. There are plenty of review articles on luminescence dating and they do not need to be repeated here - We changed the chapter about luminescence chronology focusing just on improved methods related to dating of the Middle Pleistocene loess-paleosol sequences. During the last decade significant methodological improvements happened towards more accurate dating of the Middle Pleistocene loess deposits and these have not previously been reviewed, especially in a loess context. These advances are of huge relevance and potential for correlation of Middle Pleistocene loess sequences. Because of that, we strongly disagree with removing the luminescence chapter completely. Especially if we want to discuss about 'potential improvements' in terms of stratigraphy, then age extension of numerical dating is a major part of that. Contrary to what the reviewers say, this segment of application of luminescence dating has not been reviewed before. Additionally, we also added a chapter about advances in loess chronologies based on $\mathrm{C} 14$ dating. It is obvious that approaches in those two segments of loess dating have crucial importance for development of valid loess interprofile correlations.

--717-720: Give some evidence for why these ages are considered valid. What 
is the independent age control? - This is deleted;

--753-758: mass accumulation rates were reported for most of the world in the September 2003 issue of Quaternary Science Reviews; for China, see Kohfeld and Harrison (and the earlier study by Sun, which they draw many of their data from); for Europe, see Frechen et al., etc., etc. Why are none of these papers cited? We cited these papers. Lines 603

--809: if it lacks secure chemical data, how do you know it is the same from location to location? Position of tephra layer in same loess unit L4 and typical concentration of loess sections with this tephra layer indicates potential trajectory of volcanic ash cloud spreading;

--811-814: MIS 16 is NOT 400 ka! Thanks. This is MIS 12; Line 791

--851-853: Matsura, Preece, Davies, Toms et al. studies are not in the references list. We included these articles to the reference list;

--Figure 1: this map is completely out of date, for North America, Europe, and Asia. Why loess in Alaska only considered to be "loess-like"? Pecsi is the author of this map;

Some of this

For Europe, why use Pesci's 1990 map instead of the far more carefully done difficulty needs Haase et al. (2006, QSR) map (which Pesci contributed to)? Haase et al. mapacknowledged is more detailed, but complicated and inconsistent methodology caused manyin the paperproblematic interpretations. Based on the project of INQUA Loess commission you to many of national representatives submitted loess maps of their countries. Different methodological approaches used for preparation of national maps state that the map is known not to be accurate. caused many problems and further mistakes in final compiling of Haase et al. European loess map. Thus, for the purpose of having an overview of general loess distribution, Pecsi's map is the best solution up to now;

For China, why not use Liu's map instead of something done by a European who has not even worked there? Please see our answer to reviewer's previous comment;

--References: note absences of papers cited in the text, but not in the reference list.

The senior author lists his 2012 paper three times in the reference list. Thanks we solved it; 
Go through the whole paper and check everything, please. Thanks once more for a lot of invested energy and time as well as detailed and constructive criticism which will significantly contribute to the final quality of this paper.

Reviewer \#3:

Introduction and brief historical overview are ok. However, I do not accept to refer papers, which are only submitted (line 90). We excluded this reference. That was also suggested by reviewer \#1;

Line 126

A similar sentence can be found in Pécsi 1990 about the coverage of $10 \%$ of but see my comment Earth surface by loess. Smalley et al. 2011 is a self-citation! We replaced the above: 5-10\% reference Smalley et al., 2011 with Pecsi, 1990. That was also the suggestion of reviewer \#1; Line 137

Line 126 sedimentological - Thanks we changed the section title; Line 134

Line 321

Dodonov and Zhou 2008 did not work in the frozen zone in Siberia but in Central Asia; wrong citation. We added the reference Chalchula et al., 1998; Line 333

Line 325

Self and wrong citation Markovic et al. 2015; this was already clearly stated decades before by G. Kukla. This statement of the reviewer is completely wrong. George Kukla never correlated Serbian and Chinese loess. He correlated Austrian and Czechian and Chinese loess based on compared lithostratigraphy and position of main magnetostratigraphic shifts (e.g. Kukla and Cilek, 1996, P3); 
Line 325-334

Lot of spelling mistakes - Thanks. We improved it.

Line 353

In loess - Thanks, we added space between In and loess;

Line 435

Scales in - Thanks again, we added space between Scales and in;

Line 530-542

A correlation between loess or soil layers with GI's is not as precise as claimed. Radiocarbon and luminescence dating have its own set of problems and the error has to be taken into account. A more critical view would be helpful. - Our opinion is that we provided enough critical view. We have noted that there are limitations in age models that limit the correlation of loess/soil layers with GIs (lines 538-551).

Line $616-726$

I have no idea why this luminescence part is necessary. It looks like a copy and paste from other papers. I suggest to delete the whole chapter. Please see comments to reviewer 1 . We have redefined this in the context of dating and correlating Middle Pleistocene loess. This has not been reviewed and is essential to consider in a paper dealing with loess correlations. 


\section{LOESS CORRELATIONS - BETWEEN MYTH AND REALITY}

2 Slobodan B. Marković (1), Thomas Stevens (2), Jef Vandenberghe (3), Shiling Yang (4), Dan

3 Veres $(5,6)$, Joseph Mason (6ㄱ), Gabor Ujvari (8), Alida Timar-Gabor (5), Christian Zeeden

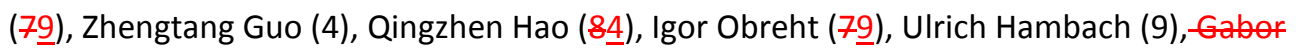
Ujvari (10), Haibin Wu (4), Milivoj B. Gavrilov (1), Christian Rolf (11), Nemanja Tomić (1), Frank Lehmkuhl (7무)

(1) Chair of Physical Geography, Faculty of Sciences, University of Novi Sad, Trg Dositeja Obradovića 3, 21000 Novi Sad, Serbia

(2) Department of Earth Sciences, Uppsala Universitet, Villavägen 16, 75236 Uppsala, Sweden

(3) Department of Earth Sciences, Vrije Universiteit, De Boelelaan 1085, 1081 HV Amsterdam, The Netherlands

(4) Key Laboratory of Cenozoic Geology and Environment, Institute of Geology and Geophysics, CAS, Beijing, China

(5) Faculty of Environmental Science, Babes-Bolyai University, Fantanele, 30, 400294 Cluj Napoca, Romania

(6) Romanian Academy, Institute of Speleology, Clinicilor 5, 400006 Clui-Napoca, Romania

(6ㄱ) Department of Geography, University of Wisconsin, Madison, 53706, United States

(8) Institute for Geological and Geochemical Research Research Centre for Astronomy and Earth Sciences, Hungarian Academy of Sciences H-9400 Sopron, Csatkai E. u. 6-8., Hungary

(79) Department of Geography, RWTH Aachen University, Templergraben 55, 52056 Aachen, Germany (810) BayCEER \& Lehrstuhl für Geomorphologie, Universität at Bayreuth, Universität atsstraße 30, 95440 Bayreuth, Germany

(10) Institute for Geological and Geochemical Research Research Centre for Astronomy and Earth Sciences, Hungarian Academy of Sciences H-9400 Sopron, Csatkai E. U. 6-8., Hungary

-(11) Leibniz Institute for Applied Geophysics (LIAG), Petrophysics and Borehole Geophysics, Stilleweg 2; D30655 Hannover, Germany 
Loess correlations are one of the most common research topics in global loess research. In spite of significant progress in the development from speculative to quantitative research methods, even in some recent investigations application of loess correlations is still in many aspects too speculative., even in some recent investigations application of loess correlations is still overestimated. The aim of this overview is to provide an adequate evaluation of accuracy of the loess correlations application on different temporal and spatial scales. This opens up possibilities for detailed temporal and spatial environmental reconstructions across the huge loess provinces of the-Eurasia and Northern America. Northern Hemispheric eontinents. In this study, we additionally evaluated the potential development of appropriate sub-millennial scale loess correlations, as well as essentially important chronological approaches for establishing valid correlations of different loess records, such

42 as current improvements in tephrochronology, ${ }^{14} \mathrm{C}$ and luminescence dating

techniquestuminescence dating techniques and tephrochronology.

Key words: correlations, loess-paleosol sequences, Northern Hemisphere, Pleistocene 


\section{INTRODUCTION}

Loess-palaeosol sequences are widespread and detailed paleoclimatic archives, especially common in the mid-latitudes of the Northern Hemisphere (e.g. Pécsi, 1990; Smalley et al., 2011, Figure 1). In most cases, these terrestrial sequences display common stratigraphic features useful in intersite correlations across wide regions, allowing for past environmental reconstruction at a continental scale (e.g. Marković et al., 2012a, 2015). However, contrary to the ice cores, deep-sea or lacustrine sediments that are characterized by more or less continuous sedimentation, loess-palaeosol sequences are more complex depositional systems with significantly different accumulation rates, more dynamic environmental thresholds and higher sensitivity to erosion (e.g. Stevens et al., 2006, 2008, 2011). In addition to recording global/hemispheric/regional climatic signals, loess-palaeosol sequences can also be influenced by the local conditions (e.g. Vandenberghe, 2012;

Vandenbeghe et al., 2014), particularly because most of them are near thenclose tomajor river systems. Understanding relationships between the widespread loess-palaeosol sequences in particular regions may provide insights into both local influences at particular locations and general regional climatic trends. Although ongoing research is yielding significant progress for inter-profile correlations and direct comparison of different palaeoclimatic records can sometimes be achieved, valid correlations on regional or even continental scale are still only possible on the first order level (i.e. at the level of Marine Isotope Stages (MIS), MIS-or glacial loess and interglacial pedocomplex units whose formation was driven by orbitally-paced changes in hydroclimate). However, rapid improvements in radiometric-dating techniques will result in a much better understanding of chronostratigraphic variations in loess sequences in the forthcoming years (e.g. Thiel et al., 2011; Murray et al., 2014). Refinement (following a well-established community-wide 
to be clear, you are proposing the aim or goals of this paper, not a past project/effort?

protocol) in the existing ehronostratigraphic models applied to loess-palaeosol sequences in Eurasia and generally, the whole Northern Hemisphere should open possibilities for more detailed temporal and spatial environmental reconstructions, particularly given the fact that loess is one ofby far the most widespread terrestrial paleoclimate archives. The establishment of such models is crucial for a better understanding of the last glacialinterglacial climatic and environmental evolution at the continental/hemispherical scale by constraining the specific local influences at particular sites and also by integrating the loesspalaeosol records within the larger grid of paleoclimate archives, such as that already achieved for lacustrine, speleothem or ice core records (Bazin et al., 2013; Veres et al., 2013). This review primarily has a Eurasian emphasis because the longest, mostly climatically controlled loess records are generally know from loess plateaus of Europe and Asia.

\section{BRIEF HISTORICAL OWERVIEW OF LOESS CORRELATIONS}

Correlations between different loess profiles or between loess stratigraphy and

paleoclimatic toess correlations between different loess profiles or to paleoclimatic (stratigraphic)-models were attempted very early in the history of loess research (e.g. Penck and Brückner, 1909; Laskarev et al., 1926; Baczak, 1942; Soergel et al., 1926; 1926;

Götzinger, 1936; Zeuner, 1938, 1956; Thorp and Smith, 1952; Simonson and Hutton, 1954; $\underline{\text { Ruhe } 1956,1969)}$. In this initial stage, loess correlations were highly speculative (e.g. Marković et al., 2016). The Sub-Commission of European Loess Stratigraphy of the International Union for Quaternary Research (INQUA) was created in 1961, at the $6^{\text {th }}$ INQUA Congress in Warsaw, Poland, and is still active as the Loess Focus Group of INQUA. This 
international research initiative succeeded, despite the strong political competition and isolation between western capitalist and eastern communist states at the time (Smalley et al., 2010). With the purpose of creating a common European loess stratigraphy, the subcommision promoted pedostratigraphic criteria as a working model for inter-profile correlations (Fink, 1962). Simultaneously, during the $6^{\text {th }}$ INQUA Congress Liu presented a long and uniform loess stratigraphic record of the Chinese Central Loess Plateau. These stratigraphical observations were published a year later in a significant publication by Liu and Chang (1962), and then loess research in China experienced a scientific hiatus+Smalley and Marković, submitted).

The pedostratigraphic concept culminated in the studies of Bronger and co-workers (Bronger, 1976, 2003; Bronger and Heinkele 1989; Bronger et al., 1998). They presented the first attempt at a Eurasian continental loess correlation. The main limitation of this correlation is an idealised concept of uniform response by such diverse terrestrial environments to global climate change.

Investigation of loess exposures at Red Hill (Červeny Kopec, Czech Republic) and Krems-Schießstättech (Austria), provided the background for correlations between terrestrial loess deposits with the oscillations recorded in deep-sea sediments, both reflecting paleoclimatic oscillations (Kukla, 1970, 1975, 1977; Fink and Kukla, 1977). In spite of the relatively speculative background of the glacial cycle concept that Kukla applied to loess-paleosol sequences, these chronostratigraphic interpretations are still valid.

The development of magnetostratigraphic techniques and opened re-opening of the Formatted: Indent: Left: $0.63 \mathrm{~cm}$ loess community China to collaboration with international scholars and completely shifted global scientific interest towards the multiple loess-paleosol couplets of the 
Chinese Loess Plateau in China-completely shifted scientific interest towards the Chinese multiple loess paleosolcouplets(Heller and Liu, 1982, 1984). Kukla (1987) and Kukla and An (1989) created a new Chinese loess chronostratigraphic model. This new stratigraphic approach, based on paleomagnetic polarity zonation and direct correlation between loess-paleosol magnetic susceptibility (MS) variations significantly improved previous stratigraphic subdivision of the Malan, Upper and Lower Lishi and Wucheng formations based on litho- and pedo-stratigraphic criteria (e.g. Liu, 1985). Observed enhancement of the magnetic signal as a consequence of pedogenic processes appears to be valid for a huge Eurasian semi-arid loess belt (e.g. Maher, 2016). Measurement of loess MS is therefore a rapid and consistent tool for inter-profile correlations, even over very long distances across Eurasia (Marković et al., 2012b, 2015). In Siberian and Alaskan LPS, the opposite pattern is observed, higher MS in unaltered loess and lower in paleosols (e.g. Beget, 1990; Chlachula et al. 1998). However, this contrasting patter, is beyond the scope of this study, since the use of MS for inter-profile correlation of Siberian and Alaskan loess-paleosol sequences has been limited, while correlations based on the model of magnetic enhancement via pedogenesis have been widely applied in the temperate Eurasian loess belt. Finally, recent improvements numerical directof fadiometric absolute-dating techniques, such as radiocarbon and luminescence dating provide new possibilities for validating loess inter-profile correlations especially of younger loess-paleosol sequences (e.g. Stevens et al., 2008; Pigati et al., 2013). Since the early 1980s when luminescence methods were first applied to loess dating, this approach has been critical in development of loess chronologies and, in turn, the development and testing of luminescence dating protocols themselves. Limitations in terms of precision and treatment of older ages do exist however, but it is envisaged that 
efforts to surmount these will also lead to significant progress in the dating of loess

through various new protocols. do exist, but it is to

surmount these would lead also to significant progress in the dating of loess through various new protocols, alongside a better understanding of sediment provenance and physic-chemicalcharacteristics.

\section{SEDIMENTOLOGICAL GENERALCHARACTERISTICS OF DIFFERENT TYPES OF LOESS} RECORDS AS A BACKGROUND FOR APPROPRIATE INTER-PROFILE CORRELATIONS

Loess and loess like deposits cover approximately $10 \%$ of continental surface (e.g. Pye, 1987; Pecsi, 1990Smalleyet al., 2011). Thus, these sediments are associated with many different landformsgeomorphological units, as well as climate and vegetation zones (Figure 1 and 2). Under these different environmental conditions, we can identify a diversity of depositional modes related to equivalent types of loess and loess like primary and secondary deposits. It has been suggested that for secure (and paleoclimatically meaningful) inter-profile correlations of loess the best approach is to focus on sections formed through dust deposition and subsequent pedogenesis on stable plateau-like landforms (sensu Pécsi, 1990; Sprafke and Obreht, 2016), as such loess-paleosol deposits are predominantly controlled by climatic variations (Figure 2). Long-term erosional processes on loess plateaus should be largely confined to relatively small and short-lived gullies close to the steep tableland margins (Marković et al., 2012a). However, even for conditions of plateau-like deposition some erosional events could be expected (e.g. Marković et al., 2011) and therefore the completeness of loess-paleosol sequences must be verified through multiproxy analyses and high-resolution dating. For example,remobilization of loess by the wind

Formatted: Font: $11 \mathrm{pt}$, English (United States) 
may occur even on relatively flat tablelands (Sweeney and Mason, 2013), especially under dry environmental conditions with sparse or diminishing vegetation cover. All types of loess deposition on slopes are associated with processes such as erosion, reworking, and redeposition, representing a more dynamic sedimentological environment that usually is not

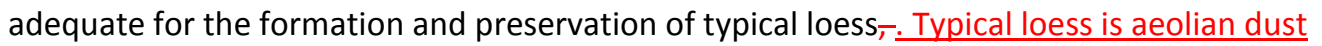
accumulated in situ and transformed by loessification prd les, but mostly preserved without significant impacts of other post-depositional processes (Sprafke and Obreht, 2016). $\underline{\text { Under specific conditions, typical loess can even be preserved as a high-resolution, though }}$ not long-term, record in sedimentary traps such as paleodepressions.

but instead, of various kinds of loess like hillstope, colluvial and alluvial sediments. However, typical loess can be preserved even as a high resolution-though not long-term-record under specific conditions in sedimentary traps such as paleodepressions.

Lithostratigraphic correlations of loess records seem to be a favorite topic in international loess research today (Antoine et al., 2016; Haesaerts, 2016; Schirmer, 2012, 2016; Lehmkuhl et al., 2016). They are often based on similar macroscopic properties of specific loess layers and paleosol horizons, apparently correspondence of ages between various sites and links with palaeoclimatic proxies. However, there are numerous potential pitfalls that may obstruct such correlations (Vandenberghe, 2012). A few examples may illustrate them.

1. Palaeosols play a crucial role for correlation purposes, especially when alternating with loess layers in long records in which they express mainly interglacial periods on an orbital times scale, and/or even the imprint of long and warm interstadials. This approach has been applied frequently in East Asian loess studies since the pioneering work of Liu 
(1985) (e.g. Kukla and An, 1989; An et al., 1990; Ding et al., 1990; Porter, 2001; Sun et al., 2006) but also in other regions (e.g. Antoine et al., 1999; Muhs, 2013) and at a continental scale ( Marković et al., 2012a). If corresponding pedostratigraphic horizons were correctly identified within and between records, such intersite correlations are of great significance in the comprehension of regional paleoclimatic evolution. Palaeosols have often been identified by characteristic proxies and sedimetological features such as decalcification, magnetic susceptibility, pollen associations and evengrain size variations. However, all these proxies are the reflection of specific pedological and geomorphological processes and environmental conditions that may have different expressions at different timescales and even at a local spatial scale. Sediment provenance and periodic fluctuations in the strength (and thus input) of different sources of material is also a crucial factor in loess characteristics. For instance, topography and vegetation cover may drastically influence soil moisture conditions and thus lead to highly diversified soil morphology. The An most illustrative example of soil variability at a scale of tens of meters is described at Ruma (Vojvodina, Serbia) by Vandenberghe et al. (2014). In that case, similary aged palaeosols vary laterally from a black organic, chernozem-like soil to a brown coloured, inorganic soil as a consequence of local topographic differentiation. Another example is the Lohne soil in German loess sections which shows strong variability as a result of local site differentiation (Sauer et al., 2016).

2. The use of another favorite proxy for correlation, the grain size of loess layers, may pose similar problems. That proxy Grain size profiles can be could be-applied convincingly in the loess records of the Chinese Loess Plateau (e.g. Liu, 1985; Vandenberghe et al., 1997), but also applied in other loess regions for correlating lithostratigraphic units in cold-warm successions (e.g. Meszner et al., 2014). In contrast to the Loess Plateau, it appeared that the 
last glacial period, encompassing MIS4-3-2, was-is very difficult to subdivide by grain size variation in records of the adjacent records of the NE Tibetan Plateau and nearby regions in central Asia (Figure 3, Vandenberghe et al., 2006). Similarly in the aforementioned case of the Vojvodina loess at Ruma only a slight grain-size difference, slightly exceeding internal variability, could be observed between glacial and interglacial loess layers in contrast to the Central Chinese Loess Plateau (Vandenberghe et al., 2014). In the Great Plains, USA, the interglacial Bignell Loess can be as coarse as underlying full- to late glacial Peoria Loess (Miao et al., 2007).

3. Lithostratigraphy based loess-palaeosol correlations mostly assume continuous loess deposition (although in the central USA, highly discontinuous deposition has been the general interpretation $€($ e.g. Antoine et al., 2001, 2013; Bettis et al., 20132003ł). However, it has been shown that important sedimentary hiatuses often occur in loess records previously thought to be continuous (Lu et al., 2006; Stevens et al., 2007). An illustrative example is the section-Tuxiangdao, at Xining where a considerable hiatus was discovered in the upper part of the last-glacial loess deposition by detailed OSL-dating (Buylaert et al., 2008; Vriend et al., 2011). Grain size analysis of the loess showed that the loess at that site is characteristically coarse-grained and was transported from a nearby fluvial terrace deposit of the Huangshui river during storm events. It will depend on the local conditions whether sediment is trapped or an interval of non-deposition is created or even older sediment is deflated by such strong storm winds. Important site conditions may be, for instance, topography (wind facing vs wind shadowing) and absence or presence of a vegetation cover to capture and protect deposited loess. Such hiatuses must not be overlooked in the case of lithostratigraphic correlations. Such a risk may appear, for instance, from the correlation between the aforementioned section of Tuxiangdao and neighboring sections on the 
Chinese Loess Plateau and central Asia (Figure3; Vandenberghe et al., 2006; Vriend et al., 2011).

4. Lithostratigraphic correlation is often based on correlation of specific proxy signals such as, for instance, pollen assemblages, grain-size properties, magnetic susceptibility, isotopes, etc. However, the existence of thresholds cannot be ignored in these correlations. As a result, different proxy sensitivity to environmental thresholds may show a specific reaction in certain conditions while not giving any expression at all in other conditions. As_a avoid repetition result, a, proxy may show a specific relationship with environmental factors under some conditions while not giving any expression at all in other conditions that are below the response threshold. Even when driving forces should be equal, the marginal conditions could be of decisive influence for expressing any reaction.Therefore, comparison between proxy record trends is sometimes a successful approach wiggle matching of proxies is sometimes-a successful-approach-(Zeeden et al., in press), whereas in other circumstances it is not (Bokhorst and Vandenberghe, 2009). In addition, some proxies need reaction time: for instance, fluvial action and vegetation adaptation show obvious delay times vis-à-vis climatic changes (Vandenberghe, 2002). Furthermore, correlation by different proxies can be even more risky since the driving factors, marginal conditions and threshold values are not the same for each proxy. Therefore, inter-linking, e.g., grain-size signals, magnetic susceptibility, isotopic or palynological data from one site to another should be avoided in the absence of isochronous marker horizons, such as tephra layers, that allow for a better quantification of proxy data integrity and the potential Eurthermore, correlation by different proxies could be even more risky since the driving actors, marginal conditions and threshold values are not the same for each proxy. Therefore, inter linking, e.g., grain-size signals, magnetic

this is confusing: do you mean that multi-proxy (multi-variate) correlation should be avoided or that correlation between profiles $A$ and $B$ by grains size but between $B$ and $C$ by susceptibility should be avoided? 
susceptibility, isotopic or palynological data from one site to another should be avoided in the absence of isochronous marker horizons, such as tephra lavers, that would allow for a better quantification of proxy data integrity in terms of paleoclimatic potential and environmental reconstructions.

5. Further, proxy signals are often tele-connected by the intermediary of climatic synchronous climate changes conditions that are supposed to be synchronous and act as the driving force behind the signals in the correlated proxies. Circular reasoning is an imminent danger when first assuming common effects of a certain climatic signal tele-connecting different proxies and then subsequently deriving a specific tele-connection between proxy signals based on the same climatic conditions. Examples are given, for instance, by Blaauw (2010).

6. The provenance analysis of sources of dust particles that form loess deposits are of considerable and growing interest (e.g. Sun, 2002; Chen et al., 2007; Aleinikoff et al. 2008; Muhs et al., 2008; Stevens et al., 2013a). Loess is a near-source archive of dust and has the capacity to provide valuable information on the activity of dust sources in the past. Given the complex relationship between atmospheric dust and climate change, knowledge of the sources of dust provides critical insight into the controls on dust emission and potential climate impact. The proper interpretation of many climate proxies from loess records, as well as a valid inter-profile correlations, also relies on detailed knowledge of dust sources. Mineral magnetic signals are influenced by detrital ferromagnetic assemblages (Maher et al., 2009, 2016) while grain-size changes and mass accumulation rates can be heavily influenced by source proximity (Újvári et al., 2016; Stevens et al., 2013b). More generally, knowledge of loess source gets to the heart of questions over the production of loess your description of 'supposed' works against your idea of teleconnection.

a specific example would be helpful here. This is a bit opaque. 
material (Smalley et al., 2009) and can provide insight into large scale landscape and climate evolution (Nie et al., 2015).

7. A final warning applies to the use of chronostratigraphical or chronological information. Of course, correlation of different lithostratigraphic units may be supported

when they have the same age. However, age information is scale dependent and not always unambiguous as appears from the evolution of individual dating technologies. In addition, each dating technique has its own precision, accuracy and reliability limitations. An example of discrepancies arising from the use of different dated proxy records is provided by the the positioning of the terrestrially defined-Hengelo interstadial defined based on investigation of terrestrial environmental records in the framework of the Greenland ice-core record (Vandenberghe and Van der Plicht, 2016).

over-riding Thus, one primordial rule should be applied to loess correlations: it is absolutely necessary to approach each potential correlation pointlink by a careful evaluation of the causal geomorphic-sedimentary-pedogenic processes that underlie the value of the concerned proxy records (Vandenberghe, 2012; Lehmkuhl et al., 2016) and the local conditions, such topography, vegetation cover, microclimate, sediment availability, that determine those processes and thus loess transport and deposition, as well as postdepositional pedogenesis.

\section{GLACIAL/INTERGLACIALSCALE LOESS CORRELATIONS}

Loess-paleosol sequences are produced by much more complex depositional systems with significantly different accumulation rates, more dynamic environmental thresholds and higher potential for erosion than the ice records, deep-sea or lacustrine sediments characterized by more or less continuous sedimentation (e.g. Stevens et al., 2007). Thus, for

give the specifics. The point here is not clear and most readers (like me) will not understand. 
loess, at the moment, convincing correlations on regional or even continental scale are only possible on the level of first order units (i.e. MIS or glacial loess and interglacial

pedocomplex units), although current research has provided significant progress in interprofile correlation and direct comparison of different palaeoclimatic records.

\subsection{HEMISPHERIC SCALE}

The North American and Eurasian loess records are significantly different, and with the current state of understanding of loess-paleosol formation, the possibility of detailed correlation on the hemispheric scale is limited. A convincing explanation for the contrasts has yet to be developed, and will require detailed comparison of the paleoclimatic setting of major loess sources during both glacials and interglacials, issues of sediment supply and ice sheet evolution on each continent. In both North America and Eurasia, a paleosol marking the last interglacial is widely recognized (i.e. S1 in Eurasia, the Sangamon Soil in North America), as is a relatively thick and rapidly deposited full-glacial loess unit (L1 in Eurasia, Peoria Loess in North America). However, both the older loess stratigraphy of previous interglacials-glacials and the detailed stratigraphy of the last glacial cycle differ substantially between continents (see Bettis et al., 2003, for a North American summary). Figure 4 illustrates especially striking contrasts in the temporal dynamics of loess-paleosol sequences during the last $16 \mathrm{ky}$ in three typical loess regions of the Northern hemisphere: the central Great Plains (Mason et al., 2008), the Middle Danube Basin (Stevens et al., 2008; Marković et al., 2014) and the central Chinese Loess Plateau (Dong et al., 2015). These generalized chronostratigraphic models show that the major episode of soil development in the central Great Plains occurred during the Late Pleistocene to Holocene transition, followed by intermittent loess accumulation throughout much of the Holocene, in contrast to the 
predominance of Holocene soil development in Eurasian loess provinces e.g. ( Dodonov and Zhou, 2008) and even in central North America east of the Missouri River (Bettis et al.,

2003). - These differences suggest that the local expression of global climate variations of the past 16 ky was different in the Great Plains than in the Eurasian loess regions, especially with regard to moisture availability. Different thresholds for dust production and the availability of source sediment may also play a role. It is also important to note that the stratigraphy shown in Figure 4 can be identified in near-source sections over a large part of the central and northern Great Plains (Mason et al., 2008), it becomes obscured over relatively over-short distances downwind.

Generally, loess-paleosol sequences in Eurasian loess plateaus are stratigraphicaly than what?

less diverse. However, there are some important differences in the onset of soil formation and the cessation of loess deposition within the Eurasian loess provinces. Dong et al. (2015) suggest that this asynchronous soil development during the transition from the last glacial to Holocene was caused by different environmental response to changes in climate forcing. If a major global climatic shift such as transition from the last glacial to Holocene does not dictate a uniform response of the terrestrial ecosystem, it is hard to imagine that climatic fluctuations of smaller magnitude during the glacial or interglacial phases would be characterized by hemispheric synchronicity in environmental changes (Figure 4).

A remarkable feature at the top of Chinese sections is LO loess unit. Still under debate is whether LO is a consequence of the East Asian Summer Monsoon weakening or instead can be connected with long and intensive human impacts to the environment of the Central Chinese Loess Plateau (e.g. Zhou et al., 2016). 

and Eurasian loess records, establishing proper chronology is essential. Thus, further steps towards appropriate hemispheric loess correlations at least for the last glacial and Holocene records, have to include high-resolution dating necessary for establishment of robust age control. Only in this case can we have a complete overview of the temporal and spatial diversity of continental environmental change on a hemispheric scale.

Loess over the Eurasian continent is characterized by a considerable diversity of loess sequences from the arid and semi-arid zones in Central China, Central Asia, Black sea and Caspian lowlands and the Lower and Middle Danube Basins to the humid periglacial European loess regions, as well as the periglacial and subarctic frozen loess zone in Siberia (e.g. Dodonov and Zhou, 2008; Chlachula et al., 1998). The oldest, thickest and most complete, as well as best prezerved loess-palaeosol successions are related to a great middle Eurasian semi arid loess zone. Spatially, this great continental loess belt spans approximately $45^{\circ}$ and $30^{\circ} \mathrm{N}$ latitude (Marković et al., 2012a).

Marković et al. (2015) presented the remarkable accordance between North Serbian (the Middle Danube Basin) and Chinese loess records (Figure 5). This approach opens up the possibility for a transcontinental correlation of European, Central Asian and Chinese loess sequences, using a standardised nomenclature and chronostratigraphic model. For a direct correlation of two very distant loess regions, the composite Danubean type sequence Mošori/Stati Slankamen (Marković et al., 2015), and the Chinese Loess type sequence of Luochuan (Hao et al., 2012) have been employed. Figure5 shows that the loess 
chronostratigraphies in Northern Serbia and in the Central Chinese Loess Plateau from S0 to S8 based on MS variations correspond strongly. This transcontinental loess correlation reveals also that there are significant similarities between these two geographicallydistant environmental magnetic loess records. Serbian and Chinese loess records have almost identical general multi-millennial and longer-terms pattern of MS variations and even often have a close correspondence on shorter timescales. This correspondence appears to be stronger than the correlation with the globally integrated marine records, potentially suggesting a similar response of continental climate to global changes that differs from shifting ice volume.

If we accept that the similarities are not solely a function of the way that the environmental magnetic record as reflected by MS is recorded and preserved in continental loess records, a similar environmental evolution needs to be postulated for these regions situated on opposite sides of the Eurasian continent. Three the most important factors promoted these similarities: 1 ) extension of the climatic trend of Pleistocene aridification from Asia to southeastern Europe, expressed as general interglacial aridification based on paleopedological and climate proxies and higher accumulation rates observed in younger loess units indicating drier and more dusty glacial conditions (e.g. Buggle et al., 2013;

Marković et al., 2015); 2) despite fundamental differences in dominant climate modes in the Danube Basin (temperate continental) and China (monsoon), the significant imprint of the dry season's influence on these distant loess records is very similar (Marković et al., 2012a) and 3) the almost parallel position of the multiple loess palaeosol sequences that have been formed and preserved inloess plateaus indicate generally the same style of deposition (Marković et al., 2012a). generally the same style of loess deposition, indicated by the 

almost parallel position of the multiple loess-palaeosol sequences that have been formed and preserved on loess plateaus (Marković et al., 2012a).

In spite of the general similarities, there are also some significant differences between these loess records. The absolute magnitude of these MS values is significantly higher in the Central Chinese Loess Plateau than in the Danube loess. The most likely reason for this is the higher background MS of the parent material. More importantly, contrary to the almost uniform amplitude of the absolute MS values in Danubian loess and palaeosol units, the Chinese palaeosols from S8 to S6 are significantly smaller in comparison to the younger fossil soils. Additionally, accumulation rates differ in the Danube Basin and China over this time interval (Figure 5).

Stevens et al. (2011) also noted specific differences between the Crvenka (Vojvodina, Serbia) and Beiguoyuan (Chinese Loess Plateau) climate and accumulation records on millennial time scales, notably in the timing of peak sedimentation and recording of abrupt fluctuations in MS and grain size. These differences suggests that while overall continental scale climate changes are relatively uniform, there are differences in shorter, more abrupt events and in the nature of certain periods. The nature and reasons for these differences is an exciting avenue of future research that should bring providesignificant insight into the dynamics and forcing of regional scale climate in the context of global and hemispheric

or that because of non-linear responses and differences in absolute temp or precipitation thresholds were crossed at different times on the same climatic transition 
Valid regional interglacial/glacial loess correlations are more frequent than those attempted intercontinental scales. The initial chronological framework for loess-palaeosol sequences was established by means of palaeomagnetism (e.g. Heller and Liu, 1982; Liu, 1985) and subsequently by using a correlation of the MS to marine isotope data (Kukla et al., 1988), later also grain size data was utilized (Porter and An, 1995; Vandenberghe et al., 1997) and direct orbital tuning was performed (e.g. Ding, 2002). Orbitally tuned MS and grain size records from quasi continuous loess-palaeosol sequences on the Chinese Loess Plateau have been generated to investigate the evolution and variability of the East Asian monsoon mostly during the Pleistocene, as well as for direct comparison with other major global records (Prokopenko et al., 2006; Tzedakis et al., 2006) or paleoclimatic models (e.g. Bassinot et al., 1994; Lisiecki and Raymo, 2005).

Similarities of environmental magnetic records of different sections in the Central Chinese Loess Plateau are significant even if they are more than $200 \mathrm{~km}$ distant. Figure 6 compares orbitally tuned MS records of type sections on the Central Chinese Loess Plateau: Luochuan (Heslop et al., 2000), Lingtai (Ding et al., 2002), Lingtai and Zhaojiachuan (Sun et al., 2006), and a composite marine oxygen isotope record from the north Atlantic (Shackleton et al., 1990, 1995). It is clear that the boundary ages of S3, S5, L9, S13, S22, S25, S28, S30-31 and S32 are different among the three age models (shown as shaded bars); more work on tuning and correlating these records to resolve the chronological details will be necessary.

Well-documented regional loess stratigraphy spanning numerous glacial-interglacial

the most recent of these references is 2006. Has nothing been done since then? Also, the current accepted marine isotope chronology is Lisiecki and Raymo, 201x cycles, as in the Central Chinese Loess Plateau, clearly provides the opportunity for statistical analysis of correlations among loess records and between those records and other 
paleoclimatic datasets. Recent work has more clearly identified potential problems with such analysis and pointed toward solutions. Correlation of proxy data sets in geosciences is classically done using the Pearson or Spearman correlation methods (Pearson, 1895; Spearman, 1904). Especially for significance testing, issues of non-normal distribution, serial correlation, and often also limited data sizes may limit their direct applicability. These potential issues are, however, often ignored for simplicity. More complex measures have been proposed (e.g. Mudelsee, 2003; Ólafsdóttir and Mudelsee, 2014), but may not always be practical in practice due to the necessity to determine multiple parameters prior to significance testing. Using differences between data points rather than the raw data may counter spurious correlations that result when using classical correlation parameters . In our opinion, testing correlation significance versus the result from a resampled set of phasefandomized surfogates(Baddouh et al., 2016; Ebisuzaki, 1997; Meyers, 2014; Zeeden et al., 2015) using classical correlation parameters may be a preferable option for many cases.

Such approaches are incorporated in the R 'astrochron' package (Meyers, 2014), including the option of correlating differences of datapoints instead of dataseries itself.

Statistical techniques can be expected to be useful for long datasets spanning at least several glacial/interglacial cycles, but may be of limited use when regarding rather short loess sections without clear patterns. For applications in loess research see (Zeeden et al., 2016).

Hilgen et al. (2014) discuss the limited use of significance for real geoscientific datasets, mainly in respect to cyclostratigraphy and time series analysis $s_{\mathbf{2}}$ large parts of their discussion can be applied to correlation and tuning of loess. It is important to realise that geological records do not represent perfect time series and proxy data are often not what does this mean? What is the distinction you are trying to make?

same again, but slightly different expression. Is the difference important to your argument (I can't tell)? 
normally distributed, limiting the strict application of statistical procedures and the explanatory power of statistical measures despite their unquestioned value.

On orbital time scales, coherence and typical frequency patterns have been used for testing correlations in marine and also loess records in mostly qualitative ways (e.g. Basarin et al., 2014; Heslop et al., 2000; Sun et al., 2006), but potential bias by previous alignment has been put forward (Shackleton et al., 1995). Amplitude investigations are favourable for testing time scales especially when wide precession filters are used (Zeeden et al., 2015), and were applied by (e.g. Sun et al., 2006).

Correspondence between MS records, as observed at the Central Chinese Loess Plateau, is also visible for Serbian loess sections during the last five glacial/interglacial cycles. Despite Mošorin and Batajnica loess sections being $45 \mathrm{~km}$ apart, the patterns of MS records are almost identical in the sections, except for the difference in thickness of the stratigraphic units. Even some details, such as the appearance of highly weathered remnants of tephra shards, observed in the loess units L2 and L3 (very base) are identified at both sections (Maković et al., 2009, 2015; Figure 67]).

Unfortunately, other examples of regional loess correlations at interglacial/glacial scalesin other European, Central Asian and North American loess provinces are not clear enough as in the case of loess sections at the Chinese or Serbian Loess Plateaus (e.g. Ding et al., 2002; Maković et al., 2015). In complicated loess deposition conditions and in more problematic stratigraphic situations related to European loess, the application of aminoacids racemisation (AAR) relative geochronology has been proved very powerful. Paleo- and environmental magnetism, coupled with numerical luminescence or radiocarbon dating, is 
general. However, This methodological approach AAR relative geochronology can provide valuable information applicable to a wide range of stratigraphic problems, depositional environments, and timescales (Penkman and Kaufman, 2012). In spite of that, paleo-and environmental magnetism, coupled with absolute luminescence or radiocarbon dating is eurrently the preferred approach for reconstructing chronostratigraphies within loess in general. Application of AAR substantially improved our understanding of European loess stratigraphy. These resulting chronostratigraphic interpretations for the four youngest glacial/interglacial cycles enabled the revision of the previous 'classical' stratigraphic schemes (Zöller et al., 1994; Oches and McCoy, 1995a, 1995b). More advanced reversephase liquid chromatography AAR methodology was subsequently applied to-northern Serbia (Marković et al., 2004, 2005, 2006, 2007, 2011) and Hungary (Novothny et al., 2009) approximately one decade later. This technique has the considerable advantage that multiple amino acids can be measured, with varying racemization rates, meaning that for the first time stadial-interstadial differentiation was achievable. The application of AAR relative geochronology to the long-term loess-palaeosol sequence at Stari Slankamen indicate that the AAR methodological approach can be a powerful tool in resolving glacial/interglacial cycles younger than the last 700 ka (Marković et al., 2015). Additionally the erosional hiatus suggested by the MS record and presence of a gravel unit at the site was confirmed using AAR and shown to indicate that pedocomplex S2 and part of the bracketing loess units are missing at the site. Recent improvements in the sensitivity of the AAR geochronological approach (Penkman and Kaufman, 2012) have the potential to improve the validity of loess-correlations in forthcoming investigations. 


\section{MILLENNIAL SCALE LOESS CORRELATIONS}

Crucial scientific discoveries in paleoclimate research in the last decades of the 20th century have been related to the identification of abrupt climate changes during the last glacial cycle in the North Atlantic region (known as Dansgaard-Oeschger and Bond cycles, and Heinrich events defined by Bond et al., 1992, Dansgaard et al., 1993). The specific patterns of numerous short relative warm intervals known as Greenland Interstadials (GI) became a stratigraphic standard for the last glacial period and development of the so-called event stratigraphy (Björck et al., 1998; Blockley et al., 2012). Similar millennial scale climate variations have been discovered in Eastern Asian speleothems representing detailed evolution of East Asian Monsoon atmospheric circulation (Wang et al., 2008; Cheng et al., 2012). However, is it possible to directly correlatęthe loess-paleosol sequences and Greenland ice-core event stratigraphy? Keeping in mind the notices, made in previous section, it should first be mentioned that even the high resolution loess records were not continuous at least on millennial timescales (Stevens et al., 2006, 2007). Second, these sedimentary gaps are also controlled by processes associated with conditions of local air borne dust trapping, paleo and recentgeomorphological dynamics and preservation conditions. This is a significant limitation factor for preservation of continuous loess records, as well as for suitable reconstruction of climatic and environmental dynamics. The main mechanism of North Atlantic abrupt climate change imprint to the loess-paleosol sequences is long distance humidity supply associated with Westerlies circulation (e.g. Vandenberghe et al., 2006). Thus, it is logic that such correlations between loess and ice core records are substantialfor sections characterized by stronger and more consistent climatic influence of Westerlies as a driver of teleconnections with climate instability in the North Atlantic region.

this sentence is too long and confusing 
However, despite these limitations some sedimentary intervals preserved in huge Eurasian loess belt hold the potential for correlation with Greenland ice-core event stratigraphy.

\subsection{REGIONAL SCALE}

Yang and Ding (2014) analyzed grain size of eight thick loess sections in the northern Chinese Loess Plateau, and constructed a stacked 249-ky-long grain size time series of millennial-scale variability (termed the "CHILOMOS" record). According to the latter authors, this stack documents most of the millennial-scale climatic events registered in Greenland and in Chinese stalagmites. As shown in Figure $7 \underline{8}$, the impact of millennial-scale climate events have been archived within loess records from in the Chinese Loess Plateau during the last and penultimate glacials, and also took place in the last and penultimate interglacial complexes, but at a relatively low frequency. In addition, the stack shows millennial-scale climatic events superimposed on a prominent cooling trend during the last and penultimate glaciations, consistent with the pattern of increasing global ice volume. Thus, the CHILOMOS record may provide a common time scale and a comparative reference for millennial-scale records of Chinese loess, and will facilitate correlation of climate records from different archives such as Chinese speleothem (Wang et al., 2008; Cheng et al., 2012), the LR04 benthic $\delta 180$ stack (Lisiecki and Raymo, 2005), the EPICA Dome C temperature anomaly in Antarctica (Jouzel et al., 2007), and the combined NGRIP $\delta 180$ record from Greenland (5-point smoothed) (North Greenland Ice Core Project members, 2004; Svensson et al., 2008). 
glacial/interglacial period (the last $133 \mathrm{ka}$ )and confirms the dominant climatic influence of the abrupt climatic events in the North Atlantic region.Additionally, the ELSA record provides important environmental evidence that during the last glacial period the atmosphere over Western and Central Europe was permanently dusty (Sirocko et al., 2005, 2013; Seelos et al., 2009). The ELSA record indicates that the coldest two periods of the last glacial period, MIS 4 and MIS 2, characterised by relatively stable climate conditions associated with accumulation of homogenous dust sediments. Conditions during MIS 3 were generally dusty, including several phases of reduced dust deposition over this interval. Even during the MIS 5 high frequencies of dust storm events during the cold events C24 and C23 (McManus et al., 1994) after the last interglacial (MIS 5e) period have been detected (Sirocko et al., 2013, 2016; Seelos et al., 2009).

The high level of correspondence between the dust records from the Greenland icecores and the Eifel maar lakes may indicate a substantial opportunity for direct linkage between marine, ice-core and terrestrial records (Sirocko et al., 2016). However, for Western and Central Euroepan loess-paleosol sequences correlations with Greenland ice stratigraphy are accurate just for some relatively short and discontinuous deposition intervals. The Schwalbenberg loess-palaeosol-sequence in the Middle Rhine valley of Germany is one of the most important sections for understanding terrestrial system responses to North Atlantic Climate Oscillations within the western part of Central Europe, especially for MIS 3 and partly for MIS 4 (Schirmer, 2012; Schirmer et al., 2012; Klasen et al., 2015). 
Nussloch, preserved high resolution recordspanningthe interval between approximately 30

to 20 ky (Antoine et al., 2001, 2013). Rousseau et al. (2002) have also been directly

correlatedthe Nussloch loess record with Greenland stadial-interstadial cycles (Figure 8).

The $14 \mathrm{C}$ and luminescence chronologies indicate that the upper part of the Nussloch loess site corresponds to the interval starting with $\mathrm{Gl} 8$ (correlated with the Lohner Boden by Zöller and Semmel, 2001) while the top loess unit is correlated with the deposition younger than the GI2 in Greenland. The tundra gleys exposed at the site, G1a, G1b, G2a, G2b, G3, G4 and G7, were correlated to GI7 to 2 in the Greenland ice (Rousseau et al., 2002, 2007; Antoine et al., 2009). Similarly, the late last glacial grain-size record at the Czechian Dolní Věstonice and Hungarian Katymar sections shows strongly contrasting grain size variations, with numerous abrupt coarse-grained events in the upper part of their profiles during same time frame like as in Nussloch (Antoine et al., 2013; Bokhorst et al., 2011).

The Dolní Věstonice site has long been believed to record the terrestrial equivalent of climatic oscillations known from marine records (Demek and Kukla, 1969; Kukla and Cilek, 1996). The lower and exceptionally well-preserved pedocomplex (PKII and PKIII) is the most complete record of dust response to environmental dynamics in the European loess belt for the period 110-70 ky. This pedocomplex is composed of three fossil chernozems intercalated with five aeolian silt layers. Kukla (1975) has definedthese silty layers as loess markers.It has been proposed, based on luminescence ages combined with sedimentological and palaeopedological analysis, that this soil complex recorded all the main climatic events expressed in the North GRIP record from GIS 25 to 19 (Antoine et al., 2013; Rousseau et al., 2013) (Figure 15). However, a great deal of questions still remain, not least whether the lowermost Bt horizon represents intensive affected by post- it is not clear if Dolni and Katymar are in contrast with each other (the basis of my corrections) or if they contrast with Nussloch or if contrast is the wrong word and you really mean 'variable'. 
depositional processes, and critically whether the luminescence chronologies are sufficiently precise to make the proposed temporal correlations with higher-resolution Greenland icecore records; moreover, that time interval in the Greenland ice core chronology is also characterized by significant chronological uncertainties (See Veres et al., 2013). Given 1 standard deviation uncertainties on a luminescence age are at best $5 \%$ this equates to \pm 3.5 5.5 ky uncertainty, far too large to allow such fine correlations over this time interval. However, the argument lies over whether the sedimentological and palaeopedological evidence can be used to tune these age estimates sufficiently to allow correlation. These sudden environmental shifts represented by the appearance of the dust markers have great stratigraphic significance (Marković et al., 2015).

Bokhorst and Vandenberghe (2009) have extensively discussed the limitations of correlating short climatic oscillations recorded in the Greenland ice cores with loess records.

They found that the reliability of tuning on the basis of They found that the reliability of tuning on the basis of the climatic proxy signal between two nearby loess sections should be considered carefully, the climatic proxy signal between two nearby loess sections should be eonsidered carefully. They argue that a multi-proxy approach can strongly improve the validity of wiggle matching between two terrestrial records because this procedure may separate local from regional or global signals. However, the issue of the precision of tuned age models is still critical here as the oscillation wave-length of a particular set of climatic shifts is often shorter than the errors on the age model, meaning that miscorrelations are statistically very likely and at the very least leads and lags are entirely lost (Marković et al., 2015).

give more detail or an example to explain this idea

This sentence seems out of place. It is not clear how it relates to the previous sentence. It simply seems to repeat the previous paragraph. 
From all these data it may be concluded that many loess records from China to

Europe show proxy-signals that reflect short climatic oscillations of the same order as those

in ice-core and marine records; however, time equivalence is not certain at present.

From all these data it may be concluded that many loess records from China to

Europe show proxy-signals that reflect short climatic oscillations of the same order as those

in ice-core and marine records, however without an absolutely certain time equivalence at

this point in time. In North America, evidence for oscillations on this timescale in loess

records has rarely been reported. Wang et al. (2003) correlated weak palaeosols in loess at

two nearby sites in Illinois with interstadials in the Greenland ice core record between 30

and $14 \mathrm{ka}$, but similar evidence has not been identified in the many other sections of loess from the same time interval across the Midwestern U.S.A.

\section{POTENTIAL IMPROVEMENTS}

\subsection{SUB MILLENNIAL SCALE CORRELATIONS}

Some loess records indicate ultra high sedimentation rates during long time intervals (several glacial/interglacial cycles), such as Mangshang section in China (Prins et al., 2009), or during some short time intervals as in the Peoria Loess in the USA (Roberts et al., 2003; Muhs et al., 2013; Pigati et al., 2013) and some European and Asian last glacial loesspaleosol sequences (Antoine et al., 2001; Fuchs et al, 2008; Ding et al., 1999; Stevens et al., 2006).

Zheng et al. (2006) showed that the upper part of the Mangshan loess-paleosol sequences formed during the last $\underset{z}{2}$ glacial/interglacial cycles $(0-97 \mathrm{~m})$ displays extremely 
high sedimentation rates. The average sedimentation rate is approximately $40 \mathrm{~cm} / \mathrm{ky}$. The unique character of the upper Mangshan loess section is clearly represented by comparing the sedimentation rate estimates for the L1 loess and S1 palaeosol units with sedimentation rates recorded in a series of loess sections distributed across the Central Chinese Loess Plateau. On average, the last glacial loess $L 1$ has a 3.1 times higher linear sedimentation rate at Mangshan than at typical sections at the Central Chinese Loess Plateau. Nevertheless, in comparison with some analyzed sections at Central Loess Plateau linear sedimentation rate for L1 horizon units at Mangshan site can be 8 times higher. The sedimentation rate observed in paleosol S1 in Mangshan section is 4.6 time higher than average sedimentation rate for the same paleosol unit in the Central Chinese Loess Plateau (Figure10; Prins et al., 2009). The last glacial/interglacial cycle loess-paleosol sequence in Mangshan has a resolution of at least several centimeters and even in some parts decameter per century.

In the central Great Plains of North America, very rapid accumulation characterized some intervals of the last glacial Peoria Loess, based on OSL dating and radiocarbon dating of gastropod shells. At Peoria Loess sections in Nebraska, sedimentation rates as high as 400 $\mathrm{cm} / \mathrm{ky}$ can be inferred for some intervals, but discrepancies between OSL and radiocarbon dating add considerable uncertainty to the interpretation of these sections (Roberts et al., 2003; Pigati et al., 2013). At Loveland, lowa, OSL and radiocarbon ages are in agreement and suggest that about $13 \mathrm{~m}$ of Peoria Loess was deposited almost instantaneously, at the resolution of the dating (Muhs et al., 2013; Pigati et al., 2013).

Thus, these ultra high-resolution sections provide a unique opportunity to better understand centennial climatic and environmental dynamics. However, for sub millennial
I am most used to seeing

'Chinese Loess

Plateau' (CLP) but at least be consistent. 
investigations in lower-resolution sections than Mangshan, application of new much more precise age dating or sampling techniques will be necessary.

\subsection{LUMINESCENCE DATING OF MIDDLE PLEISTOCENE LOESS}

Luminescence methods (TL-thermoluminescence; IRSL-infrared stimulated luminescence;

OSL-optically stimulated luminescence by blue light or violet light (VSL)) are currently the only generally accepted methods for obtaining absolute chronologies for loess deposits through the direct dating of clastic particles. Absolute dating of loess in Europe was pioneered by the applications of thermoluminescence dating performed by Wintle (1981) and luminescence dating has arguably now become the de facto independent dating tool for many loess deposits globally. Roberts (2008) thoroughly reviewed the development and application of luminescence dating methods but recently further significant advances have been made, not least with age determination of loess deposits older than standard quartz

OSL and ${ }^{14} \mathrm{C}$ age limits. The outcome of these studies holds great potential for future

breakthroughs in stratigraphic correlation over local and continental scale over the middle

Quaternary, a period of time where current correlations are rather uncertain.

Standard quartz SAR OSL dating techniques generally have an upper limit of c. 50-30

ka. Buylaert et al. (2008) used Chinese loess samples to demonstrate caution should be used in interpretation of ages where equivalent dose values exceeded $120 \mathrm{~Gy}$ ( $40 \mathrm{ka}$ ), while Lai (2010) reported underestimation for Luochuan loess in China for ages higher than about 70

ka. For loess in Crvenka in Serbia, OSL ages appear accurate to about 60-50 ka

(corresponding equivalent dose of $\sim 180 \mathrm{~Gy}$ ) while for sediments older than this, the

technique (SAR protocol) shows clear age underestimation (Stevens et al., 2011). Moreover, a series of investigations on Romanian (Timar-Gabor et al., 2011; Constantin et al., 2014), perhaps in loess. This is not the general case so please qualify this statement. 
Serbian (Timar-Gabor et al., 2015) and Chinese loess (Timar-Gabor et al., 2016) yielded ages obtained on coarse quartz $(63-90 \mu \mathrm{m})$ that were systematically higher than those on fine quartz $(4-11 \mu \mathrm{m})$ for ages $>\sim 40 \mathrm{ka}$. This limits the application of luminescence dating to loess and has driven the development of a suite of new techniques that show great promise in extending the age range of luminescence methods.

One of the earlier attempts was through use of the thermally transferred optically stimulated luminescence (TT-OSL) signal, first introduced by Wang (2006) at the Luochuan section in China. While this initially showed great promise, and TT-OSL signals have been reported to grow up to doses higher than $2000 \mathrm{~Gy}$, few ages above 400 ka have been obtained, and dealing with the effect of charge carry over in SAR sequences has limited the approach (Stevens et al., 2009). Furthermore, investigations into the thermal stability of the

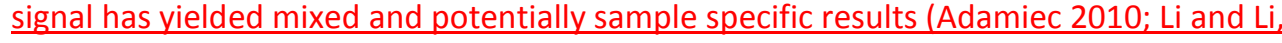
2006; Brown and Forman, 2012; Chapot et al., 2016). However, Chapot et al. (2016) suggest that by applying corrections for thermal loss, meaningful chronologies can be obtained on loess up to $500 \mathrm{ka}$.

Ideally hough a widely applicable method would not require such corrections. An alternative method using quartz is VSL (Jain, 2009). This method was again tested on Luochuan loess in China by Ankjaergaard et al. (2016) and,by applying a multiple aliquot additive dose protocol VSL ages in agreement with the CHILOPARTS chronology up until 600 ka (MIS 15) have been obtained. However, while showing great promise for improving middle Pleistocene chronologies the VSL approach is still in its development stage and $\underline{\text { requires further testing in multiple loess regions. }}$ 
The predominant use of quartz was mainly related to the anomalous fading (athermal loss of signal due to quantum mechanical tunneling) observed to affect luminescence signals from feldspars (Wintle, 1973). Conventionally, feldspars IRSL is measured at $50{ }^{\circ} \mathrm{C}$ and the effect of increasing the stimulation temperature on the fading was only recently studied (Thomsen et al., 2008). This lead to a double IR stimulation protocol, performing a first IR stimulation at $50{ }^{\circ} \mathrm{C}$ followed by a second one (post-IR IRSLpIRIR) at $225^{\circ} \mathrm{C}$. The first stimulation aimed to remove the unstable signal while the second stimulation targeted a more stable trap. Thiel et al. (2011) extended the protocol by changing the preheat and increasing the stimulation temperature to $290^{\circ} \mathrm{C}$. Using Austrian loess samples from below the Matuyama-Brunhes boundary in saturation on a laboratory dose response curve they concluded that fading is not significant. The same observation was made by Murray et al. (2014) for Serbian loess and was further confirmed for loess in the Rhine area by Schmidt et al. (2014), where an upper limit of 300 ka (MIS 8) was proposed. in this acronym pIRIR protocols have also been tested on Alaskan loess (Roberts et al., 2012). The same 300 ka barrier seems also to apply when dating Chinese loess by pIRIR (Buylaert et al., 2013) and a slightly modified protocol (multi-elevated-temperature post IR-IRSL MET-pIRIR) was tested on Chinese loess by Li and Li (2012), reaching the same conclusions on maximum age. While showing great promise, the TT-OSL and pIRIR signals are harder to bleach than the standard OSL signals, with residual doses that seem to be sample specific and can amount to a few 10s of Gy. This means that these techniques may not be suitable for younger loess deposits. Despite this and the relatively early stage of these protocols, the application of these new $\underline{\text { techniques has already enhanced middle Pleistocene chronostratigraphies for loess deposits }}$ and the stage is set for using these techniques for much wider scale loess stratigraphic correlations, both within and across loess regions. 
$\underline{\text { In the context of }{ }^{14} \mathrm{C} \text {-dating major datable phases in loess sediments are charcoals, organic }}$

matter, humic substances (humic acids), rhizoliths and mollusc shells (Hatté et al., 2001;

McGeehin et al., 2001; Pigati et al., 2013; Gocke et al., 2014; Újvári et al., 2014, 2016b).

Charcoal is commonly regarded as the best target material for ${ }^{14} \mathrm{C}$-dating (Trumbore, 2000).

Although charcoals are thought to be relatively resistant to post-depositional alteration,

there is a growing body of evidence of charcoal degradation and loss by chemical oxidation

(Cohen-Ofri et al., 2006; Ascough et al., 2011a,b), physical fragmentation (Gavin, 2003), or

fungal degradation (Ascough et al., 2010). Also, charcoal can readily adsorb a range of soluble chemical contaminants migrating in the sediment column like humic substances, which can have a different ${ }^{14} \mathrm{C}$ age than the charcoal (Alon et al., 2002; Rebollo et al., 2008;

Wild et al., 2013). This exogenous carbon is removed prior to radiocarbon dating by treating

the samples with a series of weak acid and base washes (acid-base-acid=ABA treatment; de

Vries and Barendsen, 1954; Olson and Broecker, 1958). While the ABA-technique appears to

be a robust method for contaminant removal for a number of samples (Rebollo et al., 2011;

Bird and Ascough, 2012), several studies demonstrated that it does not always remove all

contaminant carbon, which becomes critical with increasing sample ${ }^{14} \mathrm{C}$ age (Gillespie et

al.,1992; Chappell et al., 1996; Wood et al., 2012). An alternative pre-treatment technique,

called the ABOX-SC method, involves an oxidation step after the acid-base steps, which is

followed by stepped combustions at 330,630 and $850 \circ \mathrm{C}$ to remove any final traces of labile carbon (Bird et al., 1999). Although this technique proved to be very effective in removing contamination from old samples (Wood et al., 2012; Bird et al., 2014), it often leads to large this is not made particularly relevant to the topic of loess, unlike the OSL discussion. Much of this is general (and old) and should be dropped. 
losses in sample material (Bird and Ascough, 2012). In such cases charcoals can be subjected

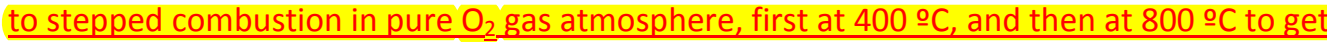
reliable ${ }^{14} \mathrm{C}$ ages (Újvári et al., 2016a).

Radiocarbon dating of organic matter may often be problematic because of the rejuvenation of organic matter in loess, which renders ${ }^{14} \mathrm{C}_{\text {org }}$ ages unreliable (Gocke et al., 2010, 2011). Others, however, found little or no evidence for $n$-alkanes in loess-paleosol sequences being significantly "contaminated" by deep subsoil rooting or microbial processes (Häggi et al., 2013; Haas et al., 2017; Zech et al., 2017). This debate is still ongoing and needs further resolution.

As for humic acids, they often originate from younger vegetation and not from in situ plant decay in the sediment to be dated (Ascough et al., 2011; Wild et al., 2013). Previous work on rhizoliths (hypocoatings), that were formed by coating of plant roots by secondary carbonate (Becze-Deák et al., 1997; Barta, 2011), demonstrated that these phases are not synsedimentary (Pustovoytov and Terhorst, 2004; Gocke et al., 2011; Újvári et al., 2014), thus cannot be used for establishing reliable loess chronologies.

Although mollusc shells are often found in loess sediments (Sümegi and Krolopp, 2002; Moine et al., 2008), they have often been considered phases yielding unreliable ages. Early studies documented that land snail shells yield radiocarbon ages that are anomalously old by up to $3000 \mathrm{yr}$, due to incorporation of old, ${ }^{14} \mathrm{C}$-free carbonate from the local substrate into shell carbonate. This phenomenon is often quoted as the 'limestone problem' (Rubin et al., 1963; Tamers, 1970; Evin et al., 1980; Goodfriend and Hood, 1983; Goodfriend and Stipp, 1983; Yates, 1986; Goodfriend, 1987). However, most of these works were biased towards gastropods having relatively large shells (>20 mm) and recent studies by Brennan 

and Quade (1997) and Pigati et al. $(2004,2010,2013)$ demonstrated that reliable ${ }^{14} \mathrm{C}$ ages can be obtained from smaller gastropods (shells $<10 \mathrm{~mm}$ ) that have largely been ignored in previous ${ }^{14} \mathrm{C}$-dating studies. Bevand the 'limestoner is to assess whether the shells behaved as close systems with respect to carbon during burial. Opensystem behavior is a serious concern in older samples (60-25 ka) where small amounts of contamination cause large bias/errors in ${ }^{14} \mathrm{C}$ ages. Rech et al. (2011) and Pigati et al. (2010, 2013) revealed, by measuring the ${ }^{14} \mathrm{C}$ activities of very old mollusc shells (800-130 ka) and testing land snail shell ages against plant macrofossil ${ }^{14} \mathrm{C}$ ages, that many fossil gastropod shells do not suffer from major (> $1 \%$ ) open-system problems. As demonstrated in independent studies of Pigati et al. (2013) and Újvári et al. (2014, 2016b), shells of some mollusc species (e.g. Succinella oblonga, Clausiliidae sp., etc.) provide reliable ages that can form the basis of robust loess chronologies, which can be highly precise on millennial and even sub-millennial timescales.

\subsection{ADVANCESIN LUMINESCENCE DATING}

Age-controlis central to the interpretation of loess climate proxies. Furthermore, knowledge of age versus depth allows calculation of dust mass accumulation rates (MAR) for loess deposits, providing valuable insight into the past dust cycle (Albaniet al., 2015). Choice of method for age-dating is critical as on sub-orbital timescales non-independent/nonradiometric dating methods such as orbital tuning can be inaccurate and fail to capture the extent of variations in loess accumulation (Stevens et al., 2007). As stated by Roberts (2008) in her review, luminescence dating methods (TL thermoluminescence; IRSL-infrared stimulated luminescence; OSt-optically stimulated luminescence by blue light or violet light 
(VSL)I have been a critical in development of loess chronologies and, in turn, the development and testing of luminescence dating protocols themselves. The key advantages of luminescence over other methods are that the technique directly dates deposition, utilises abundant clastic material such as quartz, and potentially can be used to date back over into the middle Pleistocene (Roberts, 2008; Buylaert et al., 2012). Indeed, absolute dating of loess in Europe was pioneered by the applications of thermoluminescence dating performed by Wintle (1981) and in the last 8 years more than 300 articles have been published in internationaljournals regarding both applications as well as testing of luminescence dating methods on loess deposits worldwide. Below we briefly summarise the method, recent developments in the protocols used, and results of their application to loess deposits.

\subsubsection{Basic principles of luminescence methods}

All luminescence methods rely on the properties of natural minerals such as quartz and

feldspars to store energy in the form of trapped electrons resulted from exposure to environmental radiation ${ }^{238} \mathrm{U},{ }^{235} \mathrm{U},{ }^{232} \mathrm{Th}$ series, ${ }^{40} \mathrm{~K}$, cosmic radiation) during their burial, and subsequently release this energy it in the form of light upon stimulation. The Iuminescence age reflects the time elapsed since the last exposure to light of the buried mineral. The assumption that the signalis zeroed by aeolian transport is valid especially in windblown sediments such as loess. Due to the different penetration powers of radiation, different grain sizes are usually selected for dating. For loess, the silt $(4-11 \mu \mathrm{m}, 35-50 \mu \mathrm{m}-0 \mathrm{r}$

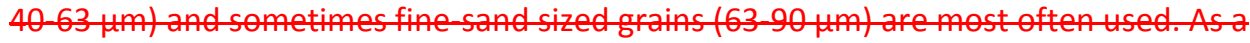
simplified equation, the age represents the ratio between the total dose of radiation absorbed during mineral burial (palaeodose $(G y)$ ) and the rate at which the radiation dose 
was delivered (annual dose $(G y / k a))$. The annual dose is calculated from measured abundances/activities of radioisotopes in the sediment plus an estimation of the cosmic fadiation dose, and usually amounts to 3-4 Gy/ka for loess. The paleodose is estimated as an equivalent dose (De). A calibrated radioactive source is used to construct a laboratory luminescence dose response curve where measured luminescence intensity (often normalised) is plotted against the laboratory administered dose. The most common method to achieve this is via the single aliquot regeneration (SAR) protocol (Murray and Wintle 2000, 2003). Under this method, natural and laboratory luminescence measurements are normalised to the luminescence response to a known, laboratory administered constant dose and dose curves constructed for multiple aliquots of a sample, to ascertain reproducibility. The sources of uncertainty are many, amounting to $5-10 \% 10$ error on an age. The reader is referred to-other sources for discussion of these in loess (Aitken, 1985, Aurray and Wintle 2000, 2003, Roberts, 2008).

Use of the SAR protocolon quartz has generally been accepted as the standard approach in loess luminescence dating. However, its applicability for dating loess samples older than about 40-70 ky (Bec. $150-200 \mathrm{~Gy}$ ) has been questioned in recent vears in both Chinese (Buylaert et al., 2008; Lai, 2010) and Serbian loess (Stevens et al., 2011). Moreover, a series of investigations carried out using SAR-OSL dating on quartz of different grain sizes from Romanian (Timar-Gabor et al., 2011), Serbian loess (Timar-Gabor et al., 2015) and Chinese loess (Timar-Gabor et al., 2016) showed that coarse quartz (63-90 um) De values were systematically higher than those on fine quartz $(4-11 \mathrm{\mu m})$ for ages $>$ $40 \mathrm{ky}$, despite the fact that that both grain fractions behaved well in the SAR protocol. On the other hand, for younger ages, agreement has been found on different grain sizes (Constantin et al., 2015, Fimar-Gabor et al., 2015). This agreement increases confidence in using the state of the art 
measurement protocols (SAR-OSL) for these young ages, as further confirmed by comparison with independent age control(Constantinet al,, 2012, Anechitei-Deacuet al., 2014; Trandafir et al, 2015). As such, currently quartz SAR OSL dating should be applied with eaution beyond these age limits. Due to these limitations, as well as the fact that truly independent age control is seldom found beyond the age range of radiocarbon, loesspaleosol sequences have been used as testing grounds for luminescence dating methods.

\subsubsection{Extending the age range of luminescence methods for dating loes deposits}

In order to extend the age range of quartz luminescence for loess deposits, thermally transferred optically stimulated luminescence (TT-OSL) was introduced as an alternative signal for dating at the classic Luochuan section in China (Wang et al., 2006). However, while TT-OSt signals are reported to grow up to doses higher than 2000 Gy, few ages above $400 \mathrm{ky}$ have been obtained, and a significant number of studies have cast doubt on the thermal stability of the signal (Adamiec 2010; Liand Li, 2006; Thielet al., 2011; Brown and Forman, 2012; Chapotet al., 2016), limiting the protocol's use to date.

Another new alternative method proposed for dating old sediments using quartz is violet stimulated luminescence (VSL) (Jain, 2009). This method was tested once more by comparing natural and laboratory generated dose response curves on the tuochuan section by Ankjaergaard et al. (2016). As in the case of SAR-OSL and uncorrected SAR-TT-OSt methods, the SAR-VSL natural and laboratory dose response curve did not overlap. However, by applying a multiple aliquot additive dose protocolVSt ages in agreement with the CHILOPARTS chronology (Ding et al., 2002) up until600ky (AMIS 15) have been obtained, 
implying that this protocol would also enable extending the age range for loess deposits worldwide. anomalous fading (athermalloss of signal die to quantum mechanical tunneling) observed to affect luminescence signals from feldspars (Wintle, 1973). Conventionally, feldspars are measured using infrared stimulation and these IRSL signals are measured while holding the sample at $50^{\ominus} \mathrm{C}$. The effect of increasing the stimulation temperature on the fading was only recently studied (Thomsen et al., 2008) and it consequently lead to rejuvenation in the use of feldspars for luminescence dating. A protocol based on a double IR stimulation was subsequently developed and tested on loess, performing a first IR stimulation at $50^{\circ} \mathrm{C}$ followed by a second one (post-IR IRSL-pIRIR) at higher temperatures (often between 225 $290^{\circ} \mathrm{C}$ ) apparently removes the unstable signal and targets a more stable trap, often with negligible to no fading (Buylaert et al., 2009, Thielet al., 2011, Buylaertet al., 2012, Murray et al., 2014). The procedure has been successfully applied to European and Chinese loess (Stevens et al., 2011, Buylaert et al., 2015). A slightly modified protocol (multi-elevatedtemperature post IR IRSL MET-pIRIR) was tested by Li and $L i(2012)$ and reached the same conclusion on the maximum age. A multiple aliquot regeneration (MAR) procedure of this protocol was applied by Chen et al (2015) on samples from the Chinese Loess Plateau and apparently the procedure allowed successfuldating of the top of paleosollayer 55 at tuochuan section ( 480 ky, corresponding to MIS 13). While questions remain about the difficulty of bleaching pIR IRSL signals and the nature of correct temperatures and test doses for different samples, the method has shown considerable promise in use to date loess at least to 250ky. 
Although many of these methods are still being tested, dating loess-paleosol units using luminescence dating methods can securely attain ages at least as old as $300 \mathrm{k}$. (corresponding to MIS8) and in some cases up to 600 ky (corresponding to MIS15) and thus further underlining the antiquity of the loess preserved world wide. While for S1 (MIS 5) and older loess units TT-OSL, VSL and especially P-IR IRSL methods seem to hold the greatest potential, for relatively young samples (equivalent doses $\sim 100$ Gy equaling ages less than about $40 \mathrm{ka}$ ) standard quartz OSL dating remains the most robust luminescence dating method. Luminescence dating is a very rapidly growing field and further advances in the following years will surely increase both the precision of the method as well as further refine the accuracy of dating old loess units.

Most fundamentally, the application of luminescence dating to loess has allowed detailed, independent age models to be developed for some of our most valuable climate archives. This allows for continental scale chronostratigraphic correlation of loess deposits into the middle Pleistocene (Marković et al., 2015) and subsequent critical insight into-continental scale climate dynamics.

The resolution of application of luminescence methods has varied freatly, ranging

from just a few samples over many metres, to sampling every $10-20 \mathrm{~cm}$. Stevens et al. $(2006,2007,2008)$ pioneered the use of high sampling resolution luminescence dating using quartz OSt, taking advantage of the use of a standarized dose response curve method for quartz, developed on loess deposits and greatly reducing sample measurement time (Roberts and Duller, 2004). These studies and subsequent quartz OSL and PIR IRSL work, 
focussed especiallyon Chinese loess (Buylaertet al., 2008, Laiet al., 2007, tai, 2010, Sun et al., 2012, Kong et al., 2014, Stevens et al., 2016), but also-on European (Stevens et al., 2011 Constantin et al., 2014, Úváriet al., 2014) and American (Masonet al., 2003, 2008; Roberts et al., 2003; Muhs et al., 2013) loess, have provided critical insight into the nature of loess stratigraphy and sedimentation. Stevens et al. (2007) and Buylaert et al. (2008) suggested that gaps exist on sub-orbital timescales on classic loess on the Chinese Loess Plateau and that soil formation on pre-deposited glacial loess was obscuring climate signals and invalidating the use of soil horizon bases as known age marker horizons. Even longer gaps However, other studies have not uncovered such hiatuses at other sites (Kong et al., 2014, Stevens et al., 2016). Whether this is due to rarity of hiatuses or an atefact of much lower sampling resolution used in many studies is a key future focus.

Irrespective of the prescence of hiatuses, luminescence dating of loess has highlighted significant variations in dust accumulation both between sites and through time. Dust MAR values have been reviewed by újváriet al. (2010) in Europe, and more recently by Kong et al. (2014) for the last glacial Chinese Loess Plateau. While independent dust MAR values remain few for European deposits, existing studies suggest significant variation between sites in Hungary and Serbia, although with potential peaks in accumulation rate during the last glacialmaximum (Fuchset al., 2008, Stevenset al., 2011, Újúriet al., 2014). InChina, MAR data is much more numerous. Stevens and Lu, (2009) demonstrated considerable variation in loess rate of accumulation between sites using quartz OSL, although-compiling data from many luminescence dated sections, Kong et al. (2014) sugigest that a peak in dust MAR of around 23-19kyoceurs across the Chinese Loess Plateau. Intriguingly, this appears to postdate a peak in dust accumulation identified in marine and ice cores $(26-23 \mathrm{ky})$, notwithstanding age uncertainty and error in all the records. However, 
recent quartz OSL dating at the Xifeng section seems to suggest a dust MAR peak more in line with the ice and marine core estimates (Stevens et al. 2016). At these sections, dust AAR values of $200-300$ or more g $m^{-2} y^{-1}$ are not uncommon. In the continental United States however, extremely large pulses in accumulation of up to $10-16,000 \mathrm{~g}^{-2} \mathrm{y}^{-1} \mathrm{have}^{-16}$ been measured in late last glacial Peoria loess at the Loveland site, along the Missouri River (Muhs et al., 2013). Values of MAR almost as high have been inferred for Peoria toess at sites in Nebraska, though with greater uncertainty in dating, as noted above (Roberts et al., 2003; Pigatiet al, 2013). These represent extraordinary rates of loess accumulation over very short periods but raise problems with regard to-calculation of MAR from luminescence dating as the rates of loess sedimentation become solarge that the errors on luminescence dates prevent meaningful age increases with depth being identified. Muhs et al. (2013) utilized Bayesian modelling to refine their chronology, and this represents a promising path to reduce uncertainty, but the problems with taking discrete point age information with significant error margins and turning these into a continuous age depth model remain problematic (as discussed in Stevens et al. (2016)).

In a flobalcompilation of Holocene MAR data from multiple dust archives, Albani et al. (2015) highlighted the paucity of data currently available from loess deposits. Given the importance of loess MAR estimates in reconstructing past dust flux, detailed, high sampling resolution luminescence dating of loess has enormous potential to contribute to major breakthroughs in understanding past dust activity, especially through addressing uncertainties in MAR calculation. As such, luminescence methods can be used with increasing confidence well into the Middle Pleistocene, providing criticalinsight into the nature of loess deposition and preservation, fully independent age models for 
970 971 972

973

974

palaeoclimate reconstruction, and detailed, independent dust MAR estimates of increasing use in assessing the role of dust in climate change. 
As already discussed, in recent years, apparent limitations in the dating of loess deposits and in isolating millennial-scale climate variability, has led to a new impetus in providing secure isochronous age markers for loess records (Marković et al., 2015). Volcanic ash beds, and particularly these dispersed over wide geographic areas played a crucial role in building chronological frameworks for paleoclimate records (Storey et al., 2012). Tephra layers have also proven their value in assessing phase relationships of climatic events, a crucial requirement for understanding the value of individual proxy-data (including these for loess) in the comparison of various palaeoclimatic archives (Abbott and Davies, 2012; Lowe et al., 2015).

The South Eastern European loess belt is located nearby volcanic centers that have been significantly productive throughout the Quaternary (see review in Tomlinson et al., 2015). The central-eastern Mediterranean marine tephrostratigraphic record, augmented by recent findings from long lacustrine records within the Balkans (Leichner et al., 2016) indicate that several well-dated volcanic eruptions provided tephra layers that could serve as excellent isochrones also for loess records.

For example, the widespread Bag tephra identified in multiple loess sites across the Carpathian Basin (Pouclet et al., 1999; Horvath 2001), albeit lacking secure chemical and chronological data, it nonetheless provides an undisputed stratigraphic marker horizon for Middle Danube loess (Fig. 5-6). Interestingly, the identification of a MIS 16-12 tephra bed within Pianico Basin in northern Italy (Brauer et al., 2007), led the authors conclude that the calc-alkaline tephra bed originating from the Campanian volcanic complex of Roccamonfina and dated to around 400 ky might be a counterpart of the widespread Bag tephra. Whilst

but see the counter-example in New Zealand loess of bioturbation and slope processes affecting the interpretation of a very significant tephra marker horizon (Almond et al.) 
the proposed link between the Bag tephra and the ash bed in the Southern Alps is tentative, it nonetheless provides a working scenario; the available chemical and mineralogical data on the Bag tephra also points to an origin in the Italian volcanic field (Pouclet et al., 1999; Horvath 2001).

Interestingly, two other laterally continuous tephra beds have been identified in the last glacial loess (Horvath 2001; Wacha, Frechen, 2011) from the Middle Danube and the Adriatic coast, and dated to around $30 \mathrm{ky}$ and respectively $34 \mathrm{ky}$ in age. As two important tephra layers have been reported in marine and terrestrial sites over that time interval, namely the Y-3 and the Coddola ashes, it is tempting to propose direct linking of records.

Whether these tephra beds should be correlated in the absence of reliable chemical data for the terrestrial occurrences is risky, but such assumptions that raise the possibility that the regional loess tephrostratigraphy could be augmented and eventually integrated within a regionally representative frame must be verified through further work. In this respect, perhaps the most compelling example is provided by the Campanian Ignimbrite/Y-5 eruption, that, due to the large volume of volcanic ejecta, excellent preservation of glass shards and a north-easterly spread of the ash plume, forms the most important visible marker horizon with independent absolute age control (de Vivo et al., 2001) for Eastern European loess. It has been identified widely in southeastern European loess (Veres et al., 2013; Fitzsimmons et al., 2013; Marković et al., 2015; Obreht et al., 2016), raising the possibility for a direct comparison of different loess profiles (Marković et al., 2015;) and also of loess with various paleoclimate records from the Balkans and beyond (Zeeden et al., 2016). Moreover, the Campanian Ignimbrite/Y-5 ash layer has been employed successfully in testing the accuracy of various multi-method luminescence-dating approaches applied to loess (Constantin et al., 2012; Veres et al., 2013; Fitzsimmons et al., 2013; Anechitei-Deacu 
et al., 2014; Zeeden et al., 2016). It is known that recent research has documented significant age discrepancies between different quartz-grain sizes of the same sample, a limitation in luminescence dating of loess not yet fully overcome (Timar and Wintle, 2013). In this respect, the Campanian Ignimbrite/Y-5 ash layer provided a chronological base line against which different luminescence dating approaches have been tested (Constantin et al., 2012; Anechitei-Deacu et al., 2014), with encouraging results. A similar approach was followed in Fattahi and Stockes (2003) and Auclair et al. (2007) through the direct luminescence dating of a tephra horizon and the embedding loess deposits at sites throughout North America.

Other notable examples of the application of tephrochronology involving loess deposits include the recent identification of Carpathian ash beds in proximal loess-derived deposits within Transylvania (Karatson et al., 2016) linked to distal areas, north of Black Sea (Wulf et al., 2016), as well as in loess profiles from Japan (Matsura et al., 2012), New Zealand (Lowe, 2011), Alaska (Preece et al., 2011; Davies et al., 2016), central-western Europe (Sirocko et al., 2013; Jens et al., 2017) or South American loess (Toms et al., 2004).

\subsection{TOWARDS IMPROVED MAGNETOSTRATIGRAPHY}

Magnetic stratigraphy represents a powerful and widely used relative dating tool. Beside environmental magnetic proxies related to environmental changes (e.g. magnetic susceptibility stratigraphy), froperties of the Earth's magnetic field are investigated and correlated to reference sections and/or datasets as usually the Geomagnetic Polarity Time

this section should be omitted or rewritten substantially. Much of it is simply recounting basic principles, not (clearly) a discussion of 'improved magnetostratigraphy'. If you can't change the focus to new developments then delete it. 
Scale (GPTS), part of the Geological Time scale (Gradstein et al., 2012; Ogg, 2012). When sedimentation rates are not dramatically changing and the polarities of Earth's magnetic field are recorded, correlation allows for establishment of a time scale on the scale of magnetic features. Polarity time scales therefore commonly have a rather low resolution due to the limited number of reversals over the Neogene and Quaternary $\left(1 / 10^{4}-10^{5} \mathrm{yrs}\right)$. Both the polarity and intensity variations can be used for time scale establishment. Especially within the recent magnetic polarity zone, the intensity of Earth's magnetic field can be valuable for dating, and reference datasets were established (e.g. Channell et al., 2009; Kissel et al., 2000; Laj et al., 2004; Valet et al., 2005; Yamamoto et al., 2007). Earliest time scales for loess have been established by magnetic polarity stratigraphy (Fink and Kukla, 1977; Heller and Liu, 1982, 1984; Kukla et al., 1988; Kukla, 1975). In their seminal papers Heller and Liu $(1982,1984)$ assigned firstly the Chinese loess record to the GPTS and demonstrated secondly via magnetic susceptibility stratigraphy the unique match between the marine isotopic record the alternation of loess and paleosoils. Ever since, correlative loess stratigraphy benefited from magnetostratigrapic age constraints, which were later on refined (e.g. Maher, 2016), when also rather short term geomagnetic excursions (e.g. Reinders and Hambach, 1995; Sun et al., 2013; Zhu et al., 1999, 2006) and paleointensity records (Hambach et al., 2008; Liu et al., 2005; Rolf et al., 2014; Zeeden et al., 2009) were used.

A comparison of paleointensity records from Europe (Figure 10) to the North Atlantic Paleointensity Stack GLOPIS (Laj et al., 2004) shows some common features, here indicated by colored circles, which were used in constraining age models for European loess sites (Hambach et al., 2008; Rolf et al., 2014; Wacha et al., in review; Zeeden et al., 2009). Also 
clear are some discrepancies, especially when comparing the longer term patterns and the amplitude of minima and maxima in paleointensity. Though relative minima and maxima can be observed and correlated, their amplitude in loess seems less homogeneous than in other archives (Roberts et al., 2013; Fig. 10). This may be caused mainly by sedimentological and magnetic grain size variations and early diagenetic effects, which in turn dependent on climatically controlled wind strength and post-depositional pedogenic processes.

\section{CONCLUSIONS}

Contrary to the ice records, deep-sea or lacustrine sediments characterized by more or less continuous sedimentation, loess-palaeosol sequences are more complex depositional systems with significantly different_accumulation rates, more dynamic environmental thresholds and higher sensitivity to erosion. Thus, valid correlations on regional or even continental scale are only possible at the level of first order units (i.e. MIS or glacial loess and interglacial pedocomplex units), although current research has provided significant progress for inter-profile correlations and direct comparison of different palaeoclimatic records . However, rapid current improvements in radiometric dating techniques, associated with tephrochronological approaches, could result in much better understanding of the chronostratigraphic mosaic in forthcoming years. Due to widespread distribution across Northern Hemisphere continents, loess records with accurate age control can be regarded as a missing link for better understanding inter hemispheric climate interactions. paleoclimatic variation and linkages across the Northern Hemisphere and globally, and between continents and oceans. 
1091

1092

1093

1094

1095

1096

1097

1098

1099

1100

1101

1102

1103

1104 study, should open possibilities for better, more detailed temporal and spatial environmental reconstructions spanning at least the Holocene, last deglaciation and last glacial period.

\section{Acknowledgements}

This research was financially supported by Project 176020 of the Serbian Ministry of Education and Science. SBM is grateful for VIFI fellowship of Chinese Academy of Sciences. F.L., C.Z., and I.O. acknowledge the financial support from a grant the Collaborative Research Center (CRC) 806 grant of the German Research Foundation (DFG). JM acknowledges support through several grants from the U.S. National Science Foundation. Dear colleagues please include details of your projects. 


\section{References}

Abbott, P.M., Davies, S.M., 2012. Volcanism and the Greenland ice-cores: the tephra record. EarthSci. Rev. 115, 173-191.

Adamiec, G., Duller, G.A.T., Roberts, H.M., Wintle, A.G., 2010. Improving the TT-OSL SAR protocol through source trap characterization. Radiat. Meas. 4, 768-777.

Aitken, M.J., 1985. Thermoluminescece Dating. Academic Press, London.

Alon, D., Mintz, G., Cohen, I., Weiner, S., Boaretto, E., 2002. The use of Raman spectroscopy to monitor the removal of humic substances from charcoal: quality control for $14 \mathrm{C}$ dating of charcoal. Radiocarbon 44, 1-11.

Aleinikoff, J. N., Muhs, D. R., Bettis, E. A., Johnson, W. C., Fanning, C. M., Benton, R., 2008. Isotopic evidence for the diversity of late Quaternary loess in Nebraska: Glaciogenic and nonglaciogenic sources, Geol. Soc. Am. Bull., 120, 1362-1377.

Albani, S., Mahowald, N.M., Winckler, G., Anderson, W.F., Bradtmiller, L.l., Delmonte, B., Francois, R., Goman, M., Heavens, N.G., Hesse, P.P., Hovan, S.A., Kang, S.G., Kohfeld, K.E., Lu, H., Maggi, V., Mason, J.A., Mayewski, P., McGee, D., Miao, X., Otto-Bliesner, B.L., Perry, A.T., Pourmand, A., Roberts, H.M., Rosenbloom, N., Stevens, T., Sun, J., 2015. Twelve thousand years of dust: the Holocene global dust cycle constrained by natural archives. Clim. Past. 11, 869-903.

An, Z., Liu, T., Lu, Y., Porter, S.C., Kukla, G., Wu, X.H., Hua, J.M. 1990. The long-term palaeomonsoon variation recorded by the loess-palaeosol sequence in central China. Quatern. Int. 7/8, 91-95.

Anechitei-Deacu, V., Timar-Gabor, A., Fitzsimmons, K.E., Veres, D., Hambach, U., 2014. Multi-method luminescence investigations on quartz grains of different sizes extracted from a loess section in southeast Romania interbedding the Campanian Ignimbrite ash layer. Geochronometria 41, 1-14.

Ankjærgaard, C., Guralnik, B., Buylaert, J.-P., Reimann, T., Yi, S.W., Wallinga, J., 2016. Violet stimulated luminescence dating of quartz from Luochuan (Chinese loess plateau): Agreement with independent chronology up to $\sim 600 \mathrm{ka}$. Quat. Geochronol. 34, 33-46.

Antoine, P., Coutard, S., Guerin, G., Deschodt, L., Goval, E., Locht, J.-L., Paris, C. 2016. UpperPleistocene loess-palaeosol records from Northern France in the European context : environmental background and dating of the Middle Palaeolithic. Quatern. Int. 411, 4-24.

Antoine, P., Rousseau, D.D., Degeai, J.P., Moine, O., Lagroix, F., Kreutzer, S., Fuchs, M., Hatté, C., Gauthier, C., Svoboda, J., Lisa, L., 2013. High-resolution record of the environmental response to climatic variations during the Last Interglacial-Glacial cycle in Central Europe: the loess-palaeosol sequence of Dolní Vestonice (Czech Republic). Quat. Sci. Rev. 67, 17-38.

Antoine, P., Rousseau, D.D., Fuchs, M., Hatte, C., Gauthier, C., Markovic, S.B., Jovanovic, M., Gaudenyi, T., Moine, O., Rossignol, J., 2009. High-resolution record of the last climatic cycle in the southern Carpathian Basin (Surduk, Vojvodina, Serbia). Quatern. Int. 198, 19-36.

Antoine, P., Rousseau, D.D., Lautridou, J.-P., Hatté, C. 1999. Last Interglacial-Glacial climatic cycle in loess-palaeosol successions of north-western France. Boreas 28, 551-563.

Antoine, P., Rousseau, D.D., Zöller, L., Lang, A., Munaut, A.V., Hatté, C., Fontugne. M., 2001. High resolution record of the Last Interglacial-Glacial cycle in the Nussloch loess-palaeosol sequences, Upper Rhine Area Germany. Quat. Int. 76-77, 211-229. 
Ascough, P., Sturrock, C.J., Bird, M.I., 2010. Investigation of growth responses in saprophytic fungi to charred biomass. Isotopes Environ. Health Stud. 46, 64-77.

Ascough, P.L., Bird, M.I., Francis, S.M., Lebl, T., 2011a. Alkali extraction of archaeological and geological charcoal: evidence for diagenetic degradation and formation of humic acids. J. Archaeol. Sci. 38, 69-78.

Ascough, P.L., Bird, M.I., Francis, S.M., Thornton, B., Midwood, A.J., Scott, A.C., Apperley, D., 2011 b. Variability in oxidative degradation of charcoal: influence of production conditions and environmental exposure. Geochim. Cosmochim. Acta 75, 2361-2378.

Bacsak, G.Y., 1942. Deie Wirkung der skandinavischen Vereisung auf die Periglazialzone. Institut fuer Meteorologie and Erdmagnetismus Neue Serie 13, Budapest, 86 pp.

Baddouh, M. , Meyers, S.R., Carroll, A.R., Beard, B.L., Johnson, C.M., 2016. Lacustrine 87Sr/86Sr as a tracer to reconstruct Milankovitch forcing of the Eocene hydrologic cycle. Earth Planet. Sci. Lett. 448, 62-68. doi:10.1016/j.epsl.2016.05.007

Basarin, B., Buggle, B., Hambach, U., Marković, S.B., Dhand, K.O., Kovačević, A., Stevens, T., Guo, Z., Lukić, T., 2014. Time-scale and astronomical forcing of serbian loess-palaeosol sequences. Glob. Planet. Change 122, 89-106. doi:10.1016/j.gloplacha.2014.08.007

Bassinot, F.V., Labeyrie, L.D., Vincent, E., Quidelleur, X., Shackleton, N.J., Lancelot, Y., 1994. The astronomical theory of climate and the age of the Brunhes-Matuyama magnetic reversal. Earth Planet. Sci. Lett. 126, 91-108.

Bazin, L., Landais, A., Lemieux-Dudon, B., Toyé, M., Kele, H., Veres, D., Parrenin, F., Martinerie, P., Ritz, C., Capron, E., Lipenkov, V., Loutre, M.-F., Raynaud, D., Vinther, B., Svensson, A., Rasmussen, S.O., Severi, M., Blunier, T., Leuenberger, M., Fischer, H., Masson-Delmotte, V., Chappellaz, J., Wolff, E., 2013. An optimized multi-proxy, multi-site Antarctic ice and gas orbital chronology (AICC2012): 120-800 ka. Clim. Past 9, 1715-1731.

Becze-Deak, J., Langohr, R., Verrecchia, E., 1997. Small scale secondary $\mathrm{CaCO}_{3} \underline{\text { accumulations in }}$ selected sections of the European loess belt: morphological forms and potential for paleoenvironmental reconstruction. Geoderma 76, 221-252.

Bettis, E.A., III, Muhs, D.R., Roberts, H.M. and Wintle, A.G., 2003. Last glacial loess in the conterminous USA. Quaternary Sci. Rev. 22, 1907-1946.

Bird, M.I., Ascough, P.L., 2012. Isotopes in pyrogenic carbon: a review. Org. Geochem. 42, 15291539.

Bird, M.I., Ayliffe, L.K., Fifield, K., Cresswell, R., Turney, C., 1999. Radiocarbon dating of 'old' charcoal using a wet oxidation-stepped combustion procedure. Radiocarbon 41, 127-140.

Björck, S., Walker, M.J.C., Cwynar, L.C., Johnsen, J., Knudsen, K.L., Lowe, J.J., Wohlfarth, B., 1998. An event stratigraphy for the Last Termination in the North Atlantic region based on the Greenland icecore record: a proposal by the INTIMATE group._. J. Quat. Sci. 13/4, 283-292.

Blaauw, M., 2010. Out of tune: the dangers of aligning proxy archives. Quat. Sci. Rev. 36, 38-49. doi: 10.1016/j.quascirev.2010.11.012.

Blockley, S.P.E., Lane, C.S., Hardiman, M., Rasmussen, S. O., Seierstad, I.K., Rasmussen, S.O., Seierstad, I.K., Steffensen, J.P., Svensson, A., Lotter, A.F., Turney, C.S.M., Ramsey, C.B. and 
INTIMATE members. 2012. Synchronisation of palaeoenvironmental records over the last 60,000 years, and an extended INTIMATE(1) event stratigraphy to 48,000 b2k. Quat. Sci. Rev. 36, 2-10.

Bokhorst, M., Vandenberghe, J., 2009. Validation of wiggle matching using a multi-proxy approach and its paleoclimatic significance. J. Quat. Sci. 24, 937-947

Bokhorst, M.P., Vandenberghe, J., Sümegi, P., Lanczont, M., Gerasimenko, N.P., Matviishina, Z.N., Markovic, S.B., Frechen, M., 2011. Atmospheric circulation patterns in Central and Eastern Europe during the Weichselian Pleniglacial inferred from loess grain-size records. Quat. Int. 234, 62-74.

Bond, G., Heinrich, H., Broecker, W., Labeyrie, L., McManus,J., Andrews, J., Huon, S., Jantschik, R., Clasen, S., Simet, C., Tedesco, K., Klas, M., Bonani, G., Ivy, S., 1992. Evidence for massive discharges of icebergs into the North Atlantic Ocean during the last glacial period. Nature 360, 245-249.

Brauer A, Wulf S, Mangili C, Moscariello A. 2007. Tephrochronological dating of varved interglacial lake deposits from Pianico-Sellere (Southern Alps, Italy) to around 400 ka. Journal of Quaternary Science 22: 85-96.

Brennan, R., Quade, J., 1997. Reliable Late-Pleistocene stratigraphic ages and shorter groundwater travel times from ${ }^{14} \mathrm{C}$ in fossil snails from the southern Great Basin. Quat. Res. 47, 329-336.

Bronger, A., 1976. Zur quartären Klima- und Landschaftsentwicklung des Karpatenbeckens auf (paläo-)pedologischer und bodengeographischer Grundlage. In Kieler geographische Schriften 45. Selbstverlag des Geographischen Instituts der Universität Kiel, Kiel.

Bronger, A., 2003. Correlation of loess-paleosol sequences in East and Central Asia with SE Central Europe - Towards a continental Quaternary pedostratigraphy and paleoclimatic history. Quat. Int. 106/107, 11-31.

Bronger, A., Heinkele, T., 1989. Micromorphology and genesis of paleosols in the Luochuan loess section, China: Pedostratigraphical and environmental implications. Geoderma 45, 123-143.

Bronger, A., Winter, R., Sedov, S.. 1998. Weathering and clay mineral formation in two Holocene soils and in buried paleosols in Tadjikistan towards a Quaternary paleoclimatic record in Central Asia. Catena 34, 19-34.

Brown, N.D., Forman, S.L., 2012. Evaluating a SAR TT-OSL protocol for dating fine-grained quartz within Late Pleistocene loess deposits in the Missouri and Mississippi river valleys, United States. Quat. Geochronol. 12, 87-97.

Buggle, B., Hambach, U., Kehl, M., Marković, S.B., Zöller, L., Glaser, B., 2013. The progressive evolution of a continental climate in SE-Central European lowlands during the Middle Pleistocene recorded in loess paleosol sequences. Geology 41, 771-774.

Buylaert, J.P., Jain, M., Murray, A.S., Thomsen, K.J., Thiel, C., Sohbati, R., 20122013. A robust feldspar luminescence dating method for Middle and Late Pleistocene sediments. Boreas 41, 435-451.

Buylaert, J.P., Murray, A.S., Thomsen, K.J., Jain, M., 2009. Testing the potential of an elevated temperature IRSL signal from K-feldspar. Radiat. Meas. 44, 560-565.

Buylaert, J.P., Murray, A.S., Vandenberghe, D., Vriend, M., De Corte, F., Van den haute, P., 2008. Optical dating of Chinese loess using sand-sized quartz: Establishing a time frame for Late Pleistocene climate changes in the western part of the Chinese Loess Plateau. Quat. Geochronol. 3, 99-113. 
Buylaert, J.P., Yeo, E. Y., Thiel, C., Yi, S., Stevens, T., Thompson, W., Frechen, M., Murray, A., Lu, H., 2015. A detailed post-IR IRSL chronology for the last interglacial soil at the Jingbian loess site (northern China). Quat. Geochronol. 30, 194-199.

Channell, J.E.T., Xuan, C., Hodell, D.A., 2009. Stacking paleointensity and oxygen isotope data for the last 1.5 Myr (PISO-1500). Earth Planet. Sci. Lett. 283, 14-23.

Chappell, J., Head, M.J., Magee, J., 1996. Beyond the radiocarbon limit in Australian archaeology and Quaternary research. Antiquity 70, 543-752.

Chapot, M.S., Roberts, H.M., Duller, G.A.T., Lai, Z.P., 2016. Natural and laboratory TT-OSL dose response curves: Testing the lifetime of the TT-OSL signal in nature. Radiat. Meas. 85, 41-50.

Chen, Y., Li, S.-H., Li, B., Hao, Q., Sun, J., 2015.Maximum age limitation in luminescence dating of Chinese loess using the multiple-aliquot MET-pIRIR signals from K-feldspar. Quat. Geochronol. 30, 207-212.

Cheng, H., Zhang, P.Z., Spötl, C., Edwards, R.L., Cai, Y.L., Zhang, D.Z., Sang, W.C., Tan, M., An, Z.S., 2012. The climatic cyclicity in semiarid-arid central Asia over the past 500,000 years. Geophys. Res. Lett. 39, L01705, doi:10.1029/2011GL050202.

Chlachula, J., Evans, M.E., Rutter, N.W., 1998. A magnetic investigation of a Late Quaternary loess/palaeosol record in Siberia. Geophysical Journal International 132, 128-132.

Cohen-Ofri, I., Weiner, L., Boaretto, E., Mintz, G., Weiner, S., 2006. Modern and fossil charcoal: aspects of structure and diagenesis. J. Archaeol. Sci. 33, 428-439.

Constantin, D., Begy, R., Vasiliniuc, S., Panaiotu, C., Necula, C., Codrea, V., Timar-Gabor, A., 2014. High-resolution OSL dating of the Costineşti section (Dobrogea, SE Romania) using fine and coarse quartz. Quat. Int. 334-335, 20-29.

Constantin, D., Cameniţă, A., Panaiotu, C., Necula, C., Codrea, V., Timar-Gabor, A., 2015. Fine and coarse-quartz SAR-OSL dating of Last Glacial loess in Southern Romania. Quat. Int. 357, 33-43.

Constantin, D., Timar-Gabor, A., Veres, D., Begy, R., Cosma, C., 2012. SAR-OSL dating of different grain-sized quartz from a sedimentary section in southern Romania interbedding the Campanian Ignimbrite/Y5 ash layer. Quat. Geochronol. 10, 81-86.

Dansgaard, W., Johnsen, S.J., Clausen, H.B., Dahl-Jensen, D., Gundestrup, N.S., Hammer, C.U., Hvidberg, C.S., Steffensen, J.P., Sveinbjörnsdottir, A.E., Jouzel, J., Bond, G., 1993. Evidence for general instability of past climate from a 250-kyr ice-core record. Nature 364, 218-220.

De Angelis, M., Steffensen, J.P., Legrand, M., Clausen, H., Hammer, C., 1997. Primary aeroso I(sea salt and soil dust) deposited in Greenland ice during the last climatic cycle: comparison with east Antarctic records. J. Geophys. Res. 102, 26681-26698.

De Vivo, B., Rolandi, G., Gans, P.B., Calvert, A., Bohrson, W.A., Spera, F.J., Belkin, H.E., 2001. New constraints on the pyroclastic eruptive history of the Campanian volcanic Plain (Italy). Miner. Petrol. 73, 47-65.

Demek, J., Kukla, G., 1969. Periglazialzone, Löss und Palaolithikum der Tschechoslowakei, Akad. Wiss. Geogr. Inst. Brno, Brno.

Ding, Z.L., Liu, T. S., Liu, X. M., Chen, M. Y. and An, Z. S., 1990. Thirty-seven climatic cycles in the last 2.5Ma. Chinese Sci. Bull. 34, 1494-1496. 
Ding, Z.L., Ranov, V., Yang, S.L., Finaev, A., Han, J.M., Wang, G.A., 2002. The loess record in southern Tajikistan and correlation with Chinese loess. Earth Planet. Sci. Lett. 200, 387-400.

Dodonov, A.E., Zhou, L.P., 2008. Loess deposition in Asia: its initiation and development before and during the Quaternary. Episodes 31, 222-225.

Dong, Y., Wu, N., Li., F., Huang, L., Wen, W., 2015. Time-transgressive nature of the magnetic susceptibility record accross the Chinese Loess Plateau at the Pleistocene/Holocene transition. Plos One 10 (7), e0133541.

Ebisuzaki, W., 1997. A Method to Estimate the Statistical Significance of a Correlation When the Data Are Serially Correlated. J. Clim. 10, 2147-2153. doi:10.1175/1520-

0442(1997)010<2147:AMTETS>2.0.CO;2

Evin, J., Marechal, J., Pachiaudi, C., 1980. Conditions involved in dating terrestrial shells. Radiocarbon $\underline{22,545-555 .}$

Fattahi, M., Stokes, S., 2003. Dating volcanic and related sediments by luminescence methods: a review. Earth-Science Reviews 62(3), 229-264.

Fink, J., 1962. Studien zur absoluten und relativen Chronologie der fossilen Böden in Österreich, II Wetzleinsdorf und Stillfried. Archaeol. Austriaca 31, 1- 18.

Fink, L., Kukla, G., 1977. Pleistocene climates in Central Europe: at least 17 interglacials after the Olduvai event. Quat. Res. 7, 363-371.

Fitzsimmons, K., Hambach, U., Veres, D., lovita, R., 2013. The Campanian Ignimbrite eruption: new data on volcanic ash dispersal and its potential impact on human evolution. PLoS One 8/6, e65839. doi:10.1371/journal.pone.0065839

Fuchs, M., Rousseau, D.D., Antoine, P., Hatté, C., Gauthier, C., 2008. Chronology of the Last Climatic Cycle (Upper Pleistocene) of the Surduk loess sequence, Vojvodina, Serbia. Boreas 37, 66-73.

Fuhrer, K., Legrand, M., 1997. Continental biogenic species in the Greenland Ice Core Project ice core: tracing back the biomass history of the North American continent. J. Geophys. Res. 102, 2673526745.

Götzinger, G., 1936. Das Lößgebiet um Göttweig und Krems an der Donau. In: Götzinger, G. (Ed.), Führer für die Quartär-Exkursionen in Österreich. Geologische Bundesanstalt, Wien, pp. 1-11.

Gradstein, F., Ogg, J., Schmitz, M., Ogg, G., 2012. The Geologic Time Scale 2012. Fac. Authored Books.

\section{Haggi, C., Zech, R., McIntyre, C., Eglinton, T., 2013. On the stratigraphic integrity of leaf-wax} biomarkers in loess-paleosols. Biogeosci. Discuss. 10, 16903-16922.

Hambach, U., Rolf, C., Schnepp, E., 2008a. Magnetic dating of Quaternary sediments, volcanites and archaeological materials: an overview. E \& G, Quaternary Science Journal, 57/1-2, 25-51

Hambach, U., Zeeden, C., Hark, M., Zöller, L., 2008b. Magnetic dating of an Upper Palaeoltihic cultural layer bearing loess from the Krems-Wachtberg site (Lower Austria). In: J. Reitner et al. (Eds.) Veränderter Lebensraum - Gestern, Heute und Morgen. DEUQUA Symposium 2008. Abhandlungen der geologischen Bundesanstalt (62): $153-157$. 
Haesaerts, P., Damblon, F. Gerasimenko, N., Spagna, P. and Pirson, S. 2016. The Late Pleistocene loess-palaeosol sequence of Midle Belgium. Quat. Int. 411, 25-43.

Hao, Q.Z., Wang, L., Oldfield, F., Peng, S.Z., Qin, L., Song, Y., Xu, B., Qiao, Y., Bloemendal, J., Guo, Z.T., 2012. Delayed build-up of Arctic ice sheets during 400,000-year minima in insolation variability. Nature 490, 393-396.

Heller F, Liu T., 1984. Magnetism of Chinese loess deposits. J. Roy. Astron. Soc. 77, 125-141.

Heller, F., Liu, T., 1982. Magnetostratigraphical dating of loess deposits in China. Nature 300, 431433.

Heslop, D., Langereis, C.G., Dekkers, M.J., 2000. A new astronomical timescale for the loess deposits of Northern China. Earth Planet. Sci. Lett. 184, 125-139. doi:10.1016/S0012-821X(00)00324-1

Hilgen, F.J., Hinnov, L.A., Aziz, H.A., Abels, H.A., Batenburg, S., Bosmans, J.H.C., Boer, B. de, Hüsing, S.K., Kuiper, K.F., Lourens, L.J., Rivera, T., Tuenter, E., Wal, R.S.W.V. de, Wotzlaw, J.-F., Zeeden, C., 2014. Stratigraphic continuity and fragmentary sedimentation: the success of cyclostratigraphy as part of integrated stratigraphy. Geol. Soc. Lond. Spec. Publ. 404, SP404.12. doi:10.1144/SP404.12

Horváth, E., 2001. Marker horizons in the loesses of the Carpathian Basin. Quat. Int. 76/77, 157-163. Jain, M., 2009. Extending the dose range: probing deep traps in quartz with $3.06 \mathrm{eV}$ photons. Radiat. Meas. 44, 445-452.

Jouzel, J., Masson-Delmotte, V., Cattani, O., Dreyfus, G., Falourd, S., Hoffmann, G., Minster, B., Nouet, J., Barnola, J.M., Chappellaz, J., Fischer, H., Gallet, J.C., Johnsen, S., Leuenberger, M., Loulergue, L., Luethi, D., Oerter, H., Parrenin, F., Raisbeck, G., Raynaud, D., Schilt, A., Schwander, J., Selmo, E., Souchez, R., Spahni, R., Stauffer, B., Steffensen, J.P., Stenni, B., Stocker, T.F., Tison, J.L., Werner, M., Wolff, E.W., 2007. Orbital and millennial Antarctic climate variability over the past 800,000 years. Science $317,793-796$.

Karátson, D., Wulf, S., Veres, D., Magyari, E.K., Gertisser, R., Timar-Gabor, A., Novothny, Á., Telbisz, T., Szalai, Z., Anechitei-Deacu, V., Appelt, O., Bormann, M., Jánosi, C., Hubay, K., Schäbitz, F., 2016. The latest explosive eruptions of Ciomadul (Csomád) volcano, East Carpathians - a tephrostratigraphic approach for the 52-29 ka BP time interval. J. Volcanol. Geoth. Res. 319, 29-51.

Kohfeld, K.E., Harrison, S.P., 2003. Glacial-interglacial changes in dust deposition on the Chinese Loess Plateau. Quaternary Science Reviews 22, 1859-1878.

Kissel, C., Mazaud, A., Channell, J.E., Beer, J., others, 2000. North Atlantic palaeointensity stack since 75ka (NAPIS-75) and the duration of the Laschamp event. Philos. Trans. R. Soc. Lond. Math. Phys. Eng. Sci. 358, 1009-1025.

Klasen, N., Fischer, P., Lehmkuhl, F., Hilgers, A., 2015. Luminescence Dating of Loess Deposits from the Remagen-Schwalbenberg Site. Geochronom. 42. 67-77.

Kong, X.G., Zhou, W., Beck, W., Xian, F., Wu, Z., 2014. Asynchronous records of Brunhes/Aatuyama reversal in marine sediments and Chinese loess: Review and discussion. Quat. Int. 319, 137-142.

Kukla, G., 1987. Loess stratigraphy in central China. Quat. Sci. Rev. 6, 191-219.

Kukla, G., An, Z., 1989. Loess stratigraphy in Central China. Palaeogeogr. Palaeoclimatol. Palaeoecol. 72, 203-225. 
Kukla, G., Heller, F., Xiu Ming, L., Sheng, A.Z., 1988. Pleistocene Climates in China Dated by Magnetic Susceptibility. Geology 16 (9), 811-814.

Kukla, G.J., 1970. Correlations between loesses and deep-sea sediments. Geologiska Foreningen i Stockholm Forhandlingar 92, 148-180.

Kukla, G.J., 1975. Loess stratigraphy of Central Europe, in: Butzer, K.W., Isaac, L.I. (Eds.), After the Australopithecines. Mouton Publishers, The Hague, pp. 99-187.

Kukla, G.J., 1977. Pleistocene land-sea correlations. Earth-Sci. Rev. 13, 307-374.

Kukla, G.J., Cilek, V., 1996. Plio-Pleistocene megacycles: record of climate and tectonics. Palaeogeogr. Palaeoclimatol. Palaeoecol. 120, 171-194.

Lai, Z., 2010. Chronology and the upper dating limit for loess samples from Luochuan section in the Chinese Loess Plateau using quartz OSL SAR protocol. J. Asian Earth Sci. 37, 176-185.

Laj, C., Kissel, C., Beer, J., 2004. High Resolution Global Paleointensity Stack Since 75 kyr (GLOPIS-75) Calibrated to Absolute Values. Timescales Paleomagn. Field 255-265.

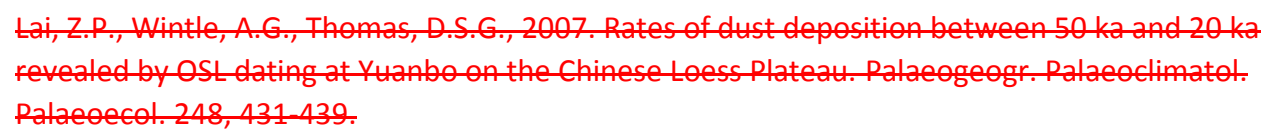

Laskarev, V., 1926. Deuxieme note sur le loess des environs de la Belgrade. Geoloski anali Balkanskoga poluostrva (Annales Geologiques de la Peninsule Balkanique) VIII (2), 1-19.

Lehmkuhl, F., Zens, J., Krauss, L., Schulte, P., Kels, H., 2016. Loess-palaeosol sequences at the northern European loess belt in Germany. Distribution, geomorphology and stratigraphy. Quat. Sci. Rev. 153,11-30.

Li, B., Li, S.-H., 2006. Studies of thermal stability of charges associated with thermal transfer of OSL from quartz. J. Phys. D. Appl. Phys. 39, 2941-2949.

Li, B., Li, S.-H., 2012. Luminescence dating of Chinese loess beyond $130 \mathrm{ka}$ using the non-fading signal from K-feldspar. Quat. Geochronol. 10, 24-31.

Lisiecki, L.E., Raymo, M.E., 2005. A Pliocene-Pleistocene stack of 57 globally distributed benthic $\delta 180$ records. Paleoceanography 20, PA1003, doi:10.1029/2004PA001071.

Liu, Q., Banerjee, S.K., Jackson, M.J., Deng, C., Pan, Y., Zhu, R., 2005. Inter-profile correlation of the Chinese loess/paleosol sequences during Marine Oxygen Isotope Stage 5 and indications of pedogenesis. Quat. Sci. Rev. 24, 195-210.

Liu, T., 1985. Loess and the environment. China Ocean Press, Beijing, 251 pp.

Liu, T., Chang, T., 1962. The "Huangtu"(loess) of China. Rept. 6th INQUA Congress, Warsaw 1961 4, 503-534.

Lowe, D.J., 2011. Tephrochronology and its application: A review. Quat. Geochronol. 6/2, 107-153.

Lu, H., Stevens, T., Yi, S.W., Sun, X.F., 2006. An erosional hiatus in Chinese loess sequences revealed by closely spaced optical dating. Chin. Sci. Bull. 51. 2253-2259.

Maher, B.A., 2016. Paleoclimatic records of the loess/palaeosol sequences of the Chinese Loess Plateau. Quat. Sci. Rev. 154, 23-84 
Maher, B.A., Mutch, T.J., Cunningham, D., 2009. Magnetic and geochemical characteristics of Gobi Desert surface sediments: implications for provenance of the Chinese Loess Plateau. Geology 37, 279-282.

Marković, S. B. Oches, E.A., Jovanović, M., Gaudenyi, T., Hambach, U., Zöller, L., Sümegi, P., 2004. Paleoclimate record in the Late Pleistocene loess-paleosol sequence at Miseluk (Vojvodina, Serbia). Quaternaire 15/4, 361-368.

Marković, S., Hambach, U., Stevens, T., Jovanović, M., O’Hara-Dhand, K., Basarin, B., Lu, H., Smalley, I., Buggle, B., Zech, M., Svirčev, Z., Sümegi, P., Milojković, N., Zöller, L., 2012a. Loess in the Vojvodina region (Northern Serbia): an essential link between European and Asian Pleistocene environments. Neth. J. Geosci. Geol. Mijnbouw 91, 173-188.

Marković, S., Hambach, U., Stevens, T., Jovanović, M., O’Hara-Dhand, K., Basarin, B., Lu, H., Smalley, I., Buggle, B., Zech, M., Svirčev, Z., Sümegi, P., Milojković, N., Zöller, L., 2012. Loess in the Vojvodina region (Northern Serbia): an essential link between European and Asian Pleistocene environments. Neth. J. Geosci. Geol. Mijnbouw 91, 173-188.

Marković, S.B., Fitzsimmons, K.E., Sprafke, T., Gavrilović, D., Smalley, I.J., Jović, V., Svirčev, Z., Gavrilov, M.B., Bešlin, M., 2016. The History of Danube Loess Research. Quat. Int. 399, 86-99.

Marković, S.B., Hambach, U, Jovanović, M., Stevens, T., O’Hara-Dhand, K., Basarin, B., Smalley. I.J., Buggle, B., Zech, M., Svirčev, Z., Milojković, N., Zöller, L., 2012b. Loess in Vojvodina region (Northern Serbia): the missing link between European and Asian Pleistocene environments. Neth. J. Geosci. 91, 173-188.

Marković, S.B., Hambach, U., Catto, N., Jovanović, M., Buggle, B., Machalett, B., Zöller, L., Glaser, B., Frechen, M., 2009. The middle and late Pleistocene loess-paleosol sequences at Batajanica, Vojvodina, Serbia. Quat. Int. 198, 255-266.

Marković, S.B., Hambach, U., Stevens, T., Kukla, G.J., Heller, F., McCoy, W.D., Oches, E.A., Buggle, B., Zöller, L., 2011. The last million years recorded at the Stari Slankamen loess-palaeosol sequence: revised chronostratigraphy and long-term environmental trends. Quat. Sci. Rev. 30, 1142-1154.

Marković, S.B., Korać, M., Mrđić, N., Buylaert, J-P., Thiel, C., McLaren, S.J., Stevens, T., Tomić, N., Petić, N., Jovanović, M., Vasiljević, D.A., Sümegi, P., Gavrilov, M.B., Obreht, I., 2014.

Palaeoenvironment and geoconservation of mammoths from the Nosak loess-palaeosol sequence (Drmno, northeastern Serbia): Initial results and perspectives. Quat. Int. 334-335, 30-39.

Marković, S.B., McCoy, W.D., Oches, E.A., Savić, S., Gaudenyi, T., Jovanović, M., Stevens, T., Walther, R., Ivanišević, P., Galić, Z., 2005. Paleoclimate record in the Upper Pleistocene loess-paleosol sequence at Petrovaradin brickyard (Vojvodina, Serbia). Geol. Carpath. 56, 545-552.

Marković, S.B., Oches, E., Sümegi, P., Jovanović, M., Gaudenyi, T., 2006. An introduction to the Upper and Middle Pleistocene loess-paleosol sequence at Ruma brickyard, Vojvodina, Serbia. Quat. Int. $149,80-86$.

Marković, S.B., Oches, E.A., McCoy, W.D., Gaudenyi, T., Frechen, M., 2007. Malacological and sedimentological evidence for "warm" glacial climate from the Irig loess sequence, Vojvodina, Serbia. Geochem. Geophys. Geosyst. 8, Q09008. http://dx.doi.org/10.1029/2006GC001565

Marković, S.B., Stevens, T., Kukla, G.J., Hambach, U., Fitzsimmons, K.E., Gibbard, P., Buggle, B., Zech, M., Guo, Z., Hao, Q., Wu, H., O’Hara-Dhand, K., Smalley, I.J., Újvári, G., Sumegi, P., Timar-Gabor, A., 
Veres, D., Sirocko, F., Vasiljević, D..A., Jary, Z., Svensson, A., Jović, V., Lehmkuhl, F., Kovacs, J., Svircev, Z., 2015. Danube loess stratigraphy - towards a pan European loess stratigraphic model. Earth-Sci. Rev. 148, 228-258.

Mason, J.A., Jacobs, P.M., Hanson, P.R., Miao, X., Goble, R.J., 2003. Sources and paleoclimatic significance of Holocene Bignell Loess, central Great Plains, USA. Quat. Res. 60, 330-339.

Mason, J.A., Miao, X., Hanson, P.R., Johnson, W.C., Jacobs, P.M., Goble, R.J., 2008. Loess record of the Pleistocene-Holocene transition on the northern and central Great Plains, USA. Quat. Sci. Rev. $27,1772-1783$

Meszner, s. Kreutzer, S., Fuchs, M., Faust, D., 2014. Identifying depositional and pedogenetic controls of late Pleistocene loess-palaeosol sequences (Saxony, Germany) by combined grain size and microscopic analyses. Z .Geomorphol. 58 Suppl 3, 63-90.

Meyers, S.R., 2014. Astrochron: An R Package for Astrochronology Version 0.6.5.

Miao, X., Xulong, W., Mason, J.A., 2007. Isolation of the syndepositional magnetic susceptibility signals from loessic paleosols of China. J. Asi. E. Sci. 27, 684-690.

Moine, O., Rousseau, D.-D., Antoine, P., 2008. The impact of Dansgaard-Oeschger cycles on the loessic environment and malacofauna of Nussloch (Germany) during the upper Weichselian. Quat. Res. 70, 91-104.

Mudelsee, M., 2003. Estimating Pearson's correlation coefficient with bootstrap confidence interval from serially dependent time series. Math. Geol. 35, 651-665.

Muhs, D.R., 2013. The geologic records of dust in the Quaternary. Aeolian Res. 9, 3-48.

Muhs, D.R., Bettis, E.A., Aleinikoff, J.N., McGeehin J.P., Beann, J., Skipp, G., Marshall, B.D., Roberts, H.M., Johnson, W.C., Reynolds, R.L., 2008. Origin and paleoclimatic signifi cance of late Quaternary loess in Nebraska: Evidence from stratigraphy, chronology, sedimentology, and geochemistry. GSA Bulletin 120 (11/12), 1378-1407.

Muhs, D.R., Bettis, E.A., Roberts, H.M., Harlan, S.S., Paces, J.B., Reynolds, R.L., 2013. Chronology and provenance of last-glacial (Peoria) loess in western lowa and paleoclimatic implications. Quat. Res. $80(3), 468-481$.

Murray, A.S., Schmidt, E.D., Stevens, T., Buylaert, J.-P., Marković, S.B., Tsukamoto, S., Frechen, M., 2014. Dating middle Pleistocene loess from Stari Slankamen (Vojvodina, Serbia) - limitations imposed by the saturation behaviour of an elevated temperature IRSL signal. Catena 117,34-42.

Aurray, A.S., Wintle, A.G., 2000. Luminescence dating of quartz using an improved single-aliquot regenerative-dose protocol. Radiat. Meas. 32, 57-73.

Murray, A.S., Wintle, A.G., 2003. The single aliquot regenerative dose protocol: potential for improvements in reliability. Radiat. Meas. 37, 377-381.

Nie, J., Stevens T., Rittner, M., Stockli, D., Garzanti, E., Limonta, M., Bird, A., Andò, S., Vermeesch, P., Saylor, J., Lu, H., Breecker, D., Hu, X., Liu, S., Resentini, A., Vezzoli, G., Peng, W., Carter, A., Ji, S., Pan, B., 2015. Loess Plateau storage of Northeastern Tibetan Plateau-derived Yellow River sediment. Nat. Commun. 6, 1-10.

North Greenland Ice Core Project members (2004), High-resolution record of Northern Hemisphere climate extending into the last interglacial period, Nature 431, 147-151. 
Novothny, Á., Frechen, M., Horváth, E., Bradák, B., Oches, E.A., McCoy, W.D., Stevens, T., 2009. Luminescence and amino acid recemization chronology of the loess-palaeosol sequence at Sütto, Hungary. Quat. Int. 198/1-2, 62-76.

Obreht, I., Zeeden, C., Hambach, U., Veres, D., Marković, S.B., Bosken, J., Svirčev, Z., Bačević, N., Gavrilov, MB., Lehmkuhl, F., 2016.Tracing of mediterranean climate on Southeastern Europe during the past 350000 years Sci Rep 6, 36334.

Oches, E.A., McCoy, W.D., 1995a. Aminostratigraphic evaluation of conflicting age estimates for the "Young Loess" of Hungary. Quat. Res. 43, 160-170.

Oches, E.A., McCoy, W.D., 1995b. Amino acid geochronology applied to the correlation and dating of central European loess deposits. Quat. Sci. Rev. 14, 767-782.

Ogg, J.G., 2012. Chapter 5 - Geomagnetic Polarity Time Scale, in: Gradstein, F.M., Ogg, J.G., Schmitz, M.D., Ogg, G.M. (Eds.), The Geologic Time Scale. Elsevier, Boston, pp. 85-113.

Ólafsdóttir, K.B., Mudelsee, M., 2014. More accurate, calibrated bootstrap confidence intervals for estimating the correlation between two time series. Math. Geosci. 46, 411-427.

Olson, E.A., Broecker, W.S., 1958. Sample contamination and reliability of radiocarbon dates. In: Transactions of the New York Academy of Science Series II, 20, pp. 593-604.

Paillard, D., Labeyrie, L., Yiou, P., 1996. Macintosh program performs time-series analysis. Eos Transactions on AGU 77, 379.

Pearson, K., 1895. Contributions to the Mathematical Theory of Evolution. III. Regression, Heredity, and Panmixia. [Abstract]. Proc. R. Soc. Lond. 59, 69-71.

Pécsi M., 1990. Loess is not just the accumulation of dust. Quat. Int. 7-8, 1-21.

Penck, A., Brückner, E., 1909. Die Eiszeiten in den nördlichen Ostalpen. Tauchnitz, Leipzig.

Penkman, K., Kaufman, D., 2012. Amino acid geochronology: Recent perspectives. Quat. Geochronol. $16,1-2$.

Pigati, J.S., Quade, J., Shanahan, T.M., Haynes Jr., C.V., 2004. Radiocarbon dating of minute gastropods and new constraints on the timing of spring-discharge deposits in southern Arizona, USA. Palaeogeogr., Palaeoclimatol., Palaeoecol. 204, 33-45.

Pigati, J.S., Rech, J.A., Nekola, J.C., 2010. Radiocarbon dating of small terrestrial gastropod shells in North America. Quat. Geochronol. 5, 519-532.

Pigati, J.S., McGeehin, J.P., Muhs, D.R., Bettis III, E.A., 2013. Radiocarbon dating late Quaternary loess deposits using small terrestrial gastropod shells. Quat. Sci. Rev. 76, 114-128.

Porter, S., 2001. Chinese loess record of monsoon climate during the last glacial-interglacial cycle. Earth-Sci. Rev. 54, 115-128.

Porter, S.C., An, Z., 1995. Correlation between climate events in the North Atlantic and China during the last glaciations. Nature 375. 305-308.

Pouclet, A., Horvath, E., Gabris, G., Juvigné, E., 1999. The Bag tephra, a widespread tephrochronological marker in Middle Europe: chemical and mineralogical investigations. Bulletin of Volcanology 60, 265-272. 
Preece, S.J., Pearce, N.J.G., Westgate, J.A., Froese, D.G., Jensen, B.J.L., Perkins, W.T., 2011. Old Crow tephra across eastern Beringia: a single cataclysmic eruption at the close of Marine Isotope Stage 6. Quat. Sci. Rev. 30, 2069-2090.

Prins, M.A., Vriend, M., Nugteren, G., Vandenberghe, J., Lu, H., Zheng, H., Weltje, G.J., 2007. Late Quaternary aeolian dust input variability on the Chinese Loess Plateau: inferences from unmixing of toess grain-size records. Quat. Sci. Rev. 26, 242-254.

Prins, M.A., Zheng, H., Beets, K., Troelstra, S., Bacon, P., Kamerling, I., Wester, W., Konert, M., Huang, X., Wang, X., Vandenberghe, J., 2009. Dust supply from river floodplains: the case of the lower Huang He (Yellow River) recorded in a loess-palaeosol sequence from the Mangshan Plateau. J. Quat. Sci. $24,75-84$

Prokopenko, A.A., Hinnov, L.A., Williams, D.F., Kuzmin, M.I., 2006. Orbital forcing of continental climate during the Pleistocene: a complete astronomically tuned climatic record from Lake Baikal, SE Siberia. Quat. Sci. Rev. 25, 3431-3457.

Pustovoytov, K., Terhorst, B., 2004. An isotopic study of a late Quaternary loessepaleosol sequence in SW Germany. Rev. Mex. Ciencias Geol. 21, 88-93.

Pye, K., 1987. Aeolian Dust and Dust Deposits. Academic Press London, p. 334.

Rech, J.A., Pigati, J.S., Lehmann, S.B., McGimpsey, C.N., Grimley, D.A., Nekola, J.C., 2011. Assessing open-system behavior of carbon-14 in terrestrial gastropod shells. Radiocarbon 53, 325-335

Rebollo, N.R., Cohen-Ofri, I., Popovitz-Biro, R., Bar-Yosef, O., Meignen, L., Goldberg, P., Weiner, S., Boaretto, E., 2008. Structural characterisation of charcoal exposed to high and low $\mathrm{pH}$; implications for $14 \mathrm{C}$ sample preparation and charcoal preservation. Radiocarbon 50, 289-307.

Rebollo, N.R., Weiner, S., Brock, F., Meignen, L., Goldberg, P., Belfer-Cohen, A., BarYosef, O., Boaretto, E., 2011. New radiocarbon dating of the transition from the Middle to the upper Paleolithic in Kebara cave, Israel. J. Archaeol. Sci. 38, 2424-2433.

Reinders, J., Hambach, U., 1995. A geomagnetic event recorded in loess deposits of the Tönchesberg (Germany): identification of the Blake magnetic polarity episode. Geophys. J. Int. 122, 407-418. doi:10.1111/j.1365-246X.1995.tb07004.x

Roberts, A. P., Tauxe, L., Heslop, D., 2013. Magnetic paleointensity stratigraphy and high-resolution Quaternary geochronology: successes and future challenges. Quaternary Science Reviews, 61, 1-16.

Roberts, H.M., 2008. The development and application of luminescence dating to loess deposits: a perspective on the past, present and future. Boreas 37, 483-507.

Roberts, H.M., Duller, G.A.T., 2004. Standardized growth curves for optical dating of sediment using multiple-grain aliquots. Radiat. Meas. 38, 241-252.

Roberts, H.M., Muhs, D.R., Wintle, A.G., Duller, G.A.T., Bettis, E.A., 2003. Unprecedented last-glacial mass accumulation rates determined by luminescence dating of loess from western Nebraska. Quat. Res. 59 (3), 411-419. 
Rolf, C., Hambach, U., Novothny, Á., Horváth, E., Schnepp, E., 2014. Dating of a Last Glacial loess sequence by relative geomagnetic palaeointensity: A case study from the Middle Danube Basin (Süttő, Hungary). Quat. Int. 319, 99-108. doi:10.1016/j.quaint.2013.08.050

Rousseau, D.-D., Antoine, P., Hatté, C., Lang, A., Zöller, L., Fontugne, M., Ben Othman, D., Luck, J.-M., Moine, O., Labonne, M., Bentaleb, I., Jolly, D., 2002. Abrupt millennial climatic changes from Nussloch (Germany) Upper Weichselian eolian records during the Last Glaciation. Quat. Sci. Rev. 21, 1577-1582.

Rousseau, D.-D., Derbyshire, E., Antoine, P., Hatté, C., 2013. Loess Records | Europe. Reference Module in Earth Systems and Environmental Sciences, from Encyclopedia of Quaternary Science (Second Edition), 606-619.

Rousseau, D.D., Sima, A., Antoine, P., Hatte, C., Lang, A., Zöller, L., 2007. Link between European and North Atlantic abrupt climate changes over the last glaciation, Geophys. Res. Lett. 34, L22713.

Rubin, M., Likins, R.C., Berry, E.G., 1963. On the validity of radiocarbon dates from snail shells. J. Geol. 71, 84-89.

Ruhe, R.V., 1956. Relations of the properties of Wisconsin loess to topography in western lowa. Amer. J. Sci. 252, 663-672.

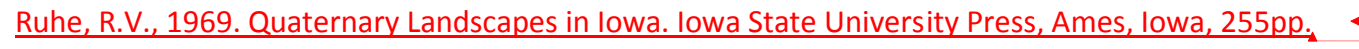

Sauer, D., Kadereit, A., Kühn, P., Kösel, M., Miller, C. E., Shinonaga, T., Kreutzer, S., Hermann, L., Fleck, W., Starkovich, B.M. and Stahr, K., 2016. The loess-palaeosol sequence of Datthausen, SW Germany: characteristics, chronology, and implications for the use of the Lohne soil as a marker soil. Catena 146, 10-29.

Schirmer, W., 2012. Rhine Loess at Schwalbenberg II - MIS 4 and 3. Quat. Sci. J. (Eiszeitalter und Gegenwart) 61, 32-47.

Schirmer, W., 2016. Late Pleistocene loess of the Lower Rhine. Quat. Int. 411, 44-61.

Schirmer, W., Ikinger, A., Nehring, F., 2012. Die terrestrischen Böden im Profil Schwalbenberg/ Mittelrhein. Mainzer geowissenschaftliche Mitteilungen 40. 53-78.

Seelos, K., Sirocko, F., Dietrich, S., 2009. A continuous high-resolution dust record for the reconstruction of wind systems in central Europe (Eifel, Western Germany) over the past $133 \mathrm{ka}$. Geophys. Res. Lett. 36, DOI: 10.1029/2009GL039716

Shackleton, N.J., Hagelberg, T.K., Crowhurst, S.J., 1995. Evaluating the success of astronomical tuning: Pitfalls of using coherence as a criterion for assessing pre-Pleistocene timescales.

Paleoceanography 10, 693-697. doi:10.1029/95PA01454

Shackleton, N.J., Imbrie, J., 1990. The $\delta^{18}$ O spectrum of oceanic deepwater over a 5-decade band. Climatic Change 16, 217-230

Shackleton, N.J., Imbrie, J., 1990. The $\delta^{18} \mathrm{O}$ spectrum of oceanic deepwater over a 5-decade band. Climatic Change 16, 217-230.

Shimek, B., 1902. The loess of Natchez, Mississippi. American Geologist 30, 279-299.

Shimek, B., 1909. The loess of Crowley's Ridge, Arkansas. lowa Academy of Science Proceedings 16, 147-155. 
Schmidt, E.D., Tsukamoto, S., Frechen, M., Murray, A.S., 2014. Elevated temperature IRSL dating of loess sections in the East Eifel region of Germany. Quaternary International, 334-335, 141-154.

Simonson, R.W., Hutton, C.E., 1954. Distribution curves for loess. American Journal of Science 252, 99-105.

Sirocko, F., Dietrich, S., Schaber, K., Seelos, K., Grootes, P.M., Kromer, B., Rein, B., Krbetschek, M., Appleby, P., Hambach, U., Rolf, C., Veres, D., Sudo, M., Grim, S., 2013. Multi-proxy-dating of Holocene maar lakes and Pleistocene dry maar sediments in the Eifel, Germany. Quat. Sci. Rev. 62, 56-76.

Sirocko, F., Knapp, H., Dreher, F., Förster, M.W., Albert, J., Brunck, H., Veres, D., Dietrich, S., Zech, M., Hambach, U., Röhner, M., Rudert, S., Schwibus, K., Adams, C., Sigl, P., 2016. The ELSAVegetation-Stack: Reconstruction of Landscape Evolution Zones (LEZ) from laminated Eifel maar sediments of the last 60,000 years. Glo. Planet. Chan. 142, 108-135.

Sirocko, F., Seelos, K., Schaber, K., Rein, B., Dreher, F., Diehl, M., Lehne, R., Jäger, K., Krbetschek, M., Degering, D., 2005. A late Eemian aridity pulse in central Europe during the last glacial inception. Nature 436, 833-836.

Smalley, I.J., Marković, S.B., O'Hara-Dhand, K., 2010. The INQUA Loess Commission as a Central European Enterprise. Cent. Eur. J. Geosci. 2, 3-8.

Smalley, I.J., Marković, S.B., Svirčev, Z., 2011. Loess is almost totally formed by the accumulation of dust. Quat. Int. 240, 4-11.

Smalley, I.J., O'Hara-Dhand, K., Wint, J., Machalett, B., Jary, Z., Jefferson, I.J., 2009. Rivers and loess: the significance of long river transportation in the complex event-sequence approach to loess deposit formation. Quat. Int. 198, 7-18.

Soergel, W., 1924. The diluvial terraces of IIm and their importance for the subdividing the Ice Age, Jena, Germany.

Spearman, C., 1904. The Proof and Measurement of Association between Two Things. Am. J. Psychol. 15, 72-101. doi:10.2307/1412159

Sprafke, T., Obreht, I., 2016. Loess: Rock, sediment or soil - What is missing for its definition? Quat. Int. 399,198-207.

Steffensen, J.P., 1997. The size distribution of microparticles from selected segments of the Greenland Ice Core Project ice core representing different climatic periods. J. Geophys. Res 102, 26755-26763.

Stevens, T., Adameic, G., Bird, A.F., Lu, H., 2013a. An abrupt shift in dust source on the Chinese Loess Plateau revealed through high sampling resolution OSL dating. Quat. Sci. Rev. 82, 121-132.

Stevens, T., Armitage, S.J., Lu, H., Thomas, D.S.G. 2006. Sedimentation and diagenesis of Chinese loess: implications for the preservation of continuous, high-resolution climate records. Geology 34, 849-852.

Stevens, T., Buylaert, J-P., Lu, H., Thiel, C., Murray, A., Frechen, M., Yi, S., Lin, Z., 2016. Mass accumulation rate and monsoon records from Xifeng, Chinese Loess Plateau, based on a luminescence age model. J. Quaternary Sci. 31, 391-405. 
Stevens, T., Carter, A., Watson, T.P., Vermeesch, P., Andò, S., Bird, A.F., Lu, H., Garzant, E., Cottam, M.A., Sevastjanova, I., 2013b. Genetic linkage between the Yellow River, the Mu Us desert and the Chinese Loess Plateau. Quat. Sci. Rev. 78, 355-368.

Stevens, T., Lu, H., 2009. Optical dating as a tool for calculating sedimentation rates in Chinese loess: comparisons to grain-size records. Sedimentology 56, 911-934.

Stevens, T., Lu, H., Thomas, D.S.G., Armitage, S.J. 2008. Optical dating of abrupt shifts in the Late Pleistocene East Asian monsoon. Geology 36, 415-418.

Stevens, T., Buylaert, J.-P., Murray, A.S., 2009. Towards development of a broadly-applicable SAR TT-

Formatted: Space After: $6 \mathrm{pt}$ OSL dating protocol for quartz. Rad. Meas. 44, 639-645.

Stevens, T., Marković, S.B., Zech, M., Hambach, U., Sümegi, P., 2011. Dust deposition and climate in the Carpathian Basin over an independently dated last glacial-interglacial cycle. Quat. Sci. Rev. 30, 662-681.

Stevens, T., Thomas, D.S.G., Armitage, S.J., Lunn, H.R., Lu, H., 2007. Reinterpreting climate proxy records from late Quaternary Chinese loess: a detailed OSL investigation. Earth-Sci. Rev. 80, 111136.

Storey, M., Roberts, R.G., Saidin, M., 2012. Astronomically calibrated 40Ar/39Ar age for the Toba supereruption and global synchronization of late Quaternary records. Proceedings of the National Academy of Sciences of the USA 109, 18684-18688.

Sümegi, P., Krolopp, E., 2002. Quartermalacological analyses for modelling of the Upper Weichselian paleoenvironmental changes in the Carpathian basin. Quat. Int. 91, 53-63.

Sun, J., 2002. Provenance of loess material and formation of loess deposits on the Chinese Loess Plateau. Earth Planet. Sci. Lett. 203, 845-859.

Sun, Y., Clemens, S.C., An, Z., Yu, Z., 2006. Astronomical timescale and palaeoclimatic implication of stacked 3.6-Myr monsoon records from the Chinese Loess Plateau. Quat. Sci. Rev. 25, 33-48. doi:10.1016/j.quascirev.2005.07.005

Sun, Y.B., Clemens, S.C., Morrill, C., Lin, X., Wang, X., An, Z., 2012. Influence of Atlantic meridional overturning circulation on the East Asian winter monsoon. Nat. Geosci. 5, 50-54.

Sun, Y., Qiang, X., Liu, Q., Bloemendal, J., Wang, X., 2013. Timing and lock-in effect of the Laschamp geomagnetic excursion in Chinese Loess. Geochem. Geophys. Geosystems 14, 4952-4961.

Svensson, A., Andersen, K.K., Bigler, M., Clausen, H.B., Dahl-Jensen, D., Davies, S.M., Johnsen, S.J., Muscheler, R., Parrenin, F., Rasmussen, S.O., Röthlisberger, R., Seierstad, I., Steffensen, J.P., Vinther, B.M., 2008. A 60000 year Greenland stratigraphic ice core chronology. Clim. Past 4, 47-57.

Sweeney, M.R., Mason, J.A., 2013. Mechanisms of dust emission from Pleistocene loess deposits, Nebraska, USA. J. Geophys. Res. 118, 1460-1471.

Tamers, M.A., 1970. Validity of radiocarbon dates on terrestrial snail shells. Am. Antiq. 35, 94-100.

Thiel, C., Buylaert, J.P., Murray, A.S., Terhorst, B., Hofer, I., Tsukamoto, S., Frechen, M., 2011. Luminescence dating of the Stratzing loess profile (Austria) - testing the potential of an elevated temperature post-IR IRSL protocol. Quat. Int. 234, 23-31.

Thomsen, K.J., Murray, A.S., Jain, M., Botter-Jensen, L., 2008. Laboratory fading rates of various luminescence signals from feldspar-rich sediment extracts. Radiat. Meas. 32, 1474-1486.
Formatted: Space After: $6 \mathrm{pt}$

Formatted: Space After: $6 \mathrm{pt}$ 
Timar-Gabor, A., Buylaert, J-P., Guralnik, B., Trandafir-Antohi, O., Constantin, D., Anechitei-Deacu, V., Jain , M., Murray, A.S. , Porat, N., Hao, Q., Wintle, A.G., 2016. On the importance of grain size in luminescence dating using quartz. Radiat. Meas., submitted.

Timar-Gabor, A., Constantin, D., Marković, S.B., Jain, M., 2015. Extending the area of investigation of fine versus coarse quartz optical ages from the Lower Danube to the Carpathian Basin. Quat. Int. $388,168-176$.

Timar-Gabor, A., Vandenberghe, D.A.G., Vasiliniuc, S., Panaoitu, C.E., Panaiotu, C.G., Dimofte, D., Cosma, C., 2011. Optical dating of Romanian loess: A comparison between silt-sized and sand-sized quartz. Quat. Int. 240, 62-70.

Tomlinson, E.L., Smith, V.C., Albert, P.G., Aydar, E., Civetta, L., Cioni, R., Cubukçu, E., Gertisser, R., Isaia, R., Menzies, M.A., Orsi, G., Rosi, M., Zanchetta, G., 2015. The major and trace element glass compositions of the productive Mediterranean volcanic sources: tools for correlating distal tephra layers in and around Europe. Quat. Sci. Rev. 118, 48-66.

Toms, P.S., King, M., Zárate, M.A., Kemp, R.A., Foit Jr., F.F., 2004. Geochemical characterization, correlation, and optical dating of tephra in alluvial sequences of central western Argentina. Quaternary Research 62, 60-75.

Trumbore, S.E., 2000. Radiocarbon geochronology. In: Noller, J.S., Sowers, J.M., Lettis, W.R. (Eds.), Quaternary Geochronology: Methods and Applications. American Geophysical Union, Washington, D.C, pp. 41-60.

Trandafir, Q., Timar-Gabor, A., Schmidt, C., Veres, D., Anghelinu, M., Hambach, U., Simon, S., 2015. OSL dating of fine and coarse quartz from a Palaeolithic sequence on the Bistrița Valley (Northeastern Romania). Quat. Geochronol. 30, 487-492.

Tzedakis, P.C., Hooghiemstra, H., Pälike, H., 2006. The last 1.35 million years at Tenaghi Philippon: revised chronostratigraphy and long term vegetation trends. Quat. Sci. Rev. 25, 3416-3430.

Újvári, G., Kok, J.F., Varga, G., Kovács, J., 2016a. The physics of wind-blown loess: implications for grain size proxy interpretations in Quaternary palaeoclimate studies. Earth-Sci. Rev. 154, 247-278.

Újvári, G., Kok, J.F., Varga, G., Kovács, J., 2016b. The physics of wind-blown loess: implications for grain size proxy interpretations in Quaternary palaeoclimate studies. Earth-Sci. Rev. 154, 247-278.

Újvári, G., Kovacs, J., Varga, G., Raucsik, B., Marković, S.B., 2010. Dust flux estimates for the Last Glacial Period in East Central Europe based on terrestrial records of loess deposits: a review. Quat. Sci. Rev. 29, 3157-3166.

Újvári, G., Molnar, D., Novothny, A., Pall-Gergely, B., Kovacs, J., Varhegyi, A., 2014. AMS 14C and OSL/IRSL dating of the Dunaszekcsö loess sequence (Hungary): chronology for 20 to 150 ka and implications for establishing reliable age-depth models for the last 40 ka. Quat. Sci. Rev. 106, 140154.

Valet, J.-P., Meynadier, L., Guyodo, Y., 2005. Geomagnetic dipole strength and reversal rate over the past two million years. Nature $435,802-805$. 
Vandenberghe, J., 2002. The relation between climate and river processes, landforms and deposits during the Quaternary. Quat. Int. 91, 17-23.

Vandenberghe, J., 2012. Multi-proxy analysis: a reflection on essence and potential pitfalls. Neth. J. Geosci. 91, 263-269.

Vandenberghe, J., An Z., Nugteren, G., Lu, H., Van Huissteden, J., 1997. New absolute time scale for the Quaternary climate in the Chinese loess region by grain-size analysis. Geology 25-1, 35-38

Vandenberghe, J., Marković, S., Jovanović, M., Hambach, U., 2014. Site-specific variability of loess and palaeosols (Ruma, Vojvodina, northern Serbia). Quat. Int. 334-335, 86-93.

Vandenberghe, J., Renssen, H., Van Huissteden, J., Nugteren, G., Konert, M., Lu, H., Dodonov, A., Buylaert, J.-P. 2006. Penetration of Atlantic westerly winds into Central and East Asia. Quat. Sci. Rev. $25,2380-2389$.

Vandenberghe, J., van der Plicht, J., 2016. The age of the Hengelo interstadial revisited. Quat. Geochronol. 32, 21-28. DOI: 10.1016/j.quageo.2015.12.004.

Veres, D., Bazin, L., Landais, A., Toyé Mahamadou Kele, H., Lemieux-Dudon, B., Parrenin, F. , Martinerie, P. ,Blayo, E., Blunier, T., Capron, E.,Chappellaz, J., Rasmussen, S.O., Severi, M., Svensson, A., Vinther, B., Wolff, E.W., 2013. The Antarctic ice core chronology (AICC2012): an optimized multiparameter and multi-site dating approach for the last 120 thousand years. Clim. Past 9, 1733-1748.

Vriend, M., Prins, M.A., Buylaert, J.P., Vandenberghe, J., Lu, H., 2011. Contrasting dust supply patterns across the north-western Chinese Loess Plateau during the last glacial-interglacial cycle. Quat. Int. 240,167-180.

Wacha, L., Frechen, M., 2011. The geochronology of the "Gorjanović loess section" in Vukovar, Croatia. Quat. Int. 240/1-2, 87-99.

Valet, J.-P., Meynadier, L., Guyodo, Y., 2005. Geomagnetic dipole strength and reversal rate over the past two million years. Nature $435,802-805$.

Wacha, L., Rolf, C., Hambach, U., Frechen, M., Galović, L., Duchoslav, M., 2017. The Last Glacial aeolian record from the Island of Susak (Croatia) as seen from a high-resolution grain-size, rock and palaeo-magnetic analysis. Quaternary International

Wang, X.L., Wintle, A.G., Lu, Y.C., 2006. Thermally transferred luminescence in fine-grained quartz from Chinese loess: Basic observations. Radiat. Meas. 41, 649-658.

Wang, Y., Cheng, H., Edwards, R.L., Kong, X., Shao, X., Chen, S., Wu, J., Jiang, X., Wang, X., An, Z., 2008. Millennial- and orbital-scale changes in the East Asian monsoon over the past 224,000 years. Nature 451, 1090-1093, doi:10.1038/nature06692.

Wintle, A.G., 1973. Anomalous fading of thermo-luminescence in mineral samples. Nature 245, $43-$ 144.

Wintle, A.G., 1981. Thermoluminescence dating of late Devensian loesses in Southern England. Nature 289, 479-480.

Wood, R.E., Douka, K., Boscato, P., Haesaerts, P., Sinitsyn, A., Higham, T.F.G., 2012. Testing the ABOx-SC method: dating known age charcoals associated with the Campanian Ignimbrite. Quat. Geochronol. 9, 16-26.

Formatted: Space After: $6 \mathrm{pt}$

Formatted: English (United Kingdom) 
Wulf, S., Federovicz, S., Veres, D., Lanczont, M., Karatson, D., Gertisser, R., Bormann, M., Magyari, E.K., Appelt, O., Hambach, U.F., Gozhyk, P.F., 2016. The Roxolany Tephra (Ukraine) - new evidence for an origin from Ciomadul volcano, East Carpathians: origin of Roxolany tephra from Ciomadul, East Carpathians. J. Quat. Sci. 31, 565-576.

Yang, S., Ding Z., 2014. A 249 kyr stack of eight loess grain size records from northern China documenting millennial-scale climate variability. Geochem. Geophy. Geosy. 15, 798-814. doi:10.1002/2013GC005113.

Yates, T., 1986. Studies of non-marine mollusks for the selection of shell samples for radiocarbon dating. Radiocarbon 28, 457-463.

Zeeden, C., Hambach, U., Steguweit, L., Fülling, A., Anghelinu, M., Zöller, L., 2009. Using the relative intensity variation of the Earth's magnetic palaeofield as correlative dating technique: A case study from loess with Upper Palaeolithic cultural layers at Poiana Cireşului, Romania. Quartär 56, 175-185.

Zeeden, C., Hambach, U., Veres, D., Fitzsimmons, K., Obreht, I., Bösken, J., Schulte, P., Lehmkuhl, F., in press. Millennial scale climate oscillations recorded in the Lower Danube loess over the last glacial period. Palaeogeogr. Palaeoclimatol. Palaeoecol.

Zeeden, C., Kels, H., Hambach, U., Schulte, P., Protze, J., Eckmeier, E., Marković, S.B., Klasen, N., Lehmkuhl, F., 2016. Three climatic cycles recorded in a loess-palaeosol sequence at Semlac (Romania) - implications for dust accumulation in south-eastern Europe. Quat. Sci. Rev. 154, 130154. doi:10.1016/j.quascirev.2016.11.002

Zeeden, C., Meyers, S.R., Lourens, L.J., Hilgen, F.J., 2015. Testing astronomically tuned age models. Paleoceanography 2014PA002762. doi:10.1002/2014PA002762

Zeuner, F.E., 1938. Die Chronologie des Pleistozäns. Académie Royale Serbe.

Zeuner, F.E., 1956. Loess and Palaeolithic chronology. Proceedings of the Prehistoric Society (New Series) 21, 51-64.

Zhu, R., Liu, Q., Pan, Y., Deng, C., Zhang, R., Wang, X., 2006. No apparent lock-in depth of the Laschamp geomagnetic excursion: evidence from the Malan loess. Sci. China Ser. Earth Sci. 49, 960 967.

Zhu, R., Pan, Y., Liu, Q., 1999. Geomagnetic excursions recorded in Chinese Loess in the last 70,000 years. Geophys. Res. Lett. 26, 505-508. doi:10.1029/1999GL900019

Zhou, X., Li, X., Yang, S., Long, H., Yang, Q., Zhao, K., Cui, J. 2016. Past changes in the vegetation density of the Chinese Loess Plateau revealed by variations in the size of Artemisia pollen grains. Rev. Pal. Palynol. 235, 71-80.

Zöller, L., Oches, E.A., McCoy, W.D., 1994. Towards a revised chronostratigraphy of loess in Austria with respect to key sections in the Czech Republic and in Hungary. Quat. Sci. Rev. 13, 465-472.

Zöller, L., Semmel, A., 2001. 175 years of loess research in Germany-long records and "unconformities". Earth-Sci. Rev. 54/1-3, 19-28. 


\section{FIGURE CAPTIONS}

Figure 1 Loess and loess-like sediments distribution (Pécsi, 1990).

a. Loess sediments; b. Loess-ike sediments.

Figure 2 Loess deposition types.

Figure 3 Time series of last-glacial loess mass accumulation rate (expressed on a logarithmic scale, in $\mathrm{g} / \mathrm{cm} 2 / \mathrm{ky}$ ) for the Tuxiangdao (Xining) and Huanxian (Loess Plateau) sections (from Vriend et al., 2011).Figure 4 Generalized comparison between loess-paleosol chronostratigraphy at three typical loess regions of the Northern hemisphere: Central Great Plain (Mason et al., 2003, 2008), the Middle Danube Basin (Stevens et al., 2008; Marković et al., 2014) and Central Chinese Loess Plateau (Dong et al., 2015) during the last 16 ky.

Figure 4 Generalized comparison between loess-paleosol chrono-stratigraphy at three typical loess regions of the Northern hemisphere: Central Great Plain (Mason et al., 2003, 2008), the Middle Danube Basin (Stevens et al., 2008; Marković et al., 2014) and Central Chinese Loess Plateau (Dong et al., 2015) during the last 16 ky.

Figure 5. Direct correlations between the Mošorin and Stari Slankamen synthetic (MSS) loess-palaeosol sequence and the Louchuan loess type section on the Central Chinese Loess Plateau (Hao et al., 2012). The uncertain stratigraphic interval in the transition between L2 and S2 units is indicated with "?" (Marković et al., 2015).

Figure 6 A) Map showing the distribution of loess deposits and locations of the main loess sections on Central Chinese Loess Plateau. LT, Lingtai; ZJC, Zhaojiachuan; PL, Pingliang; BJ, Baoji, LC, Luochuan, PX, Puxian; JB, Jingbian; JX, Jiaxian. Arrows connect the position of the sites with their records. B) Comparison of four astronomical timescales for the loesspaleosol sequences with the benthic $\delta^{18} \mathrm{O}$ records from ODP sites 677/846 (Shackleton et al., 1990 and Shackleton et al., 1995). From top to bottom: A, LC MS record on the $\mathrm{H} 2000$ age model; B, LT MS record on the D2002 age model; C, LT MS record on the S2005 age model; D, ZJC MS record on the S2005 age model. Discrepancies among these age models are denoted as shaded bars (e.g., $S_{3}, S_{5-1}, L_{9}, S_{32}$, etc). Dashed lines indicated the positions of magnetic reversal boundaries recorded in Chinese loess and marine records (Sun et al., 2006, modified).

Figure 7 Comparison between MS records of the Batajnica and Mošorin sections in Serbia with map showing distance between these sections (Marković et al., 2015).

Figure 8 Millennial-scale events documented in the stacked grain size record of Chinese loess (CHILOMOS) for the last $249 \mathrm{kyr}$, and correlation with the stalagmite $\delta 180$ record (Wang et al., 2008; Cheng et al., 2012), the LR04 benthic $\delta 180$ stack (Lisiecki and Raymo, 2005), the EPICA Dome C 
temperature anomaly in Antarctica (Jouzel et al., 2007), and the combined NGRIP $\delta 180$ record from Greenland (5-point smoothed) (North Greenland Ice Core Project members, 2004; Svensson et al., 2008). The Chinese Loess Interstadial (CLIS) events A1-A25 and B1-B24 are identified in the loess grain size records for the last and penultimate glacial-interglacial cycles, respectively. The shaded arrows indicate the long-term trend of the CHILOMOS and benthic $\delta 180$ records in each glacialinterglacial cycle.

Figure 9 Comparison between the grain-size variation in Nussloch and the atmospheric dust content over Greenland (Dansgaard et al., 1993; De Angelis et al., 1997; Fuhrer and Legrand, 1997; Steffensen, 1997) for the 31-19 kyr interval. The Nussloch time scale was calculated using the Analyseries software (Paillard et al., 1996). G1, G2, G3... - tundra gley horizons (according to Rousseau et al., 2022).

Figure 10 Linear sedimentation rate estimates for loess unit L1 and palaeosol unit S1 as recorded in the Mangshan section and a series of seven loess sections distributed across the Central Chinese Loess Plateau. Data of the LP sections are taken from Prins and Vriend (2007) and references cited therein (Prins et al. 2009).

Figure 11 Comparison of normalized relative paleointensity (RPI) data from the European loess sites Krems (Hambach et al., 2008), Süttö (Rolf et al., 2014), Susak (Wacha et al., submitted) and Poiana Ciresului (Zeeden et al., 2009) compared to the GLOPIS stack (Laj et al., 2004). In addition, the grey line represents the rough position of the Mono Lake geomagnetic excursion in these records. All records support the RPI dating independently. 


\section{LOESS CORRELATIONS - BETWEEN MYTH AND REALITY}

2 Slobodan B. Marković (1), Thomas Stevens (2), Jef Vandenberghe (3), Shiling Yang (4), Daniel

3 Veres (5,6), Joseph Mason (7), Gábor Újvári (8), , Alida Timar-Gabor (5), Christian Zeeden (9),

4 Zhengtang Guo (4), Qingzhen Hao (4), Igor Obreht (9), Ulrich Hambach (10), Haibin Wu (4),

5 Milivoj B. Gavrilov (1), Christian Rolf (11), Nemanja Tomić (1), Frank Lehmkuhl (9)

6

7 (1) Chair of Physical Geography, Faculty of Sciences, University of Novi Sad, Trg Dositeja Obradovića 3, 21000

8 Novi Sad, Serbia

9 (2) Department of Earth Sciences, Uppsala Universitet, Villavägen 16, 75236 Uppsala, Sweden

10 (3) Department of Earth Sciences, Vrije Universiteit, De Boelelaan 1085, 1081 HV Amsterdam, The Netherlands

11 (4) Key Laboratory of Cenozoic Geology and Environment, Institute of Geology and Geophysics, CAS, Beijing,

12 China

13 (5) Romanian Academy, Institute of Speleology, Clinicilor 5, 400006 Cluj-Napoca, Romania

14 (5) Faculty of Environmental Science, Babes-Bolyai University, Fantanele, 30, 400294 Cluj Napoca, Romania

(7) Department of Geography, University of Wisconsin, Madison, 53706, United States

(8) Institute for Geological and Geochemical Research Research Centre for Astronomy and Earth Sciences, Hungarian Academy of Sciences H-9400 Sopron, Csatkai E. u. 6-8., Hungary

(9) Department of Geography, RWTH Aachen University, Templergraben 55, 52056 Aachen, Germany 
Loess correlations are one of the most common research topics in global loess research. In spite of significant progress in the development from speculative to quantitative research methods, even in some recent investigations application of loess correlations is still in many aspects too speculative. The aim of this overview is to provide an adequate frame for evaluation of accuracy of the loess correlations applied on different temporal and spatial scales. This opens up possibilities for detailed temporal and spatial environmental reconstructions across the huge loess provinces of the Eurasia and Northern America. In this study, we additionally evaluated the potential development of appropriate sub-millennial scale loess correlations, as well as essentially important chronological approaches for establishing valid correlations of different loess records, such as current improvements in tephrochronology, ${ }^{14} \mathrm{C}$ and luminescence dating techniques.

Key words: correlations, loess-paleosol sequences, Northern Hemisphere, Pleistocene 
Loess-palaeosol sequences are widespread and detailed paleoclimatic archives, especially common in the mid-latitudes of the Northern Hemisphere (e.g. Pécsi, 1990; Smalley et al., 2011, Figure 1). In most cases, these terrestrial sequences display common stratigraphic features useful in intersite correlations across wide regions, allowing past environmental reconstruction at a continental scale (e.g. Marković et al., 2012a, 2015). However, contrary to the ice cores, deep-sea or lacustrine sediments that are characterized by more or less continuous sedimentation, loess-palaeosol sequences are more complex depositional systems with significantly different accumulation rates, more dynamic environmental thresholds and higher sensitivity to erosion (e.g. Stevens et al., 2006, 2008, 2011). In addition to recording global/hemispheric/regional climatic signals, loess-palaeosol sequences can also be influenced by local conditions (e.g. Vandenberghe, 2012, 2014), particularly because most of them are near major river systems. Understanding relationships between the widespread loess-palaeosol sequences in particular regions may provide insights into both local influences at particular locations and general regional climatic trends. Although ongoing research is yielding significant progress for loess profile correlation, and direct comparison of different palaeoclimatic records can sometimes be achieved, valid correlations on regional or even continental scales are still only possible on the first order level (i.e. at the level of Marine Isotope Stages (MIS), or glacial loess and interglacial pedocomplex units whose formation was driven by orbitally paced changes in hydroclimate). However, rapid improvements in dating techniques will result in a much better understanding of chronostratigraphic variations in loess sequences in forthcoming years (e.g. Thiel et al., 2011; Murray et al., 2014). Refinement (following a well-established community-wide protocol) in the existing stratigraphic models applied to loess-palaeosol 
sequences in Eurasia and more generally, the whole Northern Hemisphere,should open possibilities for more detailed temporal and spatial environmental reconstructions, particularly given the fact that loess is one of the most widespread terrestrial paleoclimate archives. The establishment of such stratigraphic models is crucial for a better understanding of glacial-interglacial climatic and environmental evolution at the continental/hemispherical scale by constraining the specific local influences at particular sites and also by integrating the loess-palaeosol records with the larger grid of paleoclimate archives, as already achieved for lacustrine, speleothem and ice core records (Bazin et al., 2013; Veres et al., 2013). This review primarily has a Eurasian emphasis because the longest, mostly climatically controlled loess records are generally know from loess plateaus of Europe and Asia.

\section{BRIEF HISTORICAL OVERVIEW OF LOESS CORRELATIONS}

Correlations between different loess profiles or between loess stratigraphy and paleoclimatic models were attempted very early in the history of loess research (e.g. Penck and Brückner, 1909; Shimek, 1902, 1909; Laskarev et al., 1926; Baczak, 1942; Soergel et al., 1926; Götzinger, 1936; Zeuner, 1938, 1956; Thorp and Smith, 1952; Simonson and Hutton, 1954; Ruhe 1956, 1969). In this initial stage, loess correlations were highly speculative (e.g. Marković et al., 2016). The Sub-Commission of European Loess Stratigraphy of the International Union for Quaternary Research (INQUA) was created in 1961, at the $6^{\text {th }}$ INQUA Congress in Warsaw, Poland, and is still active as the Loess Focus Group of INQUA. This international research initiative succeeded, despite the strong political competition and isolation between western capitalist and eastern communist states at the time (Smalley et 
al., 2010). With the purpose of creating a common European loess stratigraphy, the subcommision promoted pedostratigraphic criteria as a working model for inter-profile correlations (Fink, 1962). Simultaneously, during the $6^{\text {th }}$ INQUA Congress Liu presented a long and uniform loess stratigraphic record of the Chinese Central Loess Plateau. These stratigraphical observations were published a year later in a significant publication by Liu and Chang (1962), and then loess research in China experienced a scientific hiatus.

The pedostratigraphic concept culminated in the studies of Bronger and co-workers (Bronger, 1976, 2003; Bronger and Heinkele 1989; Bronger et al., 1998). They presented the first attempt at a Eurasian continental loess correlation. The main limitation of this correlation is an idealised concept of uniform response by such diverse terrestrial environments to global climate change.

Investigation of loess exposures at Red Hill (Červeny Kopec, Czech Republic) and Krems-Schießstättech (Austria), provided the background for correlation of terrestrial loess deposits with the oscillations recorded in deep-sea sediments, both reflecting global paleoclimatic oscillations (Kukla, 1970, 1975, 1977; Fink and Kukla, 1977). In spite of the relatively speculative background of the glacial cycle concept that Kukla applied to loesspaleosol sequences, these chronostratigraphic interpretations are still valid.

The development of magnetostratigraphic techniques opened the loess community in China to collaboration with international scholars and completely shifted global scientific interest towards the multiple loess-paleosol couplets of the Chinese Loess Plateau (Heller and Liu, 1982, 1984). Kukla (1987) and Kukla and An (1989) created a new Chinese loess chronostratigraphic model. This new stratigraphic approach, based on paleomagnetic polarity zonation and direct correlation between profiles using loess- 
paleosol magnetic susceptibility (MS) variations, significantly improved previous

stratigraphic subdivision of the Malan, Upper and Lower Lishi and Wucheng formations based on litho- and pedo-stratigraphic criteria (e.g. Liu, 1985). Observed enhancement of the magnetic signal as a consequence of pedogenic processes appears to be valid for a huge Eurasian semi-arid loess belt (e.g. Maher, 2016). Measurement of loess MS is therefore a rapid and consistent tool for inter-profile correlations, even over very long distances across Eurasia (Marković et al., 2012b, 2015). In Siberian and Alaskan LPS, the opposite pattern is observed, higher MS in unaltered loess and lower in paleosols (e.g. scope of this study, since the use of MS for inter-profile correlation of Siberian and Alaskan loess-paleosol sequences has been limited, while correlations based on the model of magnetic enhancement via pedogenesis have been widely applied in the temperate Eurasian loess belt.

Finally, recent improvements in numerical direct dating techniques, such as radiocarbon and luminescence dating provide new possibilities for validating interprofile correlations especially of younger loess-paleosol sequences (e.g. Stevens et al., 2008; Pigati et al., 2013). Since the early 1980s when luminescence methods were first applied to loess dating, this approach has been critical in development of loess chronologies and, in turn, the development and testing of luminescence dating protocols themselves. Limitations in terms of precision and treatment of older ages do exist however, but it is envisaged that efforts to surmount these will also lead to significant progress in the dating of loess through various new protocols. 


\section{AS A BACKGROUND FOR APPROPRIATE INTER-PROFILE CORRELATIONS}

Loess and loess-like deposits cover approximately $10 \%$ of the continental land surface (e.g. Pye, 1987; Pecsi, 1990). Thus, these sediments are associated with many different landforms, as well as climate and vegetation zones (Figure 1 and 2). Under these different environmental conditions, we can identify a diversity of depositional modes related to equivalent types of loess and loess-like primary and secondary deposits. It has been suggested that for secure (and paleoclimatically meaningful) inter-profile correlations of loess the best approach is to focus on sections formed through dust deposition and subsequent pedogenesis on stable plateau-like landforms (sensu Pécsi, 1990; Sprafke and Obreht, 2016), as such loess-paleosol deposits are predominantly controlled by climatic variations (Figure 2). Long-term erosional processes on loess plateaus should be largely confined to relatively small and short-lived gullies close to the steep tableland margins (Marković et al., 2012a). However, even for conditions of deposition on plateau summits some erosional events can be expected (e.g. Marković et al., 2011), and therefore the completeness of loess-paleosol sequences must be verified through multi-proxy analyses and high-resolution dating. For example, remobilization of loess by the wind may occur even on relatively flat tablelands (Sweeney and Mason, 2013), especially under dry environmental conditions with sparse or diminishing vegetation cover. All types of loess deposition on slopes are associated with processes such as erosion, reworking, and re-deposition, representing a more dynamic sedimentological environment that usually is not adequate for the formation and preservation of typical loess. Typical loess is aeolian dust accumulated in situ and transformed by loessification processes, but mostly preserved without significant 
impacts of other post-depositional processes (Sprafke and Obreht, 2016). Under specific conditions, typical loess can even be preserved as a high-resolution, though not long-term, record in sedimentary traps such as paleodepressions.

Lithostratigraphic correlations of loess records seem to be a favorite topic in international loess research today (Antoine et al., 2016; Haesaerts, 2016; Schirmer, 2012, 2016; Lehmkuhl et al., 2016). They are often based on similar macroscopic properties of specific loess layers and paleosol horizons, apparent correspondence of ages between various sites, and links with palaeoclimatic proxies. However, there are numerous potential pitfalls that may obstruct such correlations (Vandenberghe, 2012). A few examples may illustrate them.

1. Palaeosols play a crucial role for correlation purposes, especially when alternating with loess layers in long records in which they express mainly interglacial periods on an orbital timescale, and/or the imprint of long and warm interstadials. This approach has been applied frequently in East Asian loess studies since the pioneering work of Liu (1985) (e.g. Kukla and An, 1989; An et al., 1990; Ding et al., 1990; Porter, 2001; Sun et al., 2006) but also in other regions (e.g. Antoine et al., 1999; Muhs, 2013) and at a continental scale ( Marković et al., 2012a). If corresponding pedostratigraphic horizons can be correctly identified within many different records, such intersite correlations are of great significance in the comprehension of regional paleoclimatic evolution. Palaeosols have often been identified by characteristic proxies and sedimentological features such as decalcification, magnetic susceptibility, and even grain size variations. However, all these proxies are the reflection of specific pedological and geomorphological processes and environmental conditions that may have different expressions at different timescales and even at a local spatial scale. 
Sediment provenance and periodic fluctuations in the strength (and thus input) of different sources of material can also have a crucial influence on loess characteristics. For instance, local factors of soil formation such as topography and vegetation cover may lead to highly diversified soil morphology. An illustrative example of such soil variability at a scale of tens of meters is described at Ruma (Vojvodina, Serbia) by Vandenberghe et al. (2014). In that case, the same paleosol varies laterally from a black, organic, chernozem-like soil to a brown colored, inorganic soil as a consequence of local topographic differentiation and its effects on soil moisture. Another example is the Lohne soil in German loess sections which shows strong variability as a result of local site differentiation (Sauer et al., 2016).

2. The use of another favorite proxy for correlation, the grain size of loess layers, may pose similar problems related to valid inter-profile correlations. Grain size profiles can be applied convincingly in correlating the loess records of the Chinese Loess Plateau (e.g. Liu, 1985; Vandenberghe et al., 1997), and also in other loess regions for correlating lithostratigraphic units in cold-warm successions (e.g. Meszner et al., 2014). In contrast to the Chinese Loess Plateau, however, it appears that the last glacial period, encompassing MIS4-3-2, is very difficult to subdivide by grain size variation in records of the adjacent NE Tibetan Plateau and nearby regions in central Asia (Figure 3, Vandenberghe et al., 2006). Similarly in the aforementioned case of the Vojvodina loess at Ruma only a slight grain-size difference, slightly exceeding internal variability, could be observed between glacial and interglacial loess layers, in contrast to the Central Chinese Loess Plateau (Vandenberghe et al., 2014). In the Great Plains, USA, the interglacial Bignell Loess can be as coarse as underlying full- to late glacial Peoria Loess (Miao et al., 2007). 
3. Lithostratigraphy based loess-palaeosol correlations often assume continuous loess

203

deposition, although in the central USA and in Western Europe, highly discontinuous deposition has been the general interpretation (e.g. Antoine et al., 2001, 2013; Bettis et al., 2003). However, it has been shown that important sedimentary hiatuses often occur in loess records previously thought to be continuous (Lu et al., 2006; Stevens et al., 2007). An illustrative example is the section Tuxiangdao at Xining where a considerable hiatus was discovered in the upper part of the last-glacial loess, through detailed OSL-dating (Buylaert et al., 2008; Vriend et al., 2011). Grain size analysis of the loess showed that the loess at that site is characteristically coarse-grained and was transported from a nearby fluvial terrace deposit of the Huangshui river during storm events. It will depend on the local conditions whether sediment is trapped or an interval of non-deposition is created or even older sediment is deflated by such strong storm winds. Important site conditions may be, for instance, topography (wind facing vs. wind shadowing) and absence or presence of vegetation cover to capture and protect deposited loess. Such hiatuses must not be overlooked in the case of lithostratigraphic correlations. Such a risk may appear, for instance, from the correlation between the aforementioned section of Tuxiangdao and neighboring sections on the Chinese Loess Plateau and central Asia (Figure 3; Vandenberghe et al., 2006; Vriend et al., 2011). Sediment accumulation rates may vary dramatically at sites too, making correlations uncertain (Kohfeld and Harrison, 2003; Stevens et al., 2008, 2016).

4. Lithostratigraphic correlation is often based on correlation of specific proxy signals such as grain-size, geochemical and magnetic properties, etc. However, the existence of thresholds of environmental response cannot be ignored in these correlations. As a result, a proxy may show a specific relationship with environmental factors under some conditions while not giving any expression at all in other conditions that are below the response 
threshold. Therefore, comparison between proxy record trends is sometimes a successful approach (Zeeden et al., in press), whereas in other circumstances it is not (Bokhorst and Vandenberghe, 2009). In addition, some proxies need reaction time: for instance, after fluvial erosion or deposition, vegetation adaptation in the affected zone will be delayed visà-vis climatic changes (Vandenberghe, 2002). Furthermore, correlation by different proxies can be even more risky since the driving factors, marginal conditions and threshold values are not the same for each proxy. Therefore, inter-linking, e.g., grain-size signals, magnetic susceptibility, isotopic or palynological data from one site to another should be avoided in the absence of isochronous marker horizons, such as tephra layers, that allow for a better quantification of proxy data integrity and the potential for paleoclimatic and paleoenvironmental reconstructions.

5. Further, proxy signals are often assumed to be teleconnected by the intermediary of climatic conditions that are supposed to be synchronous and act as the driving force for proxy response. Circular reasoning is an imminent danger when first assuming common effects of a certain climatic signal teleconnecting different proxies and then subsequently deriving a specific teleconnection between proxy signals based on the same climatic conditions. Examples are given, for instance, by Blaauw (2010).

6. The provenance analysis of sources of dust particles that form loess deposits is of considerable and growing interest (e.g. Sun, 2002; Chen et al., 2007; Aleinikoff et al. 2008; Muhs et al., 2008; Stevens et al., 2013a). Loess is a near-source archive of dust and has the capacity to provide valuable information on the activity of dust sources in the past. Given the complex relationship between atmospheric dust and climate change, knowledge of the sources of dust provides critical insight into the controls on dust emission and potential 
climate impact. The proper interpretation of many climate proxies from loess records, as

well as valid inter-profile correlations, also rely on detailed knowledge of dust sources.

Mineral magnetic signals are influenced by detrital ferromagnetic assemblages (Maher et

al., 2009, 2016) while grain-size changes and mass accumulation rates can be heavily influenced by source proximity (Újvári et al., 2016a; Stevens et al., 2013b). More generally, knowledge of loess source gets to the heart of questions over the production of loess material (Smalley et al., 2009) and can provide insight into large scale landscape and climate evolution (Nie et al., 2015).

7. A final warning applies to the use of chronostratigraphical or chronological information. Of course, correlation of different lithostratigraphic units may be supported when they have the same age. In addition, each dating technique has its own precision, accuracy and reliability limitations. An example of discrepancies arising from the use of different dated proxy records is provided by the positioning of the Hengelo interstadial defined based on investigation of terrestrial environmental records in the framework of the Greenland ice-core record (Vandenberghe and Van der Plicht, 2016). necessary to approach each potential correlation point by a careful evaluation of the causal geomorphic-sedimentary-pedogenic processes that underlie the proxy records involved (Bokhorst and Vandenberghe, 2009; Vandenberghe, 2012; Lehmkuhl et al., 2016) and the local conditions, such as topography, vegetation cover, microclimate, and sediment availability, that determine those processes, including loess transport and deposition as well as post-depositional pedogenesis.

\section{GLACIAL/INTERGLACIAL SCALE LOESS CORRELATIONS}


Loess-paleosol sequences are produced by much more complex depositional systems with significantly different accumulation rates, more dynamic environmental thresholds and higher potential for erosion than records from ice cores or deep-sea or lacustrine sediments, characterized by more or less continuous sedimentation (e.g. Stevens et al., 2007). Thus, for loess, at the moment, convincing correlations on regional or even continental scale are only possible on the level of first order units (i.e. MIS or glacial loess and interglacial pedocomplex units), although current research has provided significant progress in interprofile correlation and direct comparison of different palaeoclimatic records.

\subsection{HEMISPHERIC SCALE}

The North American and Eurasian loess records are significantly different, and with the current state of understanding of loess-paleosol formation, the possibility of detailed correlation on the hemispheric scale is limited. A convincing explanation for the contrasts has yet to be developed, and will require detailed comparison of the paleoclimatic setting of major loess sources during both glacials and interglacials, issues of sediment supply and ice sheet evolution on each continent. In both North America and Eurasia, a paleosol marking the last interglacial is widely recognized (i.e. S1 in Eurasia, the Sangamon Soil in North America), as is a relatively thick and rapidly deposited full-glacial loess unit (L1 in Eurasia, Peoria Loess in North America). However, both the older loess stratigraphy of previous interglacials-glacials and the detailed stratigraphy of the last glacial cycle differ substantially between continents (see Bettis et al., 2003, for a North American summary). Figure 4 illustrates especially striking contrasts in the temporal dynamics of loess-paleosol sequences during the last $16 \mathrm{ky}$ in three major loess regions of the Northern hemisphere: the central Great Plains (Mason et al., 2008), the Middle Danube Basin (Stevens et al., 2011; Marković 
et al., 2014) and the central Chinese Loess Plateau (Dong et al., 2015). These generalized chronostratigraphic models show that the major episode of soil development in the central Great Plains occurred during the Late Pleistocene to Holocene transition, followed by intermittent loess accumulation throughout much of the Holocene, in contrast to the predominance of Holocene soil development in Eurasian loess provinces (e.g. Dodonov and Zhou, 2008) and even in central North America east of the Missouri River (Bettis et al., 2003). These differences suggest that the local expression of global climate variations of the past 16 ky was different in the Great Plains than in the Eurasian loess regions, especially with regard to moisture availability. Different thresholds for dust production and the 

debate is whether LO is a consequence of the East Asian Summer Monsoon weakening or instead can be connected with long and intensive human impacts to the environment of the Central Chinese Loess Plateau (e.g. Zhou et al., 2016). and Eurasian loess records, establishing proper chronology is essential. Thus, further steps towards appropriate hemispheric loess correlations at least for the last glacial and Holocene records, have to include high-resolution dating necessary for establishment of robust age diversity of continental environmental change on a hemispheric scale.

\subsection{CONTINENTAL SCALE}

Loess over the Eurasian continent is characterized by a considerable diversity of loess sequences from the arid and semi-arid zones in Central China, Central Asia, Black Sea and Caspian lowlands and the Lower and Middle Danube Basins to the humid periglacial European loess regions, as well as the periglacial and subarctic frozen loess zone in Siberia (e.g. Dodonov and Zhou, 2008; Chlachula et al., 1998). The thickest and most complete, as well as best preserved loess-palaeosol successions are related to a great middle Eurasian semi arid loess zone. Spatially, this great continental loess belt spans approximately $45^{\circ}$ and $30^{\circ} \mathrm{N}$ latitude (Marković et al., 2012a). Marković et al. (2015) presented the remarkable accordance between North Serbian (the Middle Danube Basin) and Chinese loess records (Figure 5). This approach opens up the 
possibility for a transcontinental correlation of European, Central Asian and Chinese loess sequences, using a standardised nomenclature and chronostratigraphic model. For a direct correlation of two very distant loess regions, the composite Danubean type sequence Mošorin/Stati Slankamen (Marković et al., 2015), and the Chinese Loess type sequence of Luochuan (Hao et al., 2012) have been employed. Figure 5 shows that the loess chronostratigraphies in Northern Serbia and in the Central Chinese Loess Plateau from SO to S8, based on MS variations, correspond strongly. This transcontinental loess correlation reveals also that there are significant similarities between these two geographically distant environmental magnetic loess records. Serbian and Chinese loess records have almost identical general multi-millennial and longer-terms pattern of MS variations and even often have a close correspondence on shorter timescales. If we accept that the similarities are not solely a function of the way that the environmental magnetic record as reflected by MS is recorded and preserved in continental loess records, a similar environmental evolution needs to be postulated for these regions situated on opposite sides of the Eurasian continent. The most important factors promoting these similarities include: 1 ) extension of the climatic trend of Pleistocene aridification from Asia to southeastern Europe, expressed as general interglacial aridification as indicated by paleopedological and climate proxies and as drier and more dusty glacial conditions indicated by higher accumulation rates observed in younger loess units (e.g. Buggle et al., 2013; Marković et al., 2015); 2) despite fundamental differences in dominant climate modes in the Danube Basin (temperate continental) and China (monsoon), the significant imprint of the dry season's influence on these distant loess records is very similar (Marković et al., 2012a); and 3) generally the same style of loess deposition,, indicated by the almost parallel position of the multiple loess- 
palaeosol sequences that have been formed and preserved on loess plateaus (Marković et al., 2012a).

$$
\text { In spite of these similarities, there are also some significant differences between }
$$

these loess records. The absolute magnitude of MS is significantly higher in the Central Chinese Loess Plateau than in the Danube loess. The most likely reason for this is the higher background MS of the parent material. More importantly, contrary to the almost uniform amplitude of the absolute MS values in Danubian loess and palaeosol units, the Chinese palaeosols from S8 to $\mathrm{S} 6$ are significantly smaller in comparison to the younger fossil soils (Figure 5). Additionally, accumulation rates differ in the Danube Basin and China over this time interval (Marković et al., 2012a).

Stevens et al. (2011) also noted specific differences between the Crvenka (Vojvodina, Serbia) and Beiguoyuan (Chinese Loess Plateau) climate and accumulation records on millennial timescales based on luminescence dating, notably in the timing of peak sedimentation and of abrupt fluctuations in MS and grain size. These differences suggest that while overall continental-scale climate changes are relatively uniform, there are differences in shorter, more abrupt events and in the environmental conditions of certain periods. The nature of, and reasons for, these differences are exciting avenues of future research that should provide significant insight into the dynamics and forcing of regional scale climate in the context of global and hemispheric shifts.

Valid regional interglacial/glacial loess correlations are more frequent than those attempted at intercontinental scales. The initial chronological framework for loess-palaeosol 
sequences was established by means of palaeomagnetism (e.g. Heller and Liu, 1982; Liu, 1985) and subsequently by using a correlation of MS to marine isotope data (Kukla et al., 1988). Later grain size data was also utilized (Porter and An, 1995; Vandenberghe et al., 1997) and direct orbital tuning was performed (e.g. Ding, 2002). Orbitally tuned MS and grain size records from quasi-continuous loess-palaeosol sequences on the Chinese Loess Plateau have been generated to investigate the evolution and variability of the East Asian monsoon, mostly during the Pleistocene, as well as for direct comparison with other major global records (Prokopenko et al., 2006; Tzedakis et al., 2006) or paleoclimatic models (e.g. Bassinot et al., 1994; Lisiecki and Raymo, 2005).

Similarities of environmental magnetic records of different sections in the Central Chinese Loess Plateau are significant even if they are more than $200 \mathrm{~km}$ distant. Figure 6 compares orbitally tuned MS records of type sections on the Central Chinese Loess Plateau: Luochuan (Heslop et al., 2000), Lingtai (Ding et al., 2002), Lingtai and Zhaojiachuan (Sun et al., 2006), and a composite marine oxygen isotope record from the north Atlantic (Shackleton et al., 1990, 1995). It is clear that the boundary ages of S3, S5, L9, S13, S22, S25, S28, S30-31 and S32 are different among the three age models (shown as shaded bars); more work on tuning and correlating these records to resolve the chronological details will be necessary.

Well-documented regional loess stratigraphy spanning numerous glacial-interglacial cycles, as in the Central Chinese Loess Plateau, clearly provides the opportunity for statistical analysis of correlations among loess records and between those records and other paleoclimatic datasets. Recent work has more clearly identified potential problems with such analysis and pointed toward solutions. Correlation of proxy data sets in geosciences is 
classically done using the Pearson or Spearman correlation methods (Pearson, 1895;

Spearman, 1904). Especially for significance testing, issues of non-normal distribution, serial correlation, and often also limited data sizes may limit their direct applicability. These potential issues are, however, often ignored for simplicity. More complex measures have been proposed (e.g. Mudelsee, 2003; Ólafsdóttir and Mudelsee, 2014), but may not always be practical due to the necessity to determine multiple parameters prior to significance testing. Using differences between data points rather than the raw data may counter spurious correlations that result when using classical correlation parameters (Baddouh et al., 2016; Ebisuzaki, 1997; Meyers, 2014; Zeeden et al., 2015) may be a preferable option for many cases. Such approaches are incorporated in the R 'astrochron' package (Meyers, 2014), including the option of correlating differences of datapoints instead of dataseries themselves.

Statistical techniques can be expected to be useful for long datasets spanning at least several glacial/interglacial cycles, but may be of limited use when regarding rather short loess sections without clear patterns. For applications in loess research see Zeeden et al. (2016). Hilgen et al. (2014) discuss the limited use of significance for real geoscientific datasets, mainly in respect to cyclostratigraphy and time series analysis, large parts of their discussion can be applied to correlation and tuning of loess. It is important to realise that geological records do not represent perfect time series and proxy data are often not normally distributed, limiting the strict application of statistical procedures and the explanatory power of statistical measures despite their unquestioned value.

On orbital timescales, coherence and typical frequency patterns have been used for testing correlations in marine and also loess records in mostly qualitative ways (e.g. Basarin 
et al., 2014; Heslop et al., 2000; Sun et al., 2006), but potential bias by previous alignment has been proposed (Shackleton et al., 1995). Amplitude investigations are favourable for testing time scales especially when wide precession filters are used (Zeeden et al., 2015), and were applied by, e.g., Sun et al. (2006). Plateau, is also visible for Serbian loess sections during the last five glacial/interglacial cycles. Despite Mošorin and Batajnica loess sections being $45 \mathrm{~km}$ apart, the patterns of MS records are almost identical in the sections, except for the difference in thickness of the stratigraphic units. Even some details, such as the appearance of highly weathered remnants of tephra shards, observed in the loess units L2 and L3 (very base) are identified in both sections (Marković et al., 2009, 2015; Obreht et al., 2016; Figure 7). Unfortunately, other examples of regional loess correlations at interglacial/glacial scalesin other European, Central Asian and North American loess provinces are not as clear as in the case of loess sections in the Chinese or Serbian Loess Plateaus (e.g. Ding et al., 2002; Marković et al., 2015). In complex conditions of loess deposition and in more problematic stratigraphic situations related to European loess, the application of aminoacids racemisation (AAR) relative geochronology has proven very powerful. Paleo- and environmental magnetism, coupled with numerical luminescence or radiocarbon dating, is currently the preferred approach for reconstructing chronostratigraphies within loess in general. However, AAR relative geochronology can also provide valuable information applicable to a wide range of stratigraphic problems, depositional environments, and timescales (Penkman and Kaufman, 2012). Application of AAR substantially improved our understanding of European loess stratigraphy because it made it possible to distinguish the stadial or glacial character of loess units. The resulting chronostratigraphic interpretations 
for the four youngest glacial/interglacial cycles enabled the revision of the previous 'classical' stratigraphic schemes in Austria, Czech Republic and Hungary (Zöller et al., 1994; Oches and McCoy, 1995a, 1995b). AAR methodology was applied to northern Serbia (Marković et al., 2004, 2005, 2006, 2007, 2008, 2011) and Hungary (Novothny et al., 2009) approximately one decade later. The application of AAR relative geochronology to the longterm loess-palaeosol sequence at Stari Slankamen indicates that the AAR approach can be a powerful tool in resolving glacial/interglacial cycles younger than the last 700 ky (Marković et al., 2015). Additionally the erosional hiatus suggested by the MS record and presence of a gravel unit at the site was confirmed using AAR, which indicated that pedocomplex S2 and part of the bracketing loess units are missing at this site (Marković et al., 2011). Recent improvements in the sensitivity of the AAR geochronological approach (Penkman and Kaufman, 2012) have the potential to improve the validity of loess-correlations in forthcoming investigations.

\section{MILLENNIAL SCALE LOESS CORRELATIONS}

Crucial scientific discoveries in paleoclimate research in the last decades of the 20th century have been related to the identification of abrupt climate changes during the last glacial cycle in the North Atlantic region (known as Dansgaard-Oeschger and Bond cycles, and Heinrich events defined by Bond et al., 1992, Dansgaard et al., 1993). The specific patterns of numerous short relative warm intervals known as Greenland Interstadials (GI) became a stratigraphic standard for the last glacial period and development of the so-called event stratigraphy (Björck et al., 1998; Blockley et al., 2012). Similar millennial-scale climate variations have been discovered in East Asian speleothems representing detailed evolution 
of the East Asian Monsoon circulation (Wang et al., 2008; Cheng et al., 2012). However, is it possible to directly correlate loess-paleosol sequences and Greenland ice-core event stratigraphy? Keeping in mind the cautions noted in previous section, it should first be mentioned that even high-resolution loess records are not continuous at least on millennial timescales (Stevens et al., 2006, 2007). Second, these sedimentary gaps are also controlled by processes associated with local conditions of airborne dust trapping, paleo- and recent geomorphological dynamics, and other conditions affecting preservation. This is a significant limitation on preservation of continuous loess records, as well as for suitable reconstruction of climatic and environmental dynamics. The main mechanism by which North Atlantic abrupt climate change can be imprinted on Eurasian loess-paleosol sequences is the long distance supply of moisture associated with the Westerlies circulation (e.g. Vandenberghe et al., 2006). Thus, it is logical that such correlations between loess and ice core records are substantial for sections characterized by stronger and more consistent climatic influence of the Westerlies, as a driver of teleconnections with climate instability in the North Atlantic region. However, despite these limitations some sedimentary intervals preserved in the Eurasian loess belt hold the potential for correlation with Greenland ice-core event stratigraphy.

\subsection{REGIONAL SCALE}

Yang and Ding (2014) analyzed the grain size of eight thick loess sections in the northern Chinese Loess Plateau, and constructed a stacked 249-ky-long grain size time series of millennial-scale variability (termed the "CHILOMOS" record). According to the latter authors, this stack documents most of the millennial-scale climatic events registered in 
501

502

503

504

505

506

507

508

509

510

511

512

513

514

515

516

517

518

519

520

521

522

523

Greenland and in Chinese stalagmites. As shown in Figure 8, millennial-scale climate events have been recorded in these profiles of the Chinese Loess Plateau during the last and penultimate glacials, and some are also evident within the last and penultimate interglacial complexes, but at a relatively low frequency. In addition, the stack shows millennial-scale climatic events superimposed on a prominent cooling trend during the last and penultimate glaciations, consistent with the pattern of increasing global ice volume (Yang and Ding, 2014). Thus, the CHILOMOS record may provide a common time scale and a comparative reference for millennial-scale records of Chinese loess, and will facilitate correlation of climate records from different archives such as Chinese speleothem (Wang et al., 2008; Cheng et al., 2012), the LR04 benthic $\delta 180$ stack (Lisiecki and Raymo, 2005), the EPICA Dome C temperature anomaly in Antarctica (Jouzel et al., 2007), and the combined NGRIP $\delta 180$ record from Greenland (5-point smoothed) (North Greenland Ice Core Project members, 2004; Svensson et al., 2008).

\subsection{LOCAL SCALE}

The Eifel Laminated Sediment Archive (ELSA) dust stack covers the last glacial/interglacial period (the last $133 \mathrm{ka}$ ) and confirms the dominant climatic influence of the abrupt climatic events in the North Atlantic region. The ELSA record provides additional environmental evidence that during the last glacial period the atmosphere over Western and Central Europe was permanently dusty (Sirocko et al., 2005, 2013; Seelos et al., 2009). The ELSA record indicates that the two coldest periods of the last glaciation, MIS 4 and MIS 2 , were characterised by relatively stable climate conditions associated with accumulation of homogenous dust sediments. Conditions during MIS 3 were generally dusty but include 
several phases of reduced dust deposition. Even during MIS 5, high frequencies of dust storms during the cold events C24 and C23 recorded in North Atlantic region (McManus et al., 1994) after the last interglacial period (MIS 5e) have been detected (Sirocko et al., 2013, 2016; Seelos et al., 2009).

The high level of correspondence between the dust records from the Greenland icecores and the Eifel maar lakes may indicate a substantial opportunity for direct linkage between marine, ice-core and terrestrial records (Sirocko et al., 2016). However, for Western and Central Euroepan loess-paleosol sequences synchronous variations with Greenland ice core stratigraphy are evident only for some relatively short and discontinuous intervals of deposition. The Schwalbenberg loess-palaeosol-sequence in the Middle Rhine valley of Germany is one of the most important sections for understanding terrestrial system responses to North Atlantic climate oscillations within the western part of Central Europe, especially for MIS 3 and partly for MIS 4 (Schirmer, 2012; Schirmer et al., 2012; Klasen et al., 2015).

Contrary to the Schwalbenberg site which provides detailed record of environmetal chamges from 55 to $35 \mathrm{ka}$, another Middle Rhineland loess section Nussloch, preserves a high-resolution record spanning the interval between approximately 30 and 20 ka (Antoine et al., 2001, 2013). Rousseau et al. (2002) have also directly correlated the Nussloch loess record with Greenland stadial-interstadial cycles (Figure 8). The $14 \mathrm{C}$ and luminescence chronologies suggest that the upper part of the Nussloch loess section corresponds to the interval starting with GI 8 (correlated with the Lohner Boden by Zöller and Semmel, 2001) while the top loess unit is younger than the GI2 in Greenland. The tundra gleys exposed at the site, G1a, G1b, G2a, G2b, G3, G4 and G7, were correlated to G17 to 2 in the Greenland ice 
cores (Rousseau et al., 2002, 2007; Antoine et al., 2009). Similarly, the late last-glacial grainsize records at the Czechian Dolní Věstonice and Hungarian Katymar sections show strongly expressed grain size variations with numerous abrupt coarse-grained events in the upper part of these profiles during the same time frame as the Greenland stadial-interstadial cycles identified at Nussloch (Antoine et al., 2013; Bokhorst et al., 2011).

The Dolní Věstonice site has long been believed to record the terrestrial equivalent of climatic oscillations known from marine records (Demek and Kukla, 1969; Kukla and Cilek, 1996). The lower and exceptionally well-preserved pedocomplex (PKII and PKIII) is the most complete record of dust response to environmental dynamics in the European loess belt for the period from 110 to $70 \mathrm{ka}$. This pedocomplex is composed of three fossil chernozems intercalated with five aeolian silt layers. Kukla (1975) has defined these silty layers as loess markers. It has been proposed, based on luminescence ages combined with sedimentological and palaeopedological analysis, that this soil complex recorded all the main climatic events expressed in the North GRIP record from GIS 25 to 19 (Antoine et al., 2013; Rousseau et al., 2013) (Figure 15). However, many questions still remain, not least whether the lowermost Bt horizon represents intensive postdepositional processes, and critically, as well as more generally, whether the luminescence chronologies are sufficiently precise to make the proposed temporal correlations with higher-resolution Greenland icecore records; moreover, that time interval in the Greenland ice core chronology is also characterized by significant chronological uncertainties (See Veres et al., 2013). Given one standard deviation uncertainties on a luminescence age are at best $5 \%$ this equates to \pm 3.5 5.5 ky uncertainty, far too large to allow such fine correlations over this time interval. However, the argument lies over whether the sedimentological and palaeopedological evidence can be used to tune these age estimates sufficiently to allow correlation. The 
sudden environmental shifts represented by the appearance of the dust markers have great

572 stratigraphic significance (Marković et al., 2015); therefore, their correct interpretation and correlation is a crucial issue. Similar Evidence of North Atlantic climatic instability is also observed in Central Asian (e.g. Vandenberghe et al., 2006) and Chinese loess records (e.g. Porter and An, 1995). Stevens and Lu (2009) using luminescence dating found that the taming of sedimentation rates associated with peeaks of coarser grain size only inconsistently mathed with Heinrich events. Sun et al. (2012) presented records of grain size variations from the northwestern Chinese Loess Plateau, dated by optically stimulated luminescence. Reconstructed changes in the strength of the East Asian winter monsoon over the past $60 \mathrm{ka}$ and reconstructed millennial-scale variations that are broadly correlated with temperature variations over Greenland, suggesting a common forcing.

In North America, evidence for oscillations on this timescale in loess records has rarely been reported. Wang et al. (2003) correlated weak palaeosols in loess at two nearby sites in Illinois with interstadials in the Greenland ice core record between 30 and 14 ka, but time interval across the Midwestern U.S.A.

Bokhorst and Vandenberghe (2009) have extensively discussed the limitations of correlating short climatic oscillations recorded in the Greenland ice cores with loess records. two nearby loess sections should be considered carefully. However, the issue of the precision of tuned age models is still critical here as the oscillation wave-length of a particular set of climatic shifts is often shorter than the errors on the age model, meaning that miscorrelations are statistically very likely and at the very least leads and lags are 
entirely lost (Marković et al., 2015). From all these data it may be concluded that many loess records from China to Europe show proxy-signals that reflect short climatic oscillations of the same order as those in ice-core and marine records; however, time equivalence is not certain at present.

\section{POTENTIAL IMPROVEMENTS}

\subsection{SUB MILLENNIAL SCALE CORRELATIONS}

Observed mass accumulation rates for different loess sections are spatially and temporally variable and highly dependant on (paleo) relief and distance of the dust source area (Frechen et al., 2003; Kohfeld and Harrison, 2003; Újvári et al., 2010; Stevens et al., 2016). Some loess records indicate ultra high sedimentation rates during long time intervals (several glacial/interglacial cycles), such as the Mangshan section in China (Prins et al., 2009), or during some short time intervals as in the Peoria Loess in the USA (Roberts et al., 2003; Muhs et al., 2013; Pigati et al., 2013) and some European and Asian last glacial loesspaleosol sequences (Antoine et al., 2001; Fuchs et al., 2008; Ding et al., 1999; Stevens et al., 2006).

Zheng et al. (2006) showed that the upper part (0-97 m) of the Mangshan loess-

paleosol sequence, formed during the last 2 glacial/interglacial cycles, displays extremely high sedimentation rates. The average sedimentation rate is approximately $40 \mathrm{~cm} / \mathrm{ka}$. The unique character of the upper Mangshan loess section is clearly represented by comparing the sedimentation rate estimates for the L1 loess and S1 palaeosol stratigraphic units with sedimentation rates recorded in a series of loess sections distributed across the Central Chinese Loess Plateau. On average, the last glacial loess L1 has a 3.1 times higher linear 
Plateau (eight times higher when L1 horizon units at Mangshan are compared to some other analyzed sections). The sedimentation rate observed in paleosol S1 in the Mangshan section is 4.6 times higher than the average sedimentation rate for the same paleosol unit in the

Central Chinese Loess Plateau (Figure10; Prins et al., 2009). The last glacial/interglacial cycle loess-paleosol sequence in Mangshan has a resolution of at least several centimeters and even in some parts decameter per century. These extreme high accumulation rates are giving an unique opportunity for detailed reconstruction of environmental dynamics on submillennial scale during the whole last glacial period. Even more important is the understanding of the last glacial sub-millennial climate forcing which is currently almost unknown.

In the central Great Plains of North America, very rapid accumulation characterized some intervals of the last glacial Peoria Loess, based on OSL dating and radiocarbon dating of gastropod shells. At Peoria Loess sections in Nebraska, sedimentation rates as high as 400 $\mathrm{cm} / \mathrm{ka}$ can be inferred for some intervals, but discrepancies between OSL and radiocarbon dating add considerable uncertainty to the interpretation of these sections (Roberts et al., 2003; Pigati et al., 2013). At Loveland, lowa, OSL and radiocarbon ages are in agreement and suggest that about $13 \mathrm{~m}$ of Peoria Loess was deposited almost instantaneously, at the resolution of the dating (Muhs et al., 2013; Pigati et al., 2013).

Thus, these ultra high-resolution sections provide a unique opportunity to better understand centennial climatic and environmental dynamics, especially during the last glacial and deglaciacion periods. However, for sub-millennial investigations in sections with lower resolution than Mangshan, application of new much more precise age dating or 
sampling techniques will be necessary. Sub-millenial climatic forcing is still quite unknown and loess ultra resulted records can be regarded as true paleoclimatic treasure because they can provide solution to discover sub-millenianl cycles of Sun activity as well as to evaluate climati influence of some terrestrial catastrophic events such as big volcanic eruptions.

\subsection{LUMINESCENCE DATING OF MIDDLE PLEISTOCENE LOESS}

Luminescence methods (TL-thermoluminescence; IRSL-infrared stimulated luminescence; OSL-optically stimulated luminescence by blue light or violet light (VSL)) are currently the only generally accepted methods for obtaining absolute chronologies for loess deposits through the direct dating of clastic particles. Absolute dating of loess in Europe was pioneered by the applications of thermoluminescence dating performed by Wintle (1981) and luminescence dating has arguably now become the de facto independent dating tool for many loess deposits globally. Roberts (2008) thoroughly reviewed the development and application of luminescence dating methods but recently further significant advances have been made, not least with age determination of loess deposits older than standard quartz OSL and ${ }^{14} \mathrm{C}$ age limits. The outcome of these studies holds great potential for future breakthroughs in stratigraphic correlation over local and continental scale over the middle Quaternary, a period of time where current correlations are rather uncertain.

Standard quartz SAR OSL dating techniques generally have an upper limit of c. 50-30 ka. Buylaert et al. (2008) used Chinese loess samples to demonstrate caution should be used in interpretation of ages where equivalent dose values exceeded $120 \mathrm{~Gy}$ ( $40 \mathrm{ka})$, while Lai (2010) reported underestimation for Luochuan loess in China for ages higher than about 70 ka. For loess in Crvenka in Serbia, OSL ages appear accurate to about 60-50 ka 
663 (corresponding equivalent dose of $\sim 180 \mathrm{~Gy}$ ) while for sediments older than this, the

664 technique (SAR protocol) shows clear age underestimation (Stevens et al., 2011). Moreover, 665 a series of investigations on Romanian (Timar-Gabor et al., 2011; Constantin et al., 2014), 666 Serbian (Timar-Gabor et al., 2015) and Chinese loess (Timar-Gabor et al., 2016) yielded ages 667 obtained on coarse quartz $(63-90 \mu \mathrm{m})$ that were systematically higher than those on fine 668 quartz $(4-11 \mu \mathrm{m})$ for ages $>\sim 40 \mathrm{ka}$. This limits the application of luminescence dating to loess 669 and has driven the development of a suite of new techniques that show great promise in 670 extending the age range of luminescence methods. One of the earlier attempts was through use of the thermally transferred optically stimulated luminescence (TT-OSL) signal, first introduced by Wang (2006) at the Luochuan section in China. While this initially showed great promise, and TT-OSL signals have been reported to grow up to doses higher than $2000 \mathrm{~Gy}$, few ages above 400 ka have been obtained, and dealing with the effect of charge carry over in SAR sequences has limited the approach (Stevens et al., 2009). Furthermore, investigations into the thermal stability of the signal has yielded mixed and potentially sample specific results (Adamiec 2010; Li and Li, 2006; Brown and Forman, 2012; Chapot et al., 2016). However, Chapot et al. (2016) suggest that by applying corrections for thermal loss, meaningful chronologies can be obtained on loess up to $500 \mathrm{ka}$. Ideally though a widely applicable method would not require such corrections. An alternative method using quartz is VSL (Jain, 2009). This method was again tested on Luochuan loess in China by Ankjaergaard et al. (2016) and by applying a multiple aliquot additive dose protocol VSL ages in agreement with the CHILOPARTS chronology up until 600 ka (MIS 15) have been obtained. However, while showing great promise for improving 
middle Pleistocene chronologies the VSL approach is still in its development stage and requires further testing in multiple loess regions.

The predominant use of quartz was mainly related to the anomalous fading (athermal loss of signal due to quantum mechanical tunneling) observed to affect luminescence signals from feldspars (Wintle, 1973). Conventionally, feldspars IRSL is measured at $50{ }^{\circ} \mathrm{C}$ and the effect of increasing the stimulation temperature on the fading was only recently studied (Thomsen et al., 2008). This lead to a double IR stimulation protocol, performing a first IR stimulation at $50^{\circ} \mathrm{C}$ followed by a second one (post-IR IRSLpIRIR) at $225^{\circ} \mathrm{C}$. The first stimulation aimed to remove the unstable signal while the second stimulation targeted a more stable trap. Thiel et al. (2011) extended the protocol by changing the preheat and increasing the stimulation temperature to $290{ }^{\circ} \mathrm{C}$. Using Austrian loess samples from below the Matuyama-Brunhes boundary in saturation on a laboratory dose response curve they concluded that fading is not significant. The same observation was made by Murray et al. (2014) for Serbian loess and was further confirmed for loess in the Rhine area by Schmidt et al. (2014), where an upper limit of 300 ka (MIS 8) was proposed. pIRIR protocols have also been tested on Alaskan loess (Roberts et al., 2012). The same 300 ka barrier seems also to apply when dating Chinese loess by pIRIR (Buylaert et al., 2013) and a slightly modified protocol (multi-elevated-temperature post IR-IRSL MET-pIRIR) was tested on Chinese loess by Li and Li (2012), reaching the same conclusions on maximum age. While showing great promise, the TT-OSL and pIRIR signals are harder to bleach than the standard OSL signals, with residual doses that seem to be sample specific and can amount to a few 10s of Gy. This means that these techniques may not be suitable for younger loess deposits. Despite this and the relatively early stage of these protocols, the application of these new techniques has already enhanced middle Pleistocene chronostratigraphies for loess deposits 
and the stage is set for using these techniques for much wider scale loess stratigraphic correlations, both within and across loess regions.

\subsection{ADVANCES IN LOESS CHRONOLOGIES BASED ON ${ }^{14} \mathrm{C}$-DATING}

In the context of ${ }^{14} \mathrm{C}$-dating major datable phases in loess sediments are charcoals, organic matter, humic substances (humic acids), rhizoliths and mollusc shells (Hatté et al., 2001; McGeehin et al., 2001; Pigati et al., 2013; Gocke et al., 2014; Újvári et al., 2014, 2016b). Charcoal is commonly regarded as the best target material for ${ }^{14} \mathrm{C}$-dating (Trumbore, 2000). Although charcoals are thought to be relatively resistant to post-depositional alteration, there is a growing body of evidence of charcoal degradation and loss by chemical oxidation (Cohen-Ofri et al., 2006; Ascough et al., 2011a,b), physical fragmentation (Gavin, 2003), or fungal degradation (Ascough et al., 2010). Also, charcoal can readily adsorb a range of soluble chemical contaminants migrating in the sediment column like humic substances, which can have a different ${ }^{14} \mathrm{C}$ age than the charcoal (Alon et al., 2002; Rebollo et al., 2008; Wild et al., 2013). This exogenous carbon is removed prior to radiocarbon dating by treating the samples with a series of weak acid and base washes (acid-base-acid=ABA treatment; de Vries and Barendsen, 1954; Olson and Broecker, 1958). While the ABA-technique appears to be a robust method for contaminant removal for a number of samples (Rebollo et al., 2011; Bird and Ascough, 2012), several studies demonstrated that it does not always remove all contaminant carbon, which becomes critical with increasing sample ${ }^{14} \mathrm{C}$ age (Gillespie et al.,1992; Chappell et al., 1996; Wood et al., 2012). An alternative pre-treatment technique, called the ABOX-SC method, involves an oxidation step after the acid-base steps, which is

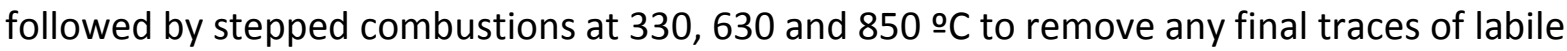


carbon (Bird et al., 1999). Although this technique proved to be very effective in removing contamination from old samples (Wood et al., 2012; Bird et al., 2014), it often leads to large losses in sample material (Bird and Ascough, 2012). In such cases charcoals can be subjected to stepped combustion in pure $\mathrm{O}_{2}$ gas atmosphere, first at $400 \stackrel{\circ}{\circ}$, and then at $800 \stackrel{\circ}{ } \mathrm{C}$ to get reliable ${ }^{14} \mathrm{C}$ ages (Újvári et al., 2016a).

Radiocarbon dating of organic matter may often be problematic because of the rejuvenation of organic matter in loess, which renders ${ }^{14} \mathrm{C}_{\text {org }}$ ages unreliable (Gocke et al., 2010, 2011). Others, however, found little or no evidence for $n$-alkanes in loess-paleosol sequences being significantly "contaminated" by deep subsoil rooting or microbial processes (Häggi et al., 2013; Haas et al., 2017; Zech et al., 2017). This debate is still ongoing and needs further resolution.

As for humic acids, they often originate from younger vegetation and not from in situ plant decay in the sediment to be dated (Ascough et al., 2011; Wild et al., 2013). Previous work on rhizoliths (hypocoatings), that were formed by coating of plant roots by secondary carbonate (Becze-Deák et al., 1997; Barta, 2011), demonstrated that these phases are not synsedimentary (Pustovoytov and Terhorst, 2004; Gocke et al., 2011; Újvári et al., 2014), thus cannot be used for establishing reliable loess chronologies.

Although mollusc shells are often found in loess sediments (Sümegi and Krolopp, 2002; Moine et al., 2008), they have often been considered phases yielding unreliable ages. Early studies documented that land snail shells yield radiocarbon ages that are anomalously old by up to $3000 \mathrm{yr}$, due to incorporation of old, ${ }^{14} \mathrm{C}$-free carbonate from the local substrate into shell carbonate. This phenomenon is often quoted as the 'limestone problem' (Rubin et al., 1963; Tamers, 1970; Evin et al., 1980; Goodfriend and Hood, 1983; Goodfriend and 
Stipp, 1983; Yates, 1986; Goodfriend, 1987). However, most of these works were biased towards gastropods having relatively large shells $(>20 \mathrm{~mm})$ and recent studies by Brennan and Quade (1997) and Pigati et al. $(2004,2010,2013)$ demonstrated that reliable ${ }^{14} \mathrm{C}$ ages can be obtained from smaller gastropods (shells $<10 \mathrm{~mm}$ ) that have largely been ignored in previous ${ }^{14} \mathrm{C}$-dating studies. Beyond the 'limestone problem', another one is to assess whether the shells behaved as close systems with respect to carbon during burial. Opensystem behavior is a serious concern in older samples (60-25 ka) where small amounts of contamination cause large bias/errors in ${ }^{14}$ C ages. Rech et al. (2011) and Pigati et al. (2010, 2013) revealed, by measuring the ${ }^{14} \mathrm{C}$ activities of very old mollusc shells ( $800-130 \mathrm{ka}$ ) and testing land snail shell ages against plant macrofossil ${ }^{14} \mathrm{C}$ ages, that many fossil gastropod shells do not suffer from major (> 1\%) open-system problems. As demonstrated in independent studies of Pigati et al. (2013) and Újvári et al. (2014, 2016b), shells of some mollusc species (e.g. Succinella oblonga, Clausiliidae sp., etc.) provide reliable ages that can form the basis of robust loess chronologies, which can be highly precise on millennial and even sub-millennial timescales.

\subsection{APPLICATION OF TEPHROCHRONOLOGY}

As already discussed, in recent years, apparent limitations on the dating of loess deposits and in isolating millennial-scale climate variability have given a new impetus to providing secure isochronous age markers for loess records (Marković et al., 2015). Volcanic ash beds, and particularly those dispersed over wide geographic areas, played a crucial role in building chronological frameworks for paleoclimate records (Storey et al., 2012). Tephra layers have also proven their value in assessing phase relationships of climatic events, a crucial 
requirement for understanding the value of individual proxy-data (including those for loess) in the comparison of various palaeoclimatic archives (Abbott and Davies, 2012; Lowe et al., 2015).

The South Eastern European loess belt is located near volcanic centers that have been significantly productive throughout the Quaternary (see review in Tomlinson et al., 2015). The central-eastern Mediterranean marine tephrostratigraphic record, augmented by recent findings from long lacustrine records within the Balkans (Leichner et al., 2016) indicate that several well-dated volcanic eruptions provided tephra layers that could serve as excellent isochrones also for loess records.

For example, the widespread Bag tephra identified in multiple loess sites across the Carpathian Basin (Pouclet et al., 1999; Horvath 2001), albeit lacking secure chemical and chronological data, nonetheless provides an undisputed stratigraphic marker horizon for Middle Danube loess (Fig. 5-6). Interestingly, the identification of a MIS 12 tephra bed within Pianico Basin in northern Italy (Brauer et al., 2007) led the authors conclude that the calc-alkaline tephra bed originating from the Campanian volcanic complex of Roccamonfina and dated to around $400 \mathrm{ky}$ might be a counterpart of the widespread Bag tephra. Whilst the proposed link between the Bag tephra and the ash bed in the Southern Alps is tentative, it nonetheless provides a working scenario; the available chemical and mineralogical data on the Bag tephra also points to an origin in the Italian volcanic field (Pouclet et al., 1999; Horvath 2001).

Interestingly, two other laterally continuous tephra beds have been identified in the last glacial loess (Horvath 2001; Wacha and Frechen, 2011) from the Middle Danube and the Adriatic coast, and dated to around $34 \mathrm{ka}$ and $30 \mathrm{ka}$. As two important tephra layers have 
been reported in marine and terrestrial sites over that time interval, namely the $Y-3$ and the

Coddola ashes, it is tempting to propose direct linking of records. Correlation of these

tephra beds in the absence of reliable chemical data for the terrestrial occurrences is risky and must be verified through further work, but this potential correlation raises the possibility that the regional loess tephrostratigraphy could be augmented and eventually integrated within a regionally representative framework. In this respect, perhaps the most compelling example is provided by the Campanian Ignimbrite/Y-5 eruption, that, due to the large volume of volcanic ejecta, excellent preservation of glass shards and a north-easterly spread of the ash plume, forms the most important visible marker horizon with independent numerical age control (de Vivo et al., 2001) for Eastern European loess. It has been identified widely in southeastern European loess (Veres et al., 2013; Fitzsimmons et al., 2013; Obreht et al., 2016), raising the possibility for a direct comparison of different loess profiles (Marković et al., 2015) and also of loess with various paleoclimatic records from the Balkans and beyond (Zeeden et al., 2016). Moreover, the Campanian Ignimbrite/Y-5 ash layer has been employed successfully in testing the accuracy of various multi-method luminescence-dating approaches applied to loess (Constantin et al., 2012; Veres et al., 2013; Fitzsimmons et al., 2013; Anechitei-Deacu et al., 2014; Zeeden et al., 2016). Recent research has documented significant age discrepancies between different quartz-grain sizes of the same sample, a limitation in luminescence dating of loess not yet fully overcome (Timar and Wintle, 2013). In this respect, the Campanian Ignimbrite/Y-5 ash layer provided a chronological base line against which different luminescence dating approaches have been tested (Constantin et al., 2012; Anechitei-Deacu et al., 2014), with encouraging results. A similar approach was followed in Fattahi and Stockes (2003) and Auclair et al. (2007) 
through the direct luminescence dating of a tephra horizon and the embedding loess deposits at sites throughout North America.

Other notable examples of the application of tephrochronology involving loess deposits include the recent identification of Carpathian ash beds in proximal loess-derived deposits within Transylvania (Karatson et al., 2016) linked to distal areas, north of Black Sea (Wulf et al., 2016), as well as in loess profiles from Japan (Matsura et al., 2012), New Zealand (Lowe, 2011), Alaska (Preece et al., 2011), central-western Europe (Sirocko et al., 2013) or South American loess (Toms et al., 2004).

\subsection{TOWARDS IMPROVED MAGNETOSTRATIGRAPHY}

Magnetic stratigraphy represents a powerful and widely used relative dating tool. Beside environmental magnetic proxies related to environmental changes (e.g. magnetic susceptibility stratigraphy), properties of the Earth's magnetic field are investigated and correlated to reference sections and/or datasets as usually the Geomagnetic Polarity Time Scale (GPTS), part of the Geological Time scale (Gradstein et al., 2012; Ogg, 2012). When sedimentation rates are not dramatically changing and the polarities of Earth's magnetic field are recorded, correlation allows for establishment of a time scale on the scale of magnetic features. Polarity time scales therefore commonly have a rather low resolution due to the limited number of reversals over the Neogene and Quaternary $\left(1 / 10^{4}-10^{5} \mathrm{yrs}\right)$. Both the polarity and intensity variations can be used for time scale establishment.

Especially within the recent magnetic polarity zone, the intensity of Earth's magnetic field 
can be valuable for dating, and reference datasets were established (e.g. Channell et al., 2009; Kissel et al., 2000; Laj et al., 2004; Valet et al., 2005).

Earliest time scales for loess have been established by magnetic polarity stratigraphy (Fink and Kukla, 1977; Heller and Liu, 1982, 1984; Kukla et al., 1988; Kukla, 1975). In their seminal papers Heller and Liu $(1982,1984)$ assigned firstly the Chinese loess record to the GPTS and demonstrated secondly via magnetic susceptibility stratigraphy the unique match between the marine isotopic record the alternation of loess and paleosoils. Ever since, correlative loess stratigraphy benefited from magnetostratigrapic age constraints, which were later on refined (e.g. Maher, 2016), when also rather short term geomagnetic excursions (e.g. Reinders and Hambach, 1995; Sun et al., 2013; Zhu et al., 1999, 2006) and paleointensity records (Hambach et al., 2008; Liu et al., 2005; Rolf et al., 2014; Zeeden et al., 2009) were used.

A comparison of paleointensity records from Europe (Figure 10) to the North Atlantic Paleointensity Stack GLOPIS (Laj et al., 2004) shows some common features, here indicated by colored circles, which were used in constraining age models for European loess sites (Hambach et al., 2008; Rolf et al., 2014; Zeeden et al., 2009). Also clear are some discrepancies, especially when comparing the longer term patterns and the amplitude of minima and maxima in paleointensity. Though relative minima and maxima can be observed and correlated, their amplitude in loess seems less homogeneous than in other archives (Roberts et al., 2013; Fig. 10). This may be caused mainly by sedimentological and magnetic grain size variations and early diagenetic effects, which in turn dependent on climatically controlled wind strength and post-depositional pedogenic processes. 


\section{CONCLUSIONS}

871 Contrary to the records derived from ice cores and deep-sea or lacustrine sediments,

872 characterized by more or less continuous sedimentation, loess-palaeosol sequences are the

873 product of more complex depositional systems with significantly varying accumulation rates,

874 more dynamic environmental thresholds and higher sensitivity to erosion. Thus, valid

875 correlations on regional or even continental scales are only possible at the level of first

876 order units (i.e. MIS or glacial loess and interglacial pedocomplex units), although recent

877 research has resulted in significant progress on inter-profile correlations and direct

878 comparison of different palaeoclimatic records. However, rapid current improvements in

879 numerical dating techniques, associated with tephrochronological approaches, could result

880 in much better understanding of the chronostratigraphic mosaic in forthcoming years. Due

881 to widespread distribution across Northern Hemisphere continents, loess records with

882 accurate age control can be regarded as a missing link for better understanding

883 paleoclimatic variation and linkages across the Northern Hemisphere and globally, and

884 between continents and oceans.

885

Additionally, improvements in loess correlations and age dating summarized in this

study should open possibilities for better, more detailed temporal and spatial environmental reconstructions spanning at least the Holocene, last deglaciation and last glacial period.

\section{Acknowledgements}

890

This research was financially supported by Project 176020 of the Serbian Ministry of

891 Education and Science. SBM is grateful for VIFI fellowship of Chinese Academy of Sciences. 

(NSF).

\section{References}

Abbotts, P.M., Davies, S.M., 2012. Volcanism and the Greenland ice-cores: the tephra record. EarthSci. Rev. 115, 173-191.

Adamiec, G., Duller, G.A.T., Roberts, H.M., Wintle, A.G., 2010. Improving the TT-OSL SAR protocol through source trap characterization. Radiation Measurements, 4, 768-777.

Alon, D., Mintz, G., Cohen, I., Weiner, S., Boaretto, E., 2002. The use of Raman spectroscopy to monitor the removal of humic substances from charcoal: quality control for $14 \mathrm{C}$ dating of charcoal. Radiocarbon 44, 1-11.

Aleinikoff, J. N., Muhs, D. R., Bettis, E. A., Johnson, W. C., Fanning, C. M., Benton, R., 2008. Isotopic evidence for the diversity of late Quaternary loess in Nebraska: Glaciogenic and nonglaciogenic sources, Geol. Soc. Am. Bull., 120, 1362-1377. An, Z., Liu, T., Lu, Y., Porter, S.C., Kukla, G., Wu, X.H., Hua, J.M. 1990. The long-term palaeomonsoon variation recorded by the loess-palaeosol sequence in central China. Quatern. Int. 7/8, 91-95.

Ankjærgaard, C., Guralnik, B., Buylaert, J.-P., Reimann, T., Yi, S.W., Wallinga, J., 2016. Violet stimulated luminescence dating of quartz from Luochuan (Chinese loess plateau): Agreement with independent chronology up to $\sim 600 \mathrm{ka}$. Quaternary Geochronology, 34, 33-46.

Anechitei-Deacu, V., Timar-Gabor, A., Fitzsimmons, K.E., Veres, D., Hambach, U., 2014. Multi-method luminescence investigations on quartz grains of different sizes extracted from a loess section in southeast Romania interbedding the Campanian Ignimbrite ash layer. Geochronometria 41, 1-14.

916 Antoine, P., Coutard, S., Guerin, G., Deschodt, L., Goval, E., Locht, J.-L., Paris, C. 2016. Upper-

917 Pleistocene loess-palaeosol records from Northern France in the European context : environmental 918 background and dating of the Middle Palaeolithic. Quatern. Int. 411, 4-24. Gauthier, C., Svoboda, J., Lisa, L., 2013. High-resolution record of the environmental response to climatic variations during the Last Interglacial-Glacial cycle in Central Europe: the loess-palaeosol sequence of Dolní Vestonice (Czech Republic). Quat. Sci. Rev. 67, 17-38. Gaudenyi, T., Moine, O., Rossignol, J., 2009. High-resolution record of the last climatic cycle in the southern Carpathian Basin (Surduk, Vojvodina, Serbia). Quatern. Int. 198, 19-36. 
Ascough, P., Sturrock, C.J., Bird, M.I., 2010. Investigation of growth responses in saprophytic fungi to charred biomass. Isotopes Environ. Health Stud. 46, 64-77.

Ascough, P.L., Bird, M.I., Francis, S.M., Lebl, T., 2011a. Alkali extraction of archaeological and geological charcoal: evidence for diagenetic degradation and formation of humic acids. J. Archaeol. Sci. 38, 69-78.

Ascough, P.L., Bird, M.I., Francis, S.M., Thornton, B., Midwood, A.J., Scott, A.C., Apperley, D., 2011b. Variability in oxidative degradation of charcoal: influence of production conditions and environmental exposure. Geochim. Cosmochim. Acta 75, 2361-2378. Auclair, M., Lamothe, M., Lagroix, F., Banerjee, S.K., 2007. Luminescence investigation of loess and tephra from Halfway House section, Central Alaska. Quat. Geochron. 2, 34-38.

Baczak, G.Y., 1942. Deie Wirkung der skandinavischen Vereisung auf die Periglazialzone. Institut fuer Meteorologie and Erdmagnetismus Neue Serie 13, Budapest, 86 pp.

Baddouh, M. , Meyers, S.R., Carroll, A.R., Beard, B.L., Johnson, C.M., 2016. Lacustrine 87Sr/86Sr as a tracer to reconstruct Milankovitch forcing of the Eocene hydrologic cycle. Earth Planet. Sci. Lett. 448, $62-68$.

Begét, J.E., Stone, D.B., Hawkins, D.B., 1990. Paleoclimatic forcing of magnetic susceptibility variations in Alaska loess during the late Quaternary. Geology 18, 40-43.

Barta, G., 2011. Secondary carbonates in loess-paleosoil sequences: a general review. Central Eur. J. Geosci. 3, 129-146.

Basarin, B., Buggle, B., Hambach, U., Marković, S.B., Dhand, K.O., Kovačević, A., Stevens, T., Guo, Z., Lukić, T., 2014. Time-scale and astronomical forcing of serbian loess-palaeosol sequences. Glob. Planet. Change 122, 89-106.

Bassinot, F.V., Labeyrie, L.D., Vincent, E., Quidelleur, X., Shackleton, N.J., Lancelot, Y., 1994. The astronomical theory of climate and the age of the Brunhes-Matuyama magnetic reversal. Earth Planet. Sci. Lett. 126, 91-108.

Bazin, L., Landais, A., Lemieux-Dudon, B., Toyé, M., Kele, H., Veres, D., Parrenin, F., Martinerie, P., Ritz, C., Capron, E., Lipenkov, V., Loutre, M.-F., Raynaud, D., Vinther, B., Svensson, A., Rasmussen, S.O., Severi, M., Blunier, T., Leuenberger, M., Fischer, H., Masson-Delmotte, V., Chappellaz, J., Wolff, E., 2013. An optimized multi-proxy, multi-site Antarctic ice and gas orbital chronology (AICC2012): 120-800 ka. Clim. Past 9, 1715-1731.

Becze-Deak, J., Langohr, R., Verrecchia, E., 1997. Small scale secondary $\mathrm{CaCO}_{3}$ accumulations in selected sections of the European loess belt: morphological forms and potential for paleoenvironmental reconstruction. Geoderma 76, 221-252.

Bettis, E.A., III, Muhs, D.R., Roberts, H.M. and Wintle, A.G., 2003. Last glacial loess in the conterminous USA. Quaternary Sci. Rev. 22, 1907-1946.

Bird, M.I., Ascough, P.L., 2012. Isotopes in pyrogenic carbon: a review. Org. Geochem. 42, 15291539.

Bird, M.I., Ayliffe, L.K., Fifield, K., Cresswell, R., Turney, C., 1999. Radiocarbon dating of 'old' charcoal using a wet oxidation-stepped combustion procedure. Radiocarbon 41, 127-140. 

event stratigraphy for the Last Termination in the North Atlantic region based on the Greenland icecore record: a proposal by the INTIMATE group. J. Quat. Sci. 13/4, 283-292.

Blaauw, M., 2010. Out of tune: the dangers of aligning proxy archives. Quat. Sci. Rev. 36, 38-49. doi: 10.1016/j.quascirev.2010.11.012.

Blockley, S.P.E., Lane, C.S., Hardiman, M., Rasmussen, S. O., Seierstad, I.K., Rasmussen, S.O., Seierstad, I.K., Steffensen, J.P., Svensson, A., Lotter, A.F., Turney, C.S.M., Ramsey, C.B. and INTIMATE members. 2012. Synchronisation of palaeoenvironmental records over the last 60,000 years, and an extended INTIMATE(1) event stratigraphy to 48,000 b2k. Quat. Sci. Rev. 36, 2-10.

Bokhorst, M., Vandenberghe, J., 2009. Validation of wiggle matching using a multi-proxy approach and its paleoclimatic significance. J. Quat. Sci. 24, 937-947

Bokhorst, M.P., Vandenberghe, J., Sümegi, P., Lanczont, M., Gerasimenko, N.P., Matviishina, Z.N., Markovic, S.B., Frechen, M., 2011. Atmospheric circulation patterns in Central and Eastern Europe during the Weichselian Pleniglacial inferred from loess grain-size records. Quat. Int. 234, 62-74. Bond, G., Heinrich, H., Broecker, W., Labeyrie, L., McManus,J., Andrews, J., Huon, S., Jantschik, R., Clasen, S., Simet, C., Tedesco, K., Klas, M., Bonani, G., Ivy, S., 1992. Evidence for massive discharges of icebergs into the North Atlantic Ocean during the last glacial period. Nature 360, 245-249.

Brauer A, Wulf S, Mangili C, Moscariello A. 2007. Tephrochronological dating of varved interglacial lake deposits from Pianico-Sellere (Southern Alps, Italy) to around 400 ka. Journal of Quaternary Science 22: 85-96.

Brennan, R., Quade, J., 1997. Reliable Late-Pleistocene stratigraphic ages and shorter groundwater travel times from ${ }^{14} \mathrm{C}$ in fossil snails from the southern Great Basin. Quat. Res. 47, 329-336.

Bronger, A., 1976. Zur quartären Klima- und Landschaftsentwicklung des Karpatenbeckens auf (paläo-)pedologischer und bodengeographischer Grundlage. In Kieler geographische Schriften 45. Selbstverlag des Geographischen Instituts der Universität Kiel, Kiel.

Bronger, A., 2003. Correlation of loess-paleosol sequences in East and Central Asia with SE Central Europe - Towards a continental Quaternary pedostratigraphy and paleoclimatic history. Quat. Int. 106/107, 11-31.

Bronger, A., Heinkele, T., 1989. Micromorphology and genesis of paleosols in the Luochuan loess section, China: Pedostratigraphical and environmental implications. Geoderma 45, 123-143. soils and in buried paleosols in Tadjikistan towards a Quaternary paleoclimatic record in Central Asia. Catena 34, 19-34.

Brown, N.D., Forman, S.L., 2012. Evaluating a SAR TT-OSL protocol for dating fine-grained quartz within Late Pleistocene loess deposits in the Missouri and Mississippi river valleys, United States. Quaternary Geochronology, 12, 87-97. evolution of a continental climate in SE-Central European lowlands during the Middle Pleistocene 99-113. 
1019

1020

1021

1022

1023

1024

1025

1026

1027

1028

1029

1030

1031

1032

1033

1034

1035

1036

1037

1038

1039

1040

1041

1042

1043

1044

1045

1046

1047

1048

1049

1050

1051

1052

1053

1054

Buylaert, J.P., Jain, M., Murray, A.S., Thomsen, K.J., Thiel, C., Sohbati, R., 2013. A robust feldspar luminescence dating method for Middle and Late Pleistocene sediments. Boreas 41, 435-451.

Channell, J.E.T., Xuan, C., Hodell, D.A., 2009. Stacking paleointensity and oxygen isotope data for the last 1.5 Myr (PISO-1500). Earth Planet. Sci. Lett. 283, 14-23.

Chappell, J., Head, M.J., Magee, J., 1996. Beyond the radiocarbon limit in Australian archaeology and Quaternary research. Antiquity 70, 543-752.

Chapot, M.S., Roberts, H.M., Duller, G.A.T., Lai, Z.P., 2016. Natural and laboratory TT-OSL dose response curves: Testing the lifetime of the TT-OSL signal in nature. Radiation Measurements, 85 , 41-50.

Chen, J., Li, G.J., Yang, J.D., Rao, W.B., Lu, H.Y., Balsam, W., Sun, Y.B., Ji, J.F., 2007. Nd and Sr isotopic characteristics of Chinese deserts: implications for the provenances of Asian dust. Geochim. Cosmochim. Acta 71, 3904-3914.

Cheng, H., Zhang, P.Z., Spötl, C., Edwards, R.L., Cai, Y.L., Zhang, D.Z., Sang, W.C., Tan, M., An, Z.S., 2012. The climatic cyclicity in semiarid-arid central Asia over the past 500,000 years. Geophys. Res. Lett. 39, L01705, doi:10.1029/2011GL050202.

Chlachula, J., Evans, M.E., Rutter, N.W., 1998. A magnetic investigation of a Late Quaternary loess/palaeosol record in Siberia. Geophysical Journal International 132, 128-132.

Cohen-Ofri, I., Weiner, L., Boaretto, E., Mintz, G., Weiner, S., 2006. Modern and fossil charcoal: aspects of structure and diagenesis. J. Archaeol. Sci. 33, 428-439.

Constantin, D., Timar-Gabor, A., Veres, D., Begy, R., Cosma, C., 2012. SAR-OSL dating of different grain-sized quartz from a sedimentary section in southern Romania interbedding the Campanian Ignimbrite/Y5 ash layer. Quat. Geochronol. 10, 81-86.

Constantin, D., Begy, R., Vasiliniuc, S., Panaiotu, C., Necula, C., Codrea, V., Timar-Gabor, A., 2014. High-resolution OSL dating of the Costineşti section (Dobrogea, SE Romania) using fine and coarse quartz. Quaternary International 334-335, 20-29.

Dansgaard, W., Johnsen, S.J., Clausen, H.B., Dahl-Jensen, D., Gundestrup, N.S., Hammer, C.U., Hvidberg, C.S., Steffensen, J.P., Sveinbjörnsdottir, A.E., Jouzel, J., Bond, G., 1993. Evidence for general instability of past climate from a 250-kyr ice-core record. Nature 364, 218-220.

De Angelis, M., Steffensen, J.P., Legrand, M., Clausen, H., Hammer, C., 1997. Primary aeroso I(sea salt and soil dust) deposited in Greenland ice during the last climatic cycle: comparison with east Antarctic records. J. Geophys. Res. 102, 26681-26698.

De Vivo, B., Rolandi, G., Gans, P.B., Calvert, A., Bohrson, W.A., Spera, F.J., Belkin, H.E., 2001. New constraints on the pyroclastic eruptive history of the Campanian volcanic Plain (Italy). Miner. Petrol. $73,47-65$.

Demek, J., Kukla, G., 1969. Periglazialzone, Löss und Palaolithikum der Tschechoslowakei, Akad. Wiss. Geogr. Inst. Brno, Brno.

Ding, Z.L., Liu, T. S., Liu, X. M., Chen, M. Y. and An, Z. S., 1990. Thirty-seven climatic cycles in the last 2.5Ma. Chinese Sci. Bull. 34, 1494-1496.

Ding, Z.L., Ren, J.Z., Yang, S.L., Liu, T.S. 1999. Climate instability during the penultimate glaciationEvidence from two high-resolution loess records, China. J.Geophys. Res. 104, 20123-20132. 
Ding, Z.L., Ranov, V., Yang, S.L., Finaev, A., Han, J.M., Wang, G.A., 2002. The loess record in southern Tajikistan and correlation with Chinese loess. Earth Planet. Sci. Lett. 200, 387-400.

Dodonov, A.E., Zhou, L.P., 2008. Loess deposition in Asia: its initiation and development before and during the Quaternary. Episodes 31, 222-225.

Dong, Y., Wu, N., Li., F., Huang, L., Wen, W., 2015. Time-transgressive nature of the magnetic susceptibility record accross the Chinese Loess Plateau at the Pleistocene/Holocene transition. Plos One 10 (7), e0133541.

Ebisuzaki, W., 1997. A Method to Estimate the Statistical Significance of a Correlation When the Data Are Serially Correlated. J. Clim. 10, 2147-2153. doi:10.1175/15200442(1997)010<2147:AMTETS>2.0.CO;2

Evin, J., Marechal, J., Pachiaudi, C., 1980. Conditions involved in dating terrestrial shells. Radiocarbon 22, 545-555.

Fattahi, M., Stokes, S., 2003. Dating volcanic and related sediments by luminescence methods: a review. Earth-Science Reviews 62(3), 229-264.

Fink, J., 1962. Studien zur absoluten und relativen Chronologie der fossilen Böden in Österreich, II Wetzleinsdorf und Stillfried. Archaeol. Austriaca 31, 1- 18.

Fink, L., Kukla, G., 1977. Pleistocene climates in Central Europe: at least 17 interglacials after the Olduvai event. Quat. Res. 7, 363-371.

Fitzsimmons, K., Hambach, U., Veres, D., lovita, R., 2013. The Campanian Ignimbrite eruption: new data on volcanic ash dispersal and its potential impact on human evolution. PLoS One 8/6, e65839. doi:10.1371/journal.pone.0065839

Fuchs, M., Rousseau, D.D., Antoine, P., Hatté, C., Gauthier, C., 2008. Chronology of the Last Climatic Cycle (Upper Pleistocene) of the Surduk loess sequence, Vojvodina, Serbia. Boreas 37, 66-73.

Fuhrer, K., Legrand, M., 1997. Continental biogenic species in the Greenland Ice Core Project ice core: tracing back the biomass history of the North American continent. J. Geophys. Res. 102, 2673526745.

Gavin, D.G., 2003. Forest soil disturbance intervals inferred from soil charcoal radiocarbon dates. Can. J. For. Res. 33, 2514-2518.

Gillespie, R., Hammond, A.P., Goh, K.M., Tonkin, P.J., Lowe, D.C., Sparks, R.J., Wallace, G., 1992. AMS radiocarbon dating of a Late Quaternary tephra site at Graham's Terrace, New Zealand. Radiocarbon 34, 21-28.

Gocke, M., Kuzyakov, Y., Wiesenberg, G.L., 2010. Rhizoliths in loessdevidence for post-sedimentary incorporation of root-derived organic matter in terrestrial sediments as assessed from molecular proxies. Org. Geochem. 41, 1198-1206.

Gocke, M., Pustovoytov, K., Kuhn, P., Wiesenberg, G., Loscher, M., Kuzyakov, Y., 2011. Carbonate rhizoliths in loess and their implications for paleoenvironmental reconstruction revealed by isotopic composition: d13C, 14C. Chem. Geol. 283, 251-260.

Gocke, M., Gulyás, S., Hambach, U., Jovanović, M., Kovács, G., Marković, S.B., Wiesenberg G.L.B. 2014. Biopores and root features as new tools for improving paleoecological understanding of terrestrial sediment-paleosol sequences. Palageogr., Palaeocli., Palaeoeco. 394, 42-58. 
Goodfriend, G.A., 1987. Radiocarbon age anomalies in shell carbonate of land snails from semi-arid areas. Radiocarbon 29, 159-167.

Goodfriend, G.A., Hood, D.G., 1983. Carbon isotope analysis of land snail shells: implications for carbon sources and radiocarbon dating. Radiocarbon $25,810-830$.

Goodfriend, G.A., Stipp, J.J., 1983. Limestone and the problem of radiocarbon dating of land-snail shell carbonate. Geology 11, 575-577.

Götzinger, G., 1936. Das Lößgebiet um Göttweig und Krems an der Donau. In: Götzinger, G. (Ed.), Führer für die Quartär-Exkursionen in Österreich. Geologische Bundesanstalt, Wien, pp. 1-11.

Gradstein, F., Ogg, J., Schmitz, M., Ogg, G., 2012. The Geologic Time Scale 2012. Fac. Authored Books.

Haesaerts, P., Damblon, F. Gerasimenko, N., Spagna, P. and Pirson, S. 2016. The Late Pleistocene loess-palaeosol sequence of Midle Belgium. Quat. Int. 411, 25-43.

Haggi, C., Zech, R., McIntyre, C., Eglinton, T., 2013. On the stratigraphic integrity of leaf-wax biomarkers in loess-paleosols. Biogeosci. Discuss. 10, 16903-16922.

Hambach, U., Rolf, C., Schnepp, E., 2008a. Magnetic dating of Quaternary sediments, volcanites and archaeological materials: an overview. E \& G, Quaternary Science Journal, 57/1-2, 25-51

Hambach, U., Zeeden, C., Hark, M., Zöller, L., 2008b. Magnetic dating of an Upper Palaeoltihic cultural layer bearing loess from the Krems-Wachtberg site (Lower Austria). In: J. Reitner et al. (Eds.) Veränderter Lebensraum - Gestern, Heute und Morgen. DEUQUA Symposium 2008. Abhandlungen der geologischen Bundesanstalt (62): 153 -157.

Hao, Q.Z., Wang, L., Oldfield, F., Peng, S.Z., Qin, L., Song, Y., Xu, B., Qiao, Y., Bloemendal, J., Guo, Z.T., 2012. Delayed build-up of Arctic ice sheets during 400,000-year minima in insolation variability. Nature 490, 393-396.

Haas, M., Bliedtner, M., Borodynkin, I., Slazar, G., Szidat, S., Eglinton, T., Zech, R., 2017. Radiocarbon Dating of Leaf Waxes in the Loess-Paleosol Sequence Kurtak, Central Siberia. Radiocarbon 59, 165176.

Hatté, C., Pessenda, L.C.R., Lang, A., Paterne, M., 2001. Development of an accurate and reliable 14C chronology for loess sequences: application to the loess sequence of Nussloch (Rhine valley, Germany). Radiocarbon 43, 611-618.

Heller F, Liu T., 1984. Magnetism of Chinese loess deposits. J. Roy. Astron. Soc. 77, 125-141.

Heller, F., Liu, T., 1982. Magnetostratigraphical dating of loess deposits in China. Nature 300, 431433.

Heslop, D., Langereis, C.G., Dekkers, M.J., 2000. A new astronomical timescale for the loess deposits of Northern China. Earth Planet. Sci. Lett. 184, 125-139. doi:10.1016/S0012-821X(00)00324-1

Hilgen, F.J., Hinnov, L.A., Aziz, H.A., Abels, H.A., Batenburg, S., Bosmans, J.H.C., Boer, B. de, Hüsing, S.K., Kuiper, K.F., Lourens, L.J., Rivera, T., Tuenter, E., Wal, R.S.W.V. de, Wotzlaw, J.-F., Zeeden, C., 2014. Stratigraphic continuity and fragmentary sedimentation: the success of cyclostratigraphy as part of integrated stratigraphy. Geol. Soc. Lond. Spec. Publ. 404, SP404.12. doi:10.1144/SP404.12 Horváth, E., 2001. Marker horizons in the loesses of the Carpathian Basin. Quat. Int. 76/77, 157-163. Jain, M., 2009. Extending the dose range: probing deep traps in quartz with $3.06 \mathrm{eV}$ photons. Radiat. Meas. 44, 445-452. 
Jouzel, J., Masson-Delmotte, V., Cattani, O., Dreyfus, G., Falourd, S., Hoffmann, G., Minster, B., Nouet, J., Barnola, J.M., Chappellaz, J., Fischer, H., Gallet, J.C., Johnsen, S., Leuenberger, M., Loulergue, L., Luethi, D., Oerter, H., Parrenin, F., Raisbeck, G., Raynaud, D., Schilt, A., Schwander, J., Selmo, E., Souchez, R., Spahni, R., Stauffer, B., Steffensen, J.P., Stenni, B., Stocker, T.F., Tison, J.L., Werner, M., Wolff, E.W., 2007. Orbital and millennial Antarctic climate variability over the past 800,000 years. Science $317,793-796$.

Karátson, D., Wulf, S., Veres, D., Magyari, E.K., Gertisser, R., Timar-Gabor, A., Novothny, Á., Telbisz, T., Szalai, Z., Anechitei-Deacu, V., Appelt, O., Bormann, M., Jánosi, C., Hubay, K., Schäbitz, F., 2016. The latest explosive eruptions of Ciomadul (Csomád) volcano, East Carpathians - a tephrostratigraphic approach for the 52-29 ka BP time interval. J. Volcanol. Geoth. Res. 319, 29-51.

Kohfeld, K.E., Harrison, S.P., 2003. Glacial-interglacial changes in dust deposition on the Chinese Loess Plateau. Quaternary Science Reviews 22, 1859-1878.

Kissel, C., Mazaud, A., Channell, J.E., Beer, J., others, 2000. North Atlantic palaeointensity stack since 75ka (NAPIS-75) and the duration of the Laschamp event. Philos. Trans. R. Soc. Lond. Math. Phys. Eng. Sci. 358, 1009-1025.

Klasen, N., Fischer, P., Lehmkuhl, F., Hilgers, A., 2015. Luminescence Dating of Loess Deposits from the Remagen-Schwalbenberg Site. Geochronom. 42. 67-77.

Kukla, G., 1987. Loess stratigraphy in central China. Quat. Sci. Rev. 6, 191-219.

Kukla, G., An, Z., 1989. Loess stratigraphy in Central China. Palaeogeogr. Palaeoclimatol. Palaeoecol. 72, 203-225.

Kukla, G., Heller, F., Xiu Ming, L., Sheng, A.Z., 1988. Pleistocene Climates in China Dated by Magnetic Susceptibility. Geology 16 (9), 811-814.

Kukla, G.J., 1970. Correlations between loesses and deep-sea sediments. Geologiska Foreningen i Stockholm Forhandlingar 92, 148-180.

Kukla, G.J., 1975. Loess stratigraphy of Central Europe, in: Butzer, K.W., Isaac, L.I. (Eds.), After the Australopithecines. Mouton Publishers, The Hague, pp. 99-187.

Kukla, G.J., 1977. Pleistocene land-sea correlations. Earth-Sci. Rev. 13, 307-374.

Kukla, G.J., Cilek, V., 1996. Plio-Pleistocene megacycles: record of climate and tectonics. Palaeogeogr. Palaeoclimatol. Palaeoecol. 120, 171-194.

Lai, Z., 2010. Chronology and the upper dating limit for loess samples from Luochuan section in the Chinese Loess Plateau using quartz OSL SAR protocol. J. Asian Earth Sci. 37, 176-185.

Laj, C., Kissel, C., Beer, J., 2004. High Resolution Global Paleointensity Stack Since 75 kyr (GLOPIS-75) Calibrated to Absolute Values. Timescales Paleomagn. Field 255-265.

Laskarev, V., 1926. Deuxieme note sur le loess des environs de la Belgrade. Geoloski anali Balkanskoga poluostrva (Annales Geologiques de la Peninsule Balkanique) VIII (2), 1-19.

Lehmkuhl, F., Zens, J., Krauss, L., Schulte, P., Kels, H., 2016. Loess-palaeosol sequences at the northern European loess belt in Germany. Distribution, geomorphology and stratigraphy. Quat. Sci. Rev. 153,11-30.

Leicher, N., Zanchetta, G., Sulpizio, R., Giaccio, B., Wagner, B., Nomade, S., Francke, A., Del Carlo, P. 2016. First tephrostratigraphic results of the DEEP site record from Lake Ohrid (Macedonia and Albania), Biogeosciences, 13, 2151-2178, doi:10.5194/bg-13-2151-2016, 2016. 
1177 Li, B., Li, S.-H., 2006. Studies of thermal stability of charges associated with thermal transfer of OSL 1178 from quartz. J. Phys. D. Appl. Phys. 39, 2941-2949.

1179 Li, B., Li, S.-H., 2012. Luminescence dating of Chinese loess beyond 130 ka using the non-fading signal 1180 from K-feldspar. Quat. Geochronol. 10, 24-31.

1181 Lisiecki, L.E., Raymo, M.E., 2005. A Pliocene-Pleistocene stack of 57 globally distributed benthic $\delta 180$ 1182 records. Paleoceanography 20, PA1003, doi:10.1029/2004PA001071.

1183 Liu, Q., Banerjee, S.K., Jackson, M.J., Deng, C., Pan, Y., Zhu, R., 2005. Inter-profile correlation of the 1184 Chinese loess/paleosol sequences during Marine Oxygen Isotope Stage 5 and indications of 1185 pedogenesis. Quat. Sci. Rev. 24, 195-210.

1186 Liu, T., 1985. Loess and the environment. China Ocean Press, Beijing, 251 pp.

1187 Liu, T., Chang, T., 1962. The "Huangtu"(loess) of China. Rept. 6th INQUA Congress, Warsaw 19614 , 1188 503-534.

1189 Lowe, D.J., 2011. Tephrochronology and its application: A review. Quat. Geochronol. 6/2, 107-153.

1190 Lu, H., Stevens, T., Yi, S.W., Sun, X.F., 2006. An erosional hiatus in Chinese loess sequences revealed 1191 by closely spaced optical dating. Chin. Sci. Bull. 51. 2253-2259.

Maher, B.A., 2016. Paleoclimatic records of the loess/palaeosol sequences of the Chinese Loess Plateau. Quat. Sci. Rev. 154, 23-84.

Maher, B.A., Mutch, T.J., Cunningham, D., 2009. Magnetic and geochemical characteristics of Gobi Desert surface sediments: implications for provenance of the Chinese Loess Plateau. Geology 37, 279-282.

Marković, S. B. Oches, E.A., Jovanović, M., Gaudenyi, T., Hambach, U., Zöller, L., Sümegi, P., 2004. Paleoclimate record in the Late Pleistocene loess-paleosol sequence at Miseluk (Vojvodina, Serbia). Quaternaire 15/4, 361-368.

1200 Marković, S.B., McCoy, W.D., Oches, E.A., Savić, S., Gaudenyi, T., Jovanović, M., Stevens, T., Walther, R., Ivanišević, P., Galić, Z., 2005. Paleoclimate record in the Upper Pleistocene loess-paleosol sequence at Petrovaradin brickyard (Vojvodina, Serbia). Geol. Carpath. 56, 545-552.

Marković, S.B., Oches, E., Sümegi, P., Jovanović, M., Gaudenyi, T., 2006. An introduction to the Upper and Middle Pleistocene loess-paleosol sequence at Ruma brickyard, Vojvodina, Serbia. Quat. Int. $149,80-86$.

Marković, S.B., Oches, E.A., McCoy, W.D., Gaudenyi, T., Frechen, M., 2007. Malacological and sedimentological evidence for "warm" glacial climate from the Irig loess sequence, Vojvodina, Serbia. Geochem. Geophys. Geosyst. 8, Q09008. http://dx.doi.org/10.1029/2006GC001565 Marković, S.B. Bokhorst, M, Vandenberghe, J., Oches, E.A., Zöller, L., McCoy, W.D., Gaudenyi, T., Jovanović, M., Hambach, U., Machalett, B. 2008. Late Pleistocene loess-paleosol sequences in the Vojvodina region, North Serbia. Journal of Quaternary Science 23, 73-84.

Marković, S.B., Hambach, U., Catto, N., Jovanović, M., Buggle, B., Machalett, B., Zöller, L., Glaser, B., Frechen, M., 2009. The middle and late Pleistocene loess-paleosol sequences at Batajanica, Vojvodina, Serbia. Quat. Int. 198, 255-266. 
Marković, S., Hambach, U., Stevens, T., Jovanović, M., O'Hara-Dhand, K., Basarin, B., Lu, H., Smalley, I., Buggle, B., Zech, M., Svirčev, Z., Sümegi, P., Milojković, N., Zöller, L., 2012a. Loess in the Vojvodina region (Northern Serbia): an essential link between European and Asian Pleistocene environments. Neth. J. Geosci. Geol. Mijnbouw 91, 173-188.

Marković, S.B., Hambach, U., Stevens, T., Basarin, B., O'Hara-Dhand, K., Gavrilov, M., Gavrilov, M., Smalley, I. \& Teofanov, N. 2012b. Relating the astronomical timescale to the loess-paleosol sequences in Vojvodina, Northern Serbia. In Climate Change: Inferences from Paleoclimate and Regional Aspects. Berger, A., Mesinger, F. \& Sijacki, D. (eds.). Vienna : Springer-Verlag, 65-78.

Marković, S.B., Korać, M., Mrđić, N., Buylaert, J-P., Thiel, C., McLaren, S.J., Stevens, T., Tomić, N., Petić, N., Jovanović, M., Vasiljević, D.A., Sümegi, P., Gavrilov, M.B., Obreht, I., 2014. Palaeoenvironment and geoconservation of mammoths from the Nosak loess-palaeosol sequence (Drmno, northeastern Serbia): Initial results and perspectives. Quat. Int. 334-335, 30-39.

Marković, S.B., Stevens, T., Kukla, G.J., Hambach, U., Fitzsimmons, K.E., Gibbard, P., Buggle, B., Zech, M., Guo, Z., Hao, Q., Wu, H., O'Hara-Dhand, K., Smalley, I.J., Újvári, G., Sumegi, P., Timar-Gabor, A., Veres, D., Sirocko, F., Vasiljević, D-.A., Jary, Z., Svensson, A., Jović, V., Lehmkuhl, F., Kovacs, J., Svircev, Z., 2015. Danube loess stratigraphy - towards a pan European loess stratigraphic model. Earth-Sci. Rev. 148, 228-258.

Marković, S.B., Fitzsimmons, K.E., Sprafke, T., Gavrilović, D., Smalley, I.J., Jović, V., Svirčev, Z., Gavrilov, M.B., Bešlin, M., 2016. The History of Danube Loess Research. Quat. Int. 399, 86-99. Mason, J.A., Jacobs, P.M., Hanson, P.R., Miao, X., Goble, R.J., 2003. Sources and paleoclimatic significance of Holocene Bignell Loess, central Great Plains, USA. Quat. Res. 60, 330-339.

Mason, J.A., Miao, X., Hanson, P.R., Johnson, W.C., Jacobs, P.M., Goble, R.J., 2008. Loess record of the Pleistocene-Holocene transition on the northern and central Great Plains, USA. Quat. Sci. Rev. $27,1772-1783$

Matsura, T., Furusawa, A., Yanagida, M., 2012. Detection and correlation of widespread cryptotephras in middle Pleistocene loess in NE Japan using cummingtonite geochemistry. J. Asian Earth Sci. 60, 49-67.

McGeehin, J.P., Burr, G.S., Jull, A.J.T., Reines, D., Gosse, J., Davis, P.T., Muhs, D., Southon, J.R., 2001. Stepped-combustion $14 \mathrm{C}$ dating of sediment: a comparison with established techniques. Radiocarbon 43, $255 \mathrm{e} 261$.

McManus, J.F., Bond, G.C., Broecker, W.S., Johnsen, S., Labeyrie, L., Higgins, S., 1994. High-resolution climate records from the North Atlantic during the last interglacial. Nature 371, 326-329.

Meszner, s. Kreutzer, S., Fuchs, M., Faust, D., 2014. Identifying depositional and pedogenetic controls of late Pleistocene loess-palaeosol sequences (Saxony, Germany) by combined grain size and microscopic analyses. Z .Geomorphol. 58 Suppl 3, 63-90.

Meyers, S.R., 2014. Astrochron: An R Package for Astrochronology Version 0.6.5.

Miao, X., Xulong, W., Mason, J.A., 2007. Isolation of the syndepositional magnetic susceptibility signals from loessic paleosols of China. J. Asi. E. Sci. 27, 684-690.

Moine, O., Rousseau, D.-D., Antoine, P., 2008. The impact of Dansgaard-Oeschger cycles on the loessic environment and malacofauna of Nussloch (Germany) during the upper Weichselian. Quat. Res. 70, 91-104. 
Mudelsee, M., 2003. Estimating Pearson's correlation coefficient with bootstrap confidence interval from serially dependent time series. Math. Geol. 35, 651-665.

Muhs, D.R., 2013. The geologic records of dust in the Quaternary. Aeolian Res. 9, 3-48.

Muhs, D.R., Bettis, E.A., Aleinikoff, J.N., McGeehin J.P., Beann, J., Skipp, G., Marshall, B.D., Roberts, H.M., Johnson, W.C., Reynolds, R.L., 2008. Origin and paleoclimatic signifi cance of late Quaternary loess in Nebraska: Evidence from stratigraphy, chronology, sedimentology, and geochemistry. GSA Bulletin 120 (11/12), 1378-1407.

Muhs, D.R., Bettis, E.A., Roberts, H.M., Harlan, S.S., Paces, J.B., Reynolds, R.L., 2013. Chronology and provenance of last-glacial (Peoria) loess in western lowa and paleoclimatic implications. Quat. Res. 80 (3), 468-481.

Murray, A.S., Schmidt, E.D., Stevens, T., Buylaert, J.-P., Marković, S.B., Tsukamoto, S., Frechen, M., 2014. Dating middle Pleistocene loess from Stari Slankamen (Vojvodina, Serbia) - limitations imposed by the saturation behaviour of an elevated temperature IRSL signal. Catena 117,34-42.

Nie, J., Stevens T., Rittner, M., Stockli, D., Garzanti, E., Limonta, M., Bird, A., Andò, S., Vermeesch, P., Saylor, J., Lu, H., Breecker, D., Hu, X., Liu, S., Resentini, A., Vezzoli, G., Peng, W., Carter, A., Ji, S., Pan, B., 2015. Loess Plateau storage of Northeastern Tibetan Plateau-derived Yellow River sediment. Nat. Commun. 6, 1-10.

North Greenland Ice Core Project members (2004), High-resolution record of Northern Hemisphere climate extending into the last interglacial period, Nature 431, 147-151.

Novothny, Á., Frechen, M., Horváth, E., Bradák, B., Oches, E.A., McCoy, W.D., Stevens, T., 2009. Luminescence and amino acid recemization chronology of the loess-palaeosol sequence at Sütto, Hungary. Quat. Int. 198/1-2, 62-76.

Obreht, I., Zeeden, C., Hambach, U., Veres, D., Marković, S.B., Bosken, J., Svirčev, Z., Bačević, N., Gavrilov, MB., Lehmkuhl, F., 2016.Tracing of mediterranean climate on Southeastern Europe during the past 350000 years Sci Rep 6, 36334.

Oches, E.A., McCoy, W.D., 1995a. Aminostratigraphic evaluation of conflicting age estimates for the "Young Loess" of Hungary. Quat. Res. 43, 160-170.

Oches, E.A., McCoy, W.D., 1995b. Amino acid geochronology applied to the correlation and dating of central European loess deposits. Quat. Sci. Rev. 14, 767-782.

Ogg, J.G., 2012. Chapter 5 - Geomagnetic Polarity Time Scale, in: Gradstein, F.M., Ogg, J.G., Schmitz, M.D., Ogg, G.M. (Eds.), The Geologic Time Scale. Elsevier, Boston, pp. 85-113.

Ólafsdóttir, K.B., Mudelsee, M., 2014. More accurate, calibrated bootstrap confidence intervals for estimating the correlation between two time series. Math. Geosci. 46, 411-427.

Olson, E.A., Broecker, W.S., 1958. Sample contamination and reliability of radiocarbon dates. In: Transactions of the New York Academy of Science Series II, 20, pp. 593-604.

Paillard, D., Labeyrie, L., Yiou, P., 1996. Macintosh program performs time-series analysis. Eos Transactions on AGU 77, 379.

Pearson, K., 1895. Contributions to the Mathematical Theory of Evolution. III. Regression, Heredity, and Panmixia. [Abstract]. Proc. R. Soc. Lond. 59, 69-71.

Pécsi M., 1990. Loess is not just the accumulation of dust. Quat. Int. 7-8, 1-21.

Penck, A., Brückner, E., 1909. Die Eiszeiten in den nördlichen Ostalpen. Tauchnitz, Leipzig. 
Penkman, K., Kaufman, D., 2012. Amino acid geochronology: Recent perspectives. Quat. Geochronol. $16,1-2$.

Pigati, J.S., Quade, J., Shanahan, T.M., Haynes Jr., C.V., 2004. Radiocarbon dating of minute gastropods and new constraints on the timing of spring-discharge deposits in southern Arizona, USA. Palaeogeogr., Palaeoclimatol., Palaeoecol. 204, 33-45.

Pigati, J.S., Rech, J.A., Nekola, J.C., 2010. Radiocarbon dating of small terrestrial gastropod shells in North America. Quat. Geochronol. 5, 519-532.

Pigati, J.S., McGeehin, J.P., Muhs, D.R., Bettis III, E.A., 2013. Radiocarbon dating late Quaternary loess deposits using small terrestrial gastropod shells. Quat. Sci. Rev. 76, 114-128.

Porter, S., 2001. Chinese loess record of monsoon climate during the last glacial-interglacial cycle. Earth-Sci. Rev. 54, 115-128.

Porter, S.C., An, Z., 1995. Correlation between climate events in the North Atlantic and China during the last glaciations. Nature 375. 305-308.

Pouclet, A., Horvath, E., Gabris, G., Juvigné, E., 1999. The Bag tephra, a widespread tephrochronological marker in Middle Europe: chemical and mineralogical investigations. Bulletin of Volcanology 60, 265-272.

Preece, S.J., Pearce, N.J.G., Westgate, J.A., Froese, D.G., Jensen, B.J.L., Perkins, W.T., 2011. Old Crow tephra across eastern Beringia: a single cataclysmic eruption at the close of Marine Isotope Stage 6. Quat. Sci. Rev. 30, 2069-2090.

Prins, M.A., Zheng, H., Beets, K., Troelstra, S., Bacon, P., Kamerling, I., Wester, W., Konert, M., Huang, X., Wang, X., Vandenberghe, J., 2009. Dust supply from river floodplains: the case of the lower Huang He (Yellow River) recorded in a loess-palaeosol sequence from the Mangshan Plateau. J. Quat. Sci. $24,75-84$

Prokopenko, A.A., Hinnov, L.A., Williams, D.F., Kuzmin, M.I., 2006. Orbital forcing of continental climate during the Pleistocene: a complete astronomically tuned climatic record from Lake Baikal, SE Siberia. Quat. Sci. Rev. 25, 3431-3457.

Pustovoytov, K., Terhorst, B., 2004. An isotopic study of a late Quaternary loessepaleosol sequence in SW Germany. Rev. Mex. Ciencias Geol. 21, 88-93.

Pye, K., 1987. Aeolian Dust and Dust Deposits. Academic Press London, p. 334.

Rech, J.A., Pigati, J.S., Lehmann, S.B., McGimpsey, C.N., Grimley, D.A., Nekola, J.C., 2011. Assessing open-system behavior of carbon-14 in terrestrial gastropod shells. Radiocarbon 53, 325-335

Rebollo, N.R., Cohen-Ofri, I., Popovitz-Biro, R., Bar-Yosef, O., Meignen, L., Goldberg, P., Weiner, S., Boaretto, E., 2008. Structural characterisation of charcoal exposed to high and low pH; implications for $14 \mathrm{C}$ sample preparation and charcoal preservation. Radiocarbon 50, 289-307.

Rebollo, N.R., Weiner, S., Brock, F., Meignen, L., Goldberg, P., Belfer-Cohen, A., BarYosef, O., Boaretto, E., 2011. New radiocarbon dating of the transition from the Middle to the upper Paleolithic in Kebara cave, Israel. J. Archaeol. Sci. 38, 2424-2433.

Reinders, J., Hambach, U., 1995. A geomagnetic event recorded in loess deposits of the Tönchesberg (Germany): identification of the Blake magnetic polarity episode. Geophys. J. Int. 122, 407-418. doi:10.1111/j.1365-246X.1995.tb07004.x 
Roberts, A. P., Tauxe, L., Heslop, D., 2013. Magnetic paleointensity stratigraphy and high-resolution Quaternary geochronology: successes and future challenges. Quaternary Science Reviews, 61, 1-16.

Roberts, H.M., 2008. The development and application of luminescence dating to loess deposits: a perspective on the past, present and future. Boreas 37, 483-507.

Roberts, H.M., 2012. Testing Post-IR IRSL protocols for minimising fading in feldspars, using Alaskan loess with independent chronological control. Radiation Measurements, 47, 716-724.

Roberts, H.M., Muhs, D.R., Wintle, A.G., Duller, G.A.T., Bettis, E.A., 2003. Unprecedented last-glacial mass accumulation rates determined by luminescence dating of loess from western Nebraska. Quat. Res. 59 (3), 411-419.

Rolf, C., Hambach, U., Novothny, Á., Horváth, E., Schnepp, E., 2014. Dating of a Last Glacial loess sequence by relative geomagnetic palaeointensity: A case study from the Middle Danube Basin (Süttő, Hungary). Quat. Int. 319, 99-108. doi:10.1016/j.quaint.2013.08.050

Rousseau, D.-D., Antoine, P., Hatté, C., Lang, A., Zöller, L., Fontugne, M., Ben Othman, D., Luck, J.-M., Moine, O., Labonne, M., Bentaleb, I., Jolly, D., 2002. Abrupt millennial climatic changes from Nussloch (Germany) Upper Weichselian eolian records during the Last Glaciation. Quat. Sci. Rev. 21, 1577-1582.

Rousseau, D.-D., Derbyshire, E., Antoine, P., Hatté, C., 2013. Loess Records | Europe. Reference Module in Earth Systems and Environmental Sciences, from Encyclopedia of Quaternary Science (Second Edition), 606-619.

Rousseau, D.D., Sima, A., Antoine, P., Hatte, C., Lang, A., Zöller, L., 2007. Link between European and North Atlantic abrupt climate changes over the last glaciation, Geophys. Res. Lett. 34, L22713.

Rubin, M., Likins, R.C., Berry, E.G., 1963. On the validity of radiocarbon dates from snail shells. J. Geol. 71, 84-89.

Ruhe, R.V., 1956. Relations of the properties of Wisconsin loess to topography in western lowa. Amer. J. Sci. 252, 663-672.

Ruhe, R.V., 1969. Quaternary Landscapes in lowa. lowa State University Press, Ames, lowa, 255pp.

Sauer, D., Kadereit, A., Kühn, P., Kösel, M., Miller, C. E., Shinonaga, T., Kreutzer, S., Hermann, L., Fleck, W., Starkovich, B.M. and Stahr, K., 2016. The loess-palaeosol sequence of Datthausen, SW Germany: characteristics, chronology, and implications for the use of the Lohne soil as a marker soil. Catena 146, 10-29.

Schirmer, W., 2012. Rhine Loess at Schwalbenberg II - MIS 4 and 3. Quat. Sci. J. (Eiszeitalter und Gegenwart) 61, 32-47.

Schirmer, W., 2016. Late Pleistocene loess of the Lower Rhine. Quat. Int. 411, 44-61.

Schirmer, W., Ikinger, A., Nehring, F., 2012. Die terrestrischen Böden im Profil Schwalbenberg/ Mittelrhein. Mainzer geowissenschaftliche Mitteilungen 40. 53-78.

Seelos, K., Sirocko, F., Dietrich, S., 2009. A continuous high-resolution dust record for the reconstruction of wind systems in central Europe (Eifel, Western Germany) over the past $133 \mathrm{ka}$. Geophys. Res. Lett. 36, DOI: 10.1029/2009GL039716

Shackleton, N.J., Hagelberg, T.K., Crowhurst, S.J., 1995. Evaluating the success of astronomical tuning: Pitfalls of using coherence as a criterion for assessing pre-Pleistocene timescales. Paleoceanography 10, 693-697. doi:10.1029/95PA01454 
Shackleton, N.J., Imbrie, J., 1990. The $\delta^{18} \mathrm{O}$ spectrum of oceanic deepwater over a 5-decade band. Climatic Change 16, 217-230.

Shimek, B., 1902. The loess of Natchez, Mississippi. American Geologist 30, 279-299.

Shimek, B., 1909. The loess of Crowley's Ridge, Arkansas. lowa Academy of Science Proceedings 16, 147-155.

Schmidt, E.D., Tsukamoto, S., Frechen, M., Murray, A.S., 2014. Elevated temperature IRSL dating of loess sections in the East Eifel region of Germany. Quaternary International, 334-335, 141-154.

Simonson, R.W., Hutton, C.E., 1954. Distribution curves for loess. American Journal of Science 252, 99-105.

Sirocko, F., Dietrich, S., Schaber, K., Seelos, K., Grootes, P.M., Kromer, B., Rein, B., Krbetschek, M., Appleby, P., Hambach, U., Rolf, C., Veres, D., Sudo, M., Grim, S., 2013. Multi-proxy-dating of Holocene maar lakes and Pleistocene dry maar sediments in the Eifel, Germany. Quat. Sci. Rev. 62, $56-76$.

Sirocko, F., Knapp, H., Dreher, F., Förster, M.W., Albert, J., Brunck, H., Veres, D., Dietrich, S., Zech, M., Hambach, U., Röhner, M., Rudert, S., Schwibus, K., Adams, C., Sigl, P., 2016. The ELSAVegetation-Stack: Reconstruction of Landscape Evolution Zones (LEZ) from laminated Eifel maar sediments of the last 60,000 years. Glo. Planet. Chan. 142, 108-135.

Sirocko, F., Seelos, K., Schaber, K., Rein, B., Dreher, F., Diehl, M., Lehne, R., Jäger, K., Krbetschek, M., Degering, D., 2005. A late Eemian aridity pulse in central Europe during the last glacial inception. Nature 436, 833-836.

Smalley, I.J., Marković, S.B., O'Hara-Dhand, K., 2010. The INQUA Loess Commission as a Central European Enterprise. Cent. Eur. J. Geosci. 2, 3-8.

Smalley, I.J., Marković, S.B., Svirčev, Z., 2011. Loess is almost totally formed by the accumulation of dust. Quat. Int. 240, 4-11.

Smalley, I.J., O'Hara-Dhand, K., Wint, J., Machalett, B., Jary, Z., Jefferson, I.J., 2009. Rivers and loess: the significance of long river transportation in the complex event-sequence approach to loess deposit formation. Quat. Int. 198, 7-18.

Soergel, W., 1924. The diluvial terraces of IIm and their importance for the subdividing the Ice Age, Jena, Germany.

Spearman, C., 1904. The Proof and Measurement of Association between Two Things. Am. J. Psychol. 15, 72-101. doi:10.2307/1412159

Sprafke, T., Obreht, I., 2016. Loess: Rock, sediment or soil - What is missing for its definition? Quat. Int. 399,198-207.

Steffensen, J.P., 1997. The size distribution of microparticles from selected segments of the Greenland Ice Core Project ice core representing different climatic periods. J. Geophys. Res 102, 26755-26763.

Stevens, T., Adameic, G., Bird, A.F., Lu, H., 2013a. An abrupt shift in dust source on the Chinese Loess Plateau revealed through high sampling resolution OSL dating. Quat. Sci. Rev. 82, 121-132.

Stevens, T., Armitage, S.J., Lu, H., Thomas, D.S.G. 2006. Sedimentation and diagenesis of Chinese loess: implications for the preservation of continuous, high-resolution climate records. Geology 34, 849-852. 
Stevens, T., Buylaert, J-P., Lu, H., Thiel, C., Murray, A., Frechen, M., Yi, S., Lin, Z., 2016. Mass accumulation rate and monsoon records from Xifeng, Chinese Loess Plateau, based on a luminescence age model. J. Quaternary Sci. 31, 391-405.

Stevens, T., Carter, A., Watson, T.P., Vermeesch, P., Andò, S., Bird, A.F., Lu, H., Garzant, E., Cottam, M.A., Sevastjanova, I., 2013b. Genetic linkage between the Yellow River, the Mu Us desert and the Chinese Loess Plateau. Quat. Sci. Rev. 78, 355-368.

Stevens, T., Lu, H., 2009. Optical dating as a tool for calculating sedimentation rates in Chinese loess: comparisons to grain-size records. Sedimentology 56, 911-934.

Stevens, T., Lu, H., Thomas, D.S.G., Armitage, S.J. 2008. Optical dating of abrupt shifts in the Late Pleistocene East Asian monsoon. Geology 36, 415-418.

Stevens, T., Buylaert, J.-P., Murray, A.S., 2009. Towards development of a broadly-applicable SAR TTOSL dating protocol for quartz. Rad. Meas. 44, 639-645.

Stevens, T., Marković, S.B., Zech, M., Hambach, U., Sümegi, P., 2011. Dust deposition and climate in the Carpathian Basin over an independently dated last glacial-interglacial cycle. Quat. Sci. Rev. 30, $662-681$.

Stevens, T., Thomas, D.S.G., Armitage, S.J., Lunn, H.R., Lu, H., 2007. Reinterpreting climate proxy records from late Quaternary Chinese loess: a detailed OSL investigation. Earth-Sci. Rev. 80, 111136.

Storey, M., Roberts, R.G., Saidin, M., 2012. Astronomically calibrated 40Ar/39Ar age for the Toba supereruption and global synchronization of late Quaternary records. Proceedings of the National Academy of Sciences of the USA 109, 18684-18688.

Sümegi, P., Krolopp, E., 2002. Quartermalacological analyses for modelling of the Upper Weichselian paleoenvironmental changes in the Carpathian basin. Quat. Int. 91, 53-63.

Sun, J., 2002. Provenance of loess material and formation of loess deposits on the Chinese Loess Plateau. Earth Planet. Sci. Lett. 203, 845-859.

Sun, Y., Clemens, S.C., An, Z., Yu, Z., 2006. Astronomical timescale and palaeoclimatic implication of stacked 3.6-Myr monsoon records from the Chinese Loess Plateau. Quat. Sci. Rev. 25, 33-48. doi:10.1016/j.quascirev.2005.07.005

Sun, Y.B., Clemens, S.C., Morrill, C., Lin, X., Wang, X., An, Z., 2012. Influence of Atlantic meridional overturning circulation on the East Asian winter monsoon. Nat. Geosci. 5, 50-54.

Sun, Y., Qiang, X., Liu, Q., Bloemendal, J., Wang, X., 2013. Timing and lock-in effect of the Laschamp geomagnetic excursion in Chinese Loess. Geochem. Geophys. Geosystems 14, 4952-4961.

Svensson, A., Andersen, K.K., Bigler, M., Clausen, H.B., Dahl-Jensen, D., Davies, S.M., Johnsen, S.J., Muscheler, R., Parrenin, F., Rasmussen, S.O., Röthlisberger, R., Seierstad, I., Steffensen, J.P., Vinther, B.M., 2008. A 60000 year Greenland stratigraphic ice core chronology. Clim. Past 4, 47-57.

Sweeney, M.R., Mason, J.A., 2013. Mechanisms of dust emission from Pleistocene loess deposits, Nebraska, USA. J. Geophys. Res. 118, 1460-1471.

Tamers, M.A., 1970. Validity of radiocarbon dates on terrestrial snail shells. Am. Antiq. 35, 94-100.

Thiel, C., Buylaert, J.P., Murray, A.S., Terhorst, B., Hofer, I., Tsukamoto, S., Frechen, M., 2011.

Luminescence dating of the Stratzing loess profile (Austria) - testing the potential of an elevated temperature post-IR IRSL protocol. Quat. Int. 234, 23-31. 
Thomsen, K.J., Murray, A.S., Jain, M., Botter-Jensen, L., 2008. Laboratory fading rates of various luminescence signals from feldspar-rich sediment extracts. Radiat. Meas. 32, 1474-1486.

Thorp, J., Smith, H.T.U., 1952. Pleistocene eolian deposits of the United States, Alaska, and parts of Canada. National Research Council Committee for the Study of Eolian Deposits, Geological Society of America, scale 1:2,500,000

Timar-Gabor, A., Vandenberghe, D.A.G., Vasiliniuc, S., Panaoitu, C.E., Panaiotu, C.G., Dimofte, D., Cosma, C., 2011. Optical dating of Romanian loess: A comparison between silt-sized and sand-sized quartz. Quaternary International 240, 62-70.

Timar-Gabor, A., Constantin, D., Marković, S.B., Jain, M., 2015. Extending the area of investigation of fine versus coarse quartz optical ages from the Lower Danube to the Carpathian Basin. Quaternary International 388, 168-176.

Timar-Gabor, A., Buylaert, J-P., Guralnik, B., Trandafir-Antohi, O., Constantin, D., Anechitei-Deacu, V., Jain , M., Murray, A.S. , Porat, N., Hao, Q., Wintle, A.G., 2017. On the importance of grain size in luminescence dating using quartz. Radiation Measurements, online published.

Tomlinson, E.L., Smith, V.C., Albert, P.G., Aydar, E., Civetta, L., Cioni, R., Çubukçu, E., Gertisser, R., Isaia, R., Menzies, M.A., Orsi, G., Rosi, M., Zanchetta, G., 2015. The major and trace element glass compositions of the productive Mediterranean volcanic sources: tools for correlating distal tephra layers in and around Europe. Quat. Sci. Rev. 118, 48-66.

Toms, P.S., King, M., Zárate, M.A., Kemp, R.A., Foit Jr., F.F., 2004. Geochemical characterization, correlation, and optical dating of tephra in alluvial sequences of central western Argentina. Quaternary Research 62, 60-75.

Trumbore, S.E., 2000. Radiocarbon geochronology. In: Noller, J.S., Sowers, J.M., Lettis, W.R. (Eds.), Quaternary Geochronology: Methods and Applications. American Geophysical Union, Washington, D.C, pp. 41-60.

Tzedakis, P.C., Hooghiemstra, H., Pälike, H., 2006. The last 1.35 million years at Tenaghi Philippon: revised chronostratigraphy and long term vegetation trends. Quat. Sci. Rev. 25, 3416-3430.

Újvári, G., Molnár. M., Páll-Gergely, B., 2016a. Charcoal and mollusc shell 14C-dating of the Dunaszekcső loess record, Hungary. Quat. Geochron. 35, 43-53.

Újvári, G., Kok, J.F., Varga, G., Kovács, J., 2016b. The physics of wind-blown loess: implications for grain size proxy interpretations in Quaternary palaeoclimate studies. Earth-Sci. Rev. 154, 247-278.

Újvári, G., Kovacs, J., Varga, G., Raucsik, B., Marković, S.B., 2010. Dust flux estimates for the Last Glacial Period in East Central Europe based on terrestrial records of loess deposits: a review. Quat. Sci. Rev. 29, 3157-3166.

Újvári, G., Molnar, D., Novothny, A., Pall-Gergely, B., Kovacs, J., Varhegyi, A., 2014. AMS 14C and OSL/IRSL dating of the Dunaszekcsö loess sequence (Hungary): chronology for 20 to 150 ka and implications for establishing reliable age-depth models for the last 40 ka. Quat. Sci. Rev. 106, 140154.

Valet, J.-P., Meynadier, L., Guyodo, Y., 2005. Geomagnetic dipole strength and reversal rate over the past two million years. Nature 435, 802-805.

Vandenberghe, J., 2002. The relation between climate and river processes, landforms and deposits during the Quaternary. Quat. Int. 91, 17-23. 
1504

1505

1506

1507

1508

1509

1510

1511

1512

1513

1514

1515

1516

1517

1518

1519

1520

1521

1522

1523

1524

1525

1526

1527

1528

1529

1530

1531

1532

1533

1534

1535

1536

1537

1538

1539

1540

1541

1542

1543

Vandenberghe, J., 2012. Multi-proxy analysis: a reflection on essence and potential pitfalls. Neth. J. Geosci. 91, 263-269.

Vandenberghe, J., An Z., Nugteren, G., Lu, H., Van Huissteden, J., 1997. New absolute time scale for the Quaternary climate in the Chinese loess region by grain-size analysis. Geology 25-1, 35-38

Vandenberghe, J., Marković, S., Jovanović, M., Hambach, U., 2014. Site-specific variability of loess and palaeosols (Ruma, Vojvodina, northern Serbia). Quat. Int. 334-335, 86-93.

Vandenberghe, J., Renssen, H., Van Huissteden, J., Nugteren, G., Konert, M., Lu, H., Dodonov, A., Buylaert, J.-P. 2006. Penetration of Atlantic westerly winds into Central and East Asia. Quat. Sci. Rev. $25,2380-2389$.

Vandenberghe, J., van der Plicht, J., 2016. The age of the Hengelo interstadial revisited. Quat. Geochronol. 32, 21-28.

Veres, D., Bazin, L., Landais, A., Toyé Mahamadou Kele, H., Lemieux-Dudon, B., Parrenin, F. , Martinerie, P. ,Blayo, E., Blunier, T., Capron, E.,Chappellaz, J., Rasmussen, S.O., Severi, M., Svensson, A., Vinther, B., Wolff, E.W., 2013. The Antarctic ice core chronology (AICC2012): an optimized multiparameter and multi-site dating approach for the last 120 thousand years. Clim. Past 9, 1733-1748.

Wacha, L., Frechen, M., 2011. The geochronology of the "Gorjanović loess section" in Vukovar, Croatia. Quat. Int. 240/1-2, 87-99.

Wacha, L., Rolf, C., Hambach, U., Frechen, M., Galović, L., Duchoslav, M., 2017. The Last Glacial aeolian record from the Island of Susak (Croatia) as seen from a high-resolution grain-size, rock and palaeo-magnetic analysis. Quaternary International

Wang, X.L., Wintle, A.G., Lu, Y.C., 2006. Thermally transferred luminescence in fine-grained quartz from Chinese loess: Basic observations. Radiation Measurements 41, 649-658.

Wild, E.M., Steier, P., Fischer, P., Höflmayer, F., 2013. 14C dating of humic acids from Bronze and Iron Age plant remains from the eastern Mediterranean. Radiocarbon 55, 599-607.

Wintle, A.G., 1973. Anomalous fading of thermo-luminescence in mineral samples. Nature, 245, pp. 143-144.

Wintle, A.G., 1981. Thermoluminescence dating of late Devensian loesses in Southern England. Nature, 289, pp. 479-480.

Vriend, M., Prins, M.A., Buylaert, J.P., Vandenberghe, J., Lu, H., 2011. Contrasting dust supply patterns across the north-western Chinese Loess Plateau during the last glacial-interglacial cycle. Quat. Int. 240, 167-180.

de Vries, H., Barendsen, G.W., 1954. Measurements of age by the carbon-14 technique. Nature 174, 1138-1141.

Wacha, L., Frechen, M., 2011. The geochronology of the Gorjanović loess section in Vukovar, Croatia. Quat. Int. 240, 87-99.

Wang, X.L., Wintle, A.G., Lu, Y.C., 2006. Thermally transferred luminescence in fine-grained quartz from Chinese loess: Basic observations. Radiat. Meas. 41, 649-658.

Wang, Y., Cheng, H., Edwards, R.L., Kong, X., Shao, X., Chen, S., Wu, J., Jiang, X., Wang, X., An, Z., 2008. Millennial- and orbital-scale changes in the East Asian monsoon over the past 224,000 years. Nature 451, 1090-1093, doi:10.1038/nature06692. 
Wood, R.E., Douka, K., Boscato, P., Haesaerts, P., Sinitsyn, A., Higham, T.F.G., 2012. Testing the $\mathrm{ABOx}-\mathrm{SC}$ method: dating known age charcoals associated with the Campanian Ignimbrite. Quat. Geochronol. 9, 16-26.

Wulf, S., Federovicz, S., Veres, D., Lanczont, M., Karatson, D., Gertisser, R., Bormann, M., Magyari, E.K., Appelt, O., Hambach, U.F., Gozhyk, P.F., 2016. The Roxolany Tephra (Ukraine) - new evidence for an origin from Ciomadul volcano, East Carpathians: origin of Roxolany tephra from Ciomadul, East Carpathians. J. Quat. Sci. 31, 565-576.

Yang, S., Ding Z., 2014. A 249 kyr stack of eight loess grain size records from northern China documenting millennial-scale climate variability. Geochem. Geophy. Geosy. 15, 798-814. doi:10.1002/2013GC005113.

Yates, T., 1986. Studies of non-marine mollusks for the selection of shell samples for radiocarbon dating. Radiocarbon 28, 457-463.

Zeeden, C., Hambach, U., Steguweit, L., Fülling, A., Anghelinu, M., Zöller, L., 2009. Using the relative intensity variation of the Earth's magnetic palaeofield as correlative dating technique: A case study from loess with Upper Palaeolithic cultural layers at Poiana Cireşului, Romania. Quartär 56, 175-185.

Zeeden, C., Hambach, U., Veres, D., Fitzsimmons, K., Obreht, I., Bösken, J., Schulte, P., Lehmkuhl, F., in press. Millennial scale climate oscillations recorded in the Lower Danube loess over the last glacial period. Palaeogeogr. Palaeoclimatol. Palaeoecol.

Zeeden, C., Kels, H., Hambach, U., Schulte, P., Protze, J., Eckmeier, E., Marković, S.B., Klasen, N., Lehmkuhl, F., 2016. Three climatic cycles recorded in a loess-palaeosol sequence at Semlac (Romania) - implications for dust accumulation in south-eastern Europe. Quat. Sci. Rev. 154, 130154. doi:10.1016/j.quascirev.2016.11.002

Zech, M., Kreutzer, S., Zech, R., Goszlar, T., Meszner, S., McIntyre, C., Häggi, C., Eglinton, T., Faust, D., Fuchs, M., 2017. Comparative $14 C$ and OSL dating of loess-paleosol sequences to evaluate postdepositional contamination of $n$-alkane biomarkers. Quaternary Research 87, 180-189.

Zeeden, C., Meyers, S.R., Lourens, L.J., Hilgen, F.J., 2015. Testing astronomically tuned age models. Paleoceanography 2014PA002762. doi:10.1002/2014PA002762

Zeuner, F.E., 1938. Die Chronologie des Pleistozäns. Académie Royale Serbe.

Zeuner, F.E., 1956. Loess and Palaeolithic chronology. Proceedings of the Prehistoric Society (New Series) 21, 51-64.

Zheng, H., Huang, X., Ji, J., Liu, R., Zeng. Q., Jiang, F., 2006. Ultra-high rates of loess sedimentation at Zhengzhou since Stage 7: implication for the Yellow River erosion of the Sanmen Gorge.

Geomorphology 85, 131-142.

Zhu, R., Liu, Q., Pan, Y., Deng, C., Zhang, R., Wang, X., 2006. No apparent lock-in depth of the Laschamp geomagnetic excursion: evidence from the Malan loess. Sci. China Ser. Earth Sci. 49, 960 967.

Zhu, R., Pan, Y., Liu, Q., 1999. Geomagnetic excursions recorded in Chinese Loess in the last 70,000 years. Geophys. Res. Lett. 26, 505-508. doi:10.1029/1999GL900019

Zhou, X., Li, X., Yang, S., Long, H., Yang, Q., Zhao, K., Cui, J. 2016. Past changes in the vegetation density of the Chinese Loess Plateau revealed by variations in the size of Artemisia pollen grains. Rev. Pal. Palynol. 235, 71-80. 
1585 Zöller, L., Oches, E.A., McCoy, W.D., 1994. Towards a revised chronostratigraphy of loess in Austria 1586 with respect to key sections in the Czech Republic and in Hungary. Quat. Sci. Rev. 13, 465-472.

1587 Zöller, L., Semmel, A., 2001. 175 years of loess research in Germany-long records and 1588 "unconformities". Earth-Sci. Rev. 54/1-3, 19-28.

1589

1590 
Figure 1 Loess and loess-like sediments distribution (Pécsi, 1990).

a. Loess sediments; b. Loess-ike sediments.

Figure 2 Loess deposition types.

1597

1598

1599

1600

1601

1602

1603

1604

1605

1606

1607

1608

1609

1610

1611

1612

1613

1614

1615

1616

1617

1618

1619

1620

1621

1622

1623

Figure 3 Time series of last-glacial loess mass accumulation rate (expressed on a logarithmic scale, in $\mathrm{g} / \mathrm{cm} 2 / \mathrm{ky}$ ) for the Tuxiangdao (Xining) and Huanxian (Loess Plateau) sections (from Vriend et al., 2011).Figure 4 Generalized comparison between loess-paleosol chronostratigraphy at three typical loess regions of the Northern hemisphere: Central Great Plain (Mason et al., 2003, 2008), the Middle Danube Basin (Stevens et al., 2008; Marković et al., 2014) and Central Chinese Loess Plateau (Dong et al., 2015) during the last 16 ky.

Figure 4 Generalized comparison between loess-paleosol chrono-stratigraphy at three typical loess regions of the Northern hemisphere: Central Great Plain (Mason et al., 2003, 2008), the Middle Danube Basin (Stevens et al., 2008; Marković et al., 2014) and Central Chinese Loess Plateau (Dong et al., 2015) during the last 16 ky.

Figure 5. Direct correlations between the Mošorin and Stari Slankamen synthetic (MSS) loess-palaeosol sequence and the Louchuan loess type section on the Central Chinese Loess Plateau (Hao et al., 2012). The uncertain stratigraphic interval in the transition between L2 and S2 units is indicated with "?" (Marković et al., 2015).

Figure 6 A) Map showing the distribution of loess deposits and locations of the main loess sections on Central Chinese Loess Plateau. LT, Lingtai; ZJC, Zhaojiachuan; PL, Pingliang; BJ, Baoji, LC, Luochuan, PX, Puxian; JB, Jingbian; JX, Jiaxian. Arrows connect the position of the sites with their records. B) Comparison of four astronomical timescales for the loesspaleosol sequences with the benthic $\delta^{18}$ O records from ODP sites 677/846 (Shackleton et al., 1990 and Shackleton et al., 1995). From top to bottom: A, LC MS record on the H2000 age model; B, LT MS record on the D2002 age model; C, LT MS record on the S2005 age model; D, ZJC MS record on the S2005 age model. Discrepancies among these age models are denoted as shaded bars (e.g., $S_{3}, S_{5-1}, L_{9}, S_{32}$, etc). Dashed lines indicated the positions of magnetic reversal boundaries recorded in Chinese loess and marine records (Sun et al., 2006, modified).

Figure 7 Comparison between MS records of the Batajnica and Mošorin sections in Serbia with map showing distance between these sections (Marković et al., 2015).

Figure 8 Millennial-scale events documented in the stacked grain size record of Chinese loess (CHILOMOS) for the last $249 \mathrm{kyr}$, and correlation with the stalagmite $\delta 180$ record (Wang et al., 2008; Cheng et al., 2012), the LR04 benthic $\delta 180$ stack (Lisiecki and Raymo, 2005), the EPICA Dome $C$ 
.

temperature anomaly in Antarctica (Jouzel et al., 2007), and the combined NGRIP $\delta 180$ record from Greenland (5-point smoothed) (North Greenland Ice Core Project members, 2004; Svensson et al., 2008). The Chinese Loess Interstadial (CLIS) events A1-A25 and B1-B24 are identified in the loess grain size records for the last and penultimate glacial-interglacial cycles, respectively. The shaded arrows indicate the long-term trend of the CHILOMOS and benthic $\delta 180$ records in each glacialinterglacial cycle.

Figure 9 Comparison between the grain-size variation in Nussloch and the atmospheric dust content over Greenland (Dansgaard et al., 1993; De Angelis et al., 1997; Fuhrer and Legrand, 1997; Steffensen, 1997) for the 31-19 kyr interval. The Nussloch time scale was calculated using the Analyseries software (Paillard et al., 1996). G1, G2, G3... - tundra gley horizons (according to Rousseau et al., 2022).

Figure 10 Linear sedimentation rate estimates for loess unit L1 and palaeosol unit S1 as recorded in the Mangshan section and a series of seven loess sections distributed across the Central Chinese Loess Plateau. Data of the LP sections are taken from Prins and Vriend (2007) and references cited therein (Prins et al. 2009).

Figure 11 Comparison of normalized relative paleointensity (RPI) data from the European loess sites Krems (Hambach et al., 2008), Süttö (Rolf et al., 2014), Susak (Wacha et al., submitted) and Poiana Ciresului (Zeeden et al., 2009) compared to the GLOPIS stack (Laj et al., 2004). In addition, the grey line represents the rough position of the Mono Lake geomagnetic excursion in these records. All records support the RPI dating independently.

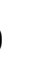
年

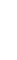




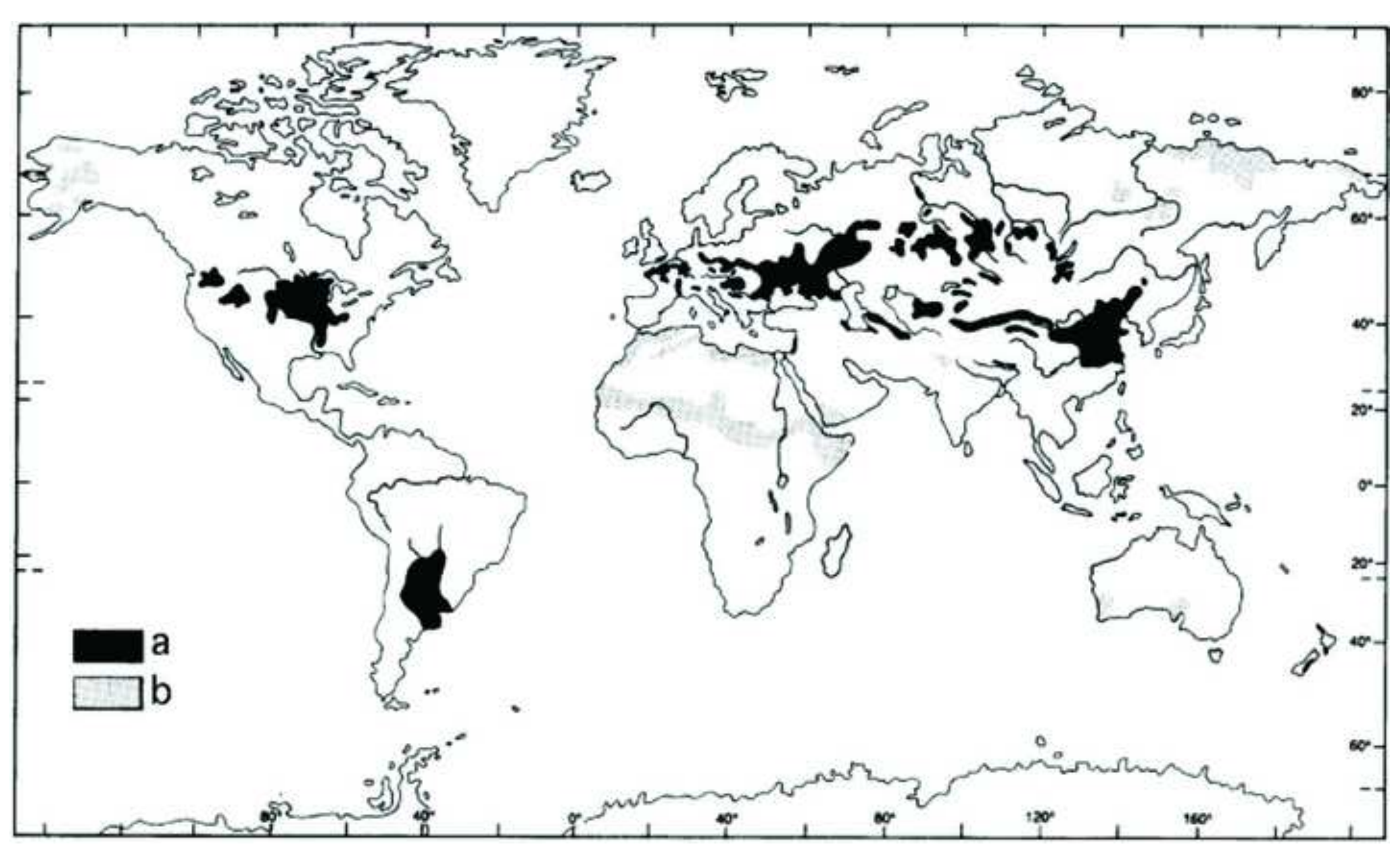


Click here to download high resolution image

suitable for long-term inter-profile correlation

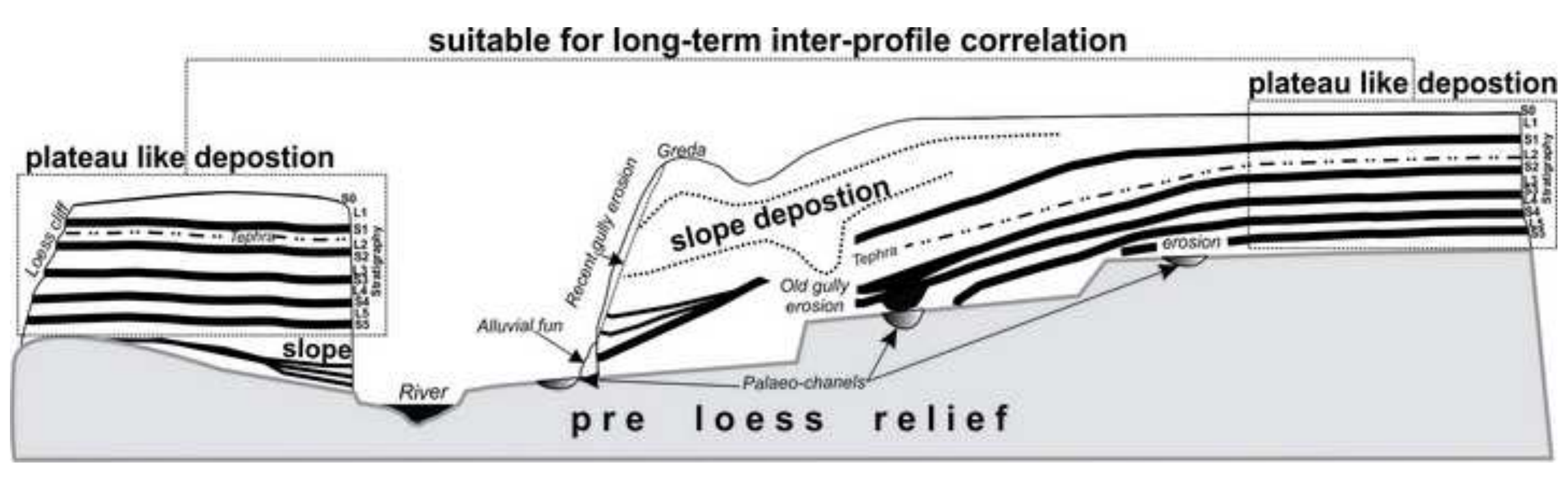


$\log$ MAR $\left(\mathrm{g} / \mathrm{cm}^{2} / \mathrm{kyr}\right)$

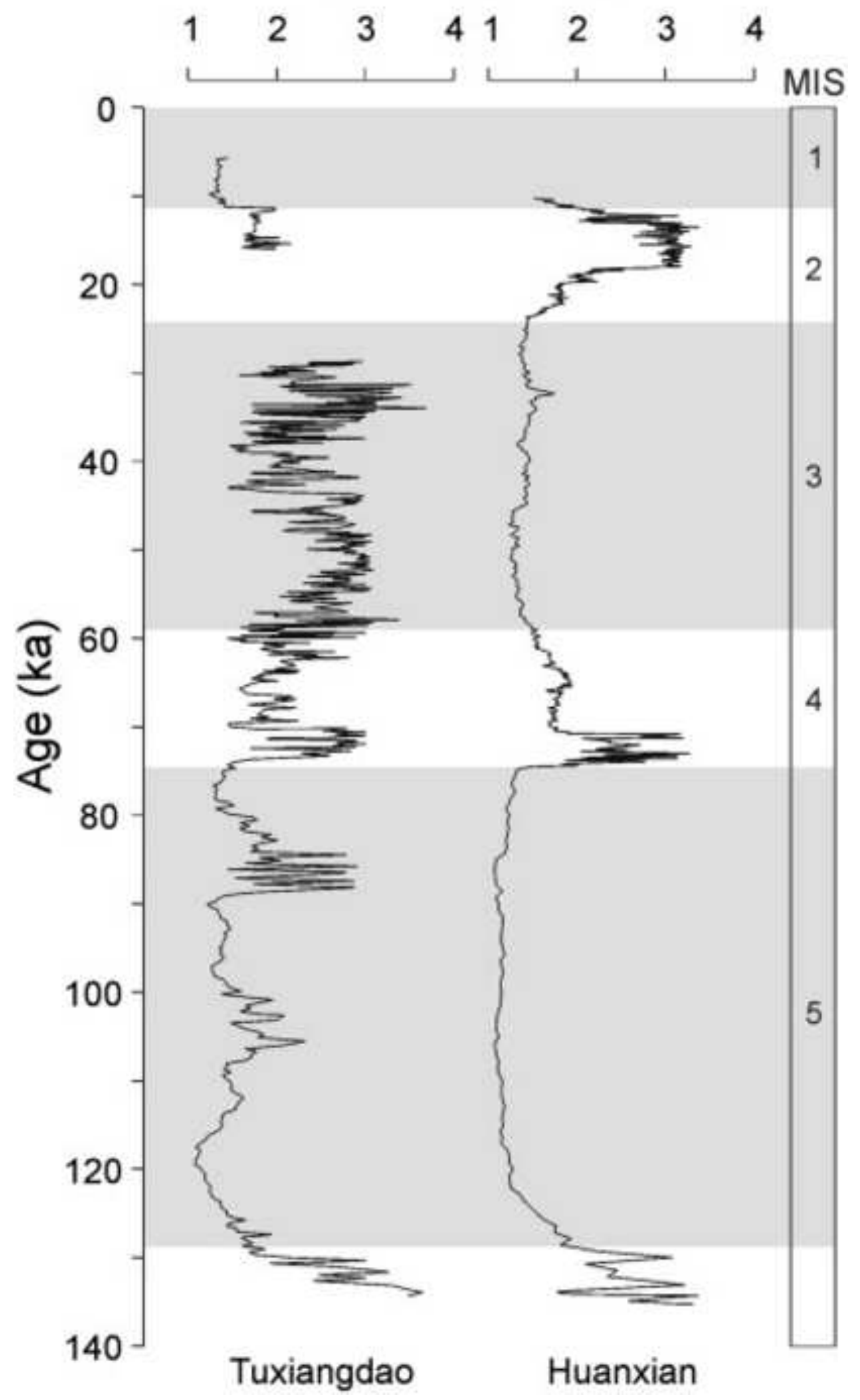


CGP

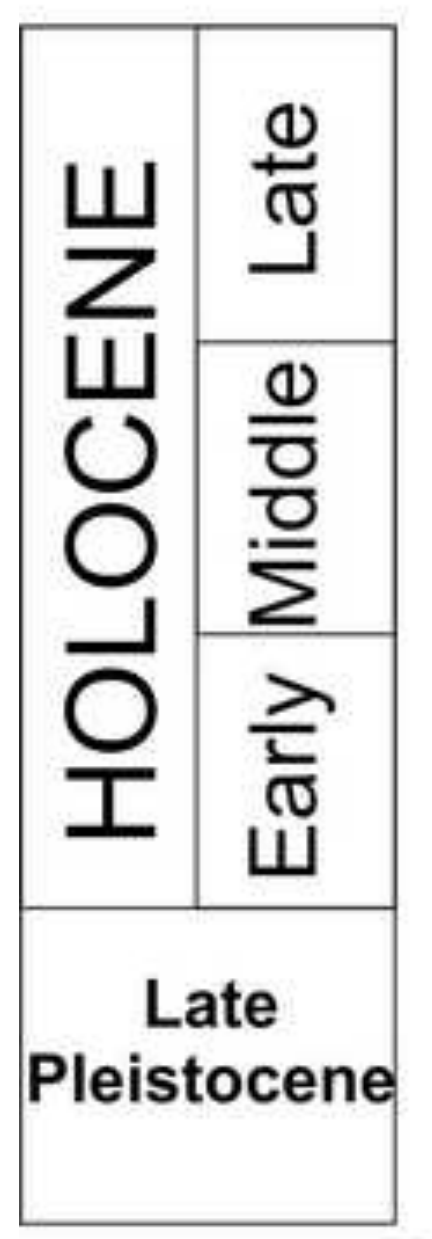

MDB

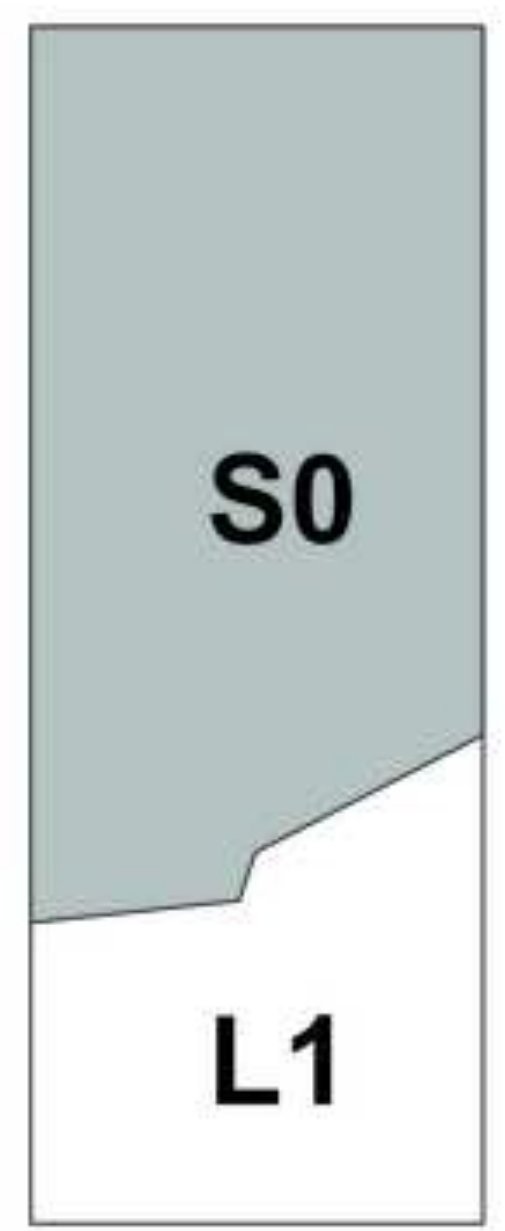

CCLP

?LO

So

L1

Time (ky)

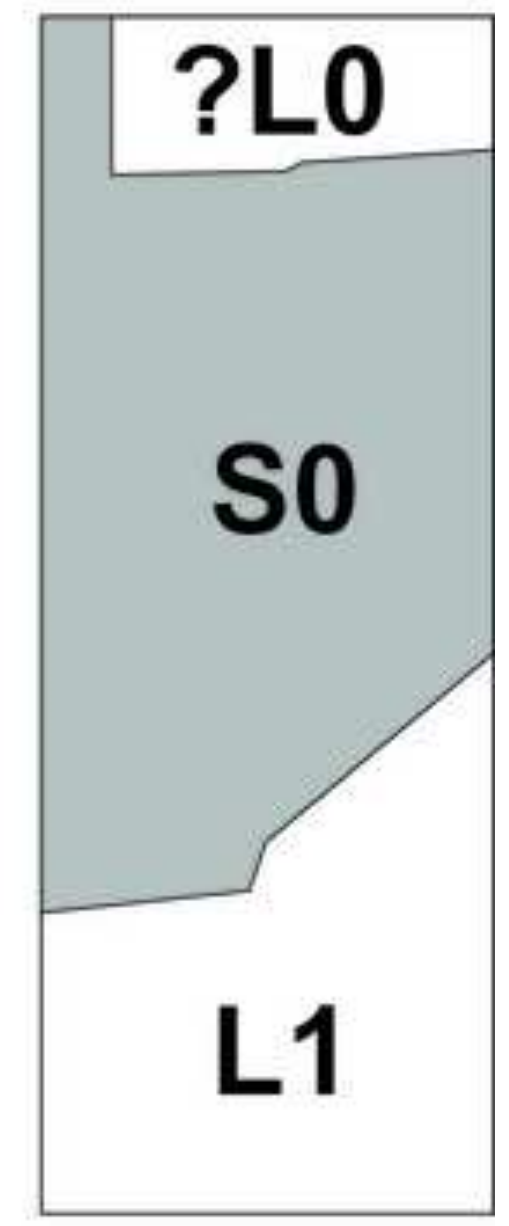


Click here to download high resolution image

$$
\begin{array}{cc}
\text { Mošorin/Stari Slankamen, Serbia } & \text { Luochuan, China } \\
x\left[10^{-1} \mathrm{~m}^{3} \mathrm{~kg}\right] & \mathrm{x}\left[10^{-1} \mathrm{~m}^{1} \mathrm{~kg}\right]
\end{array}
$$

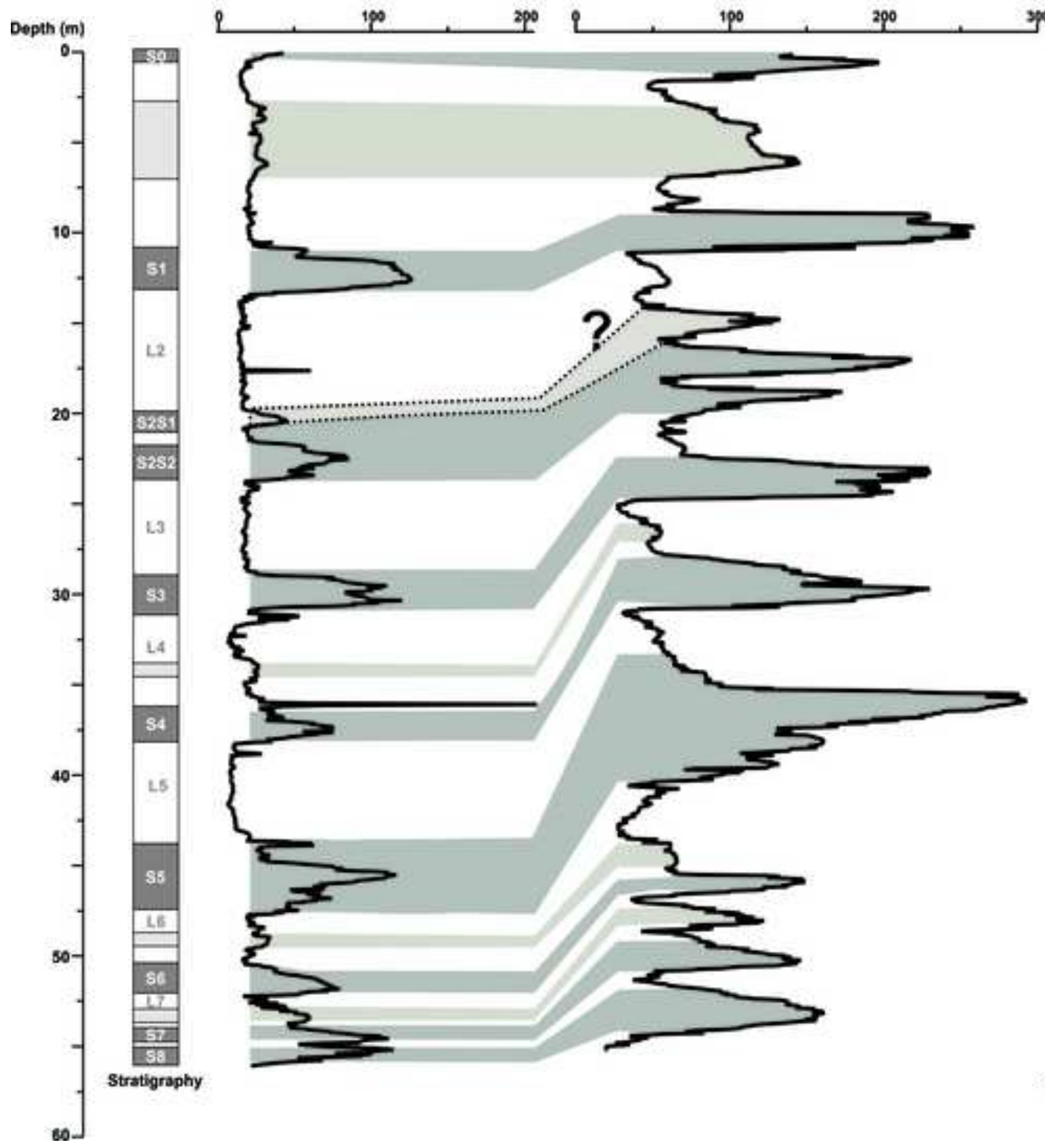




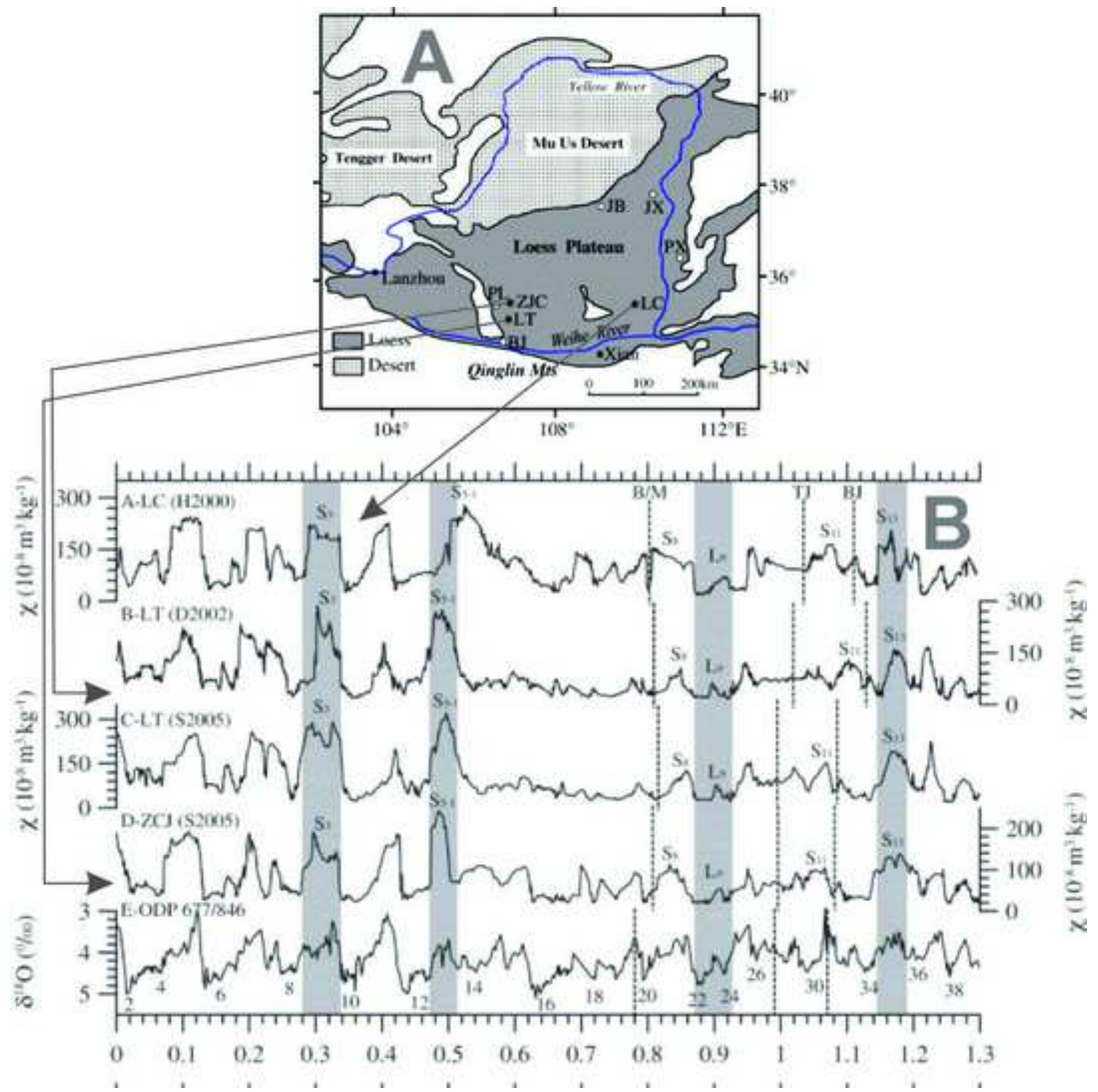




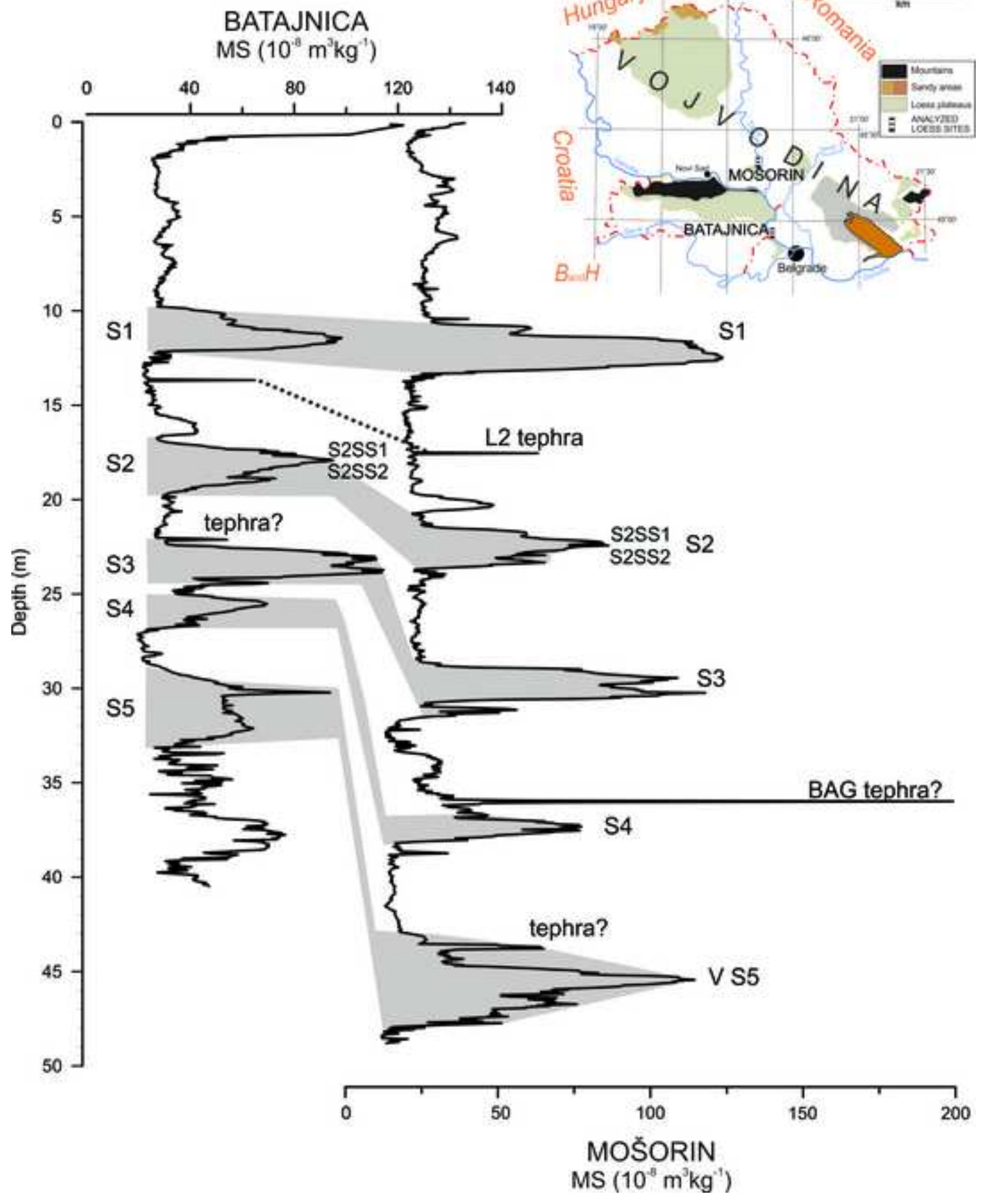




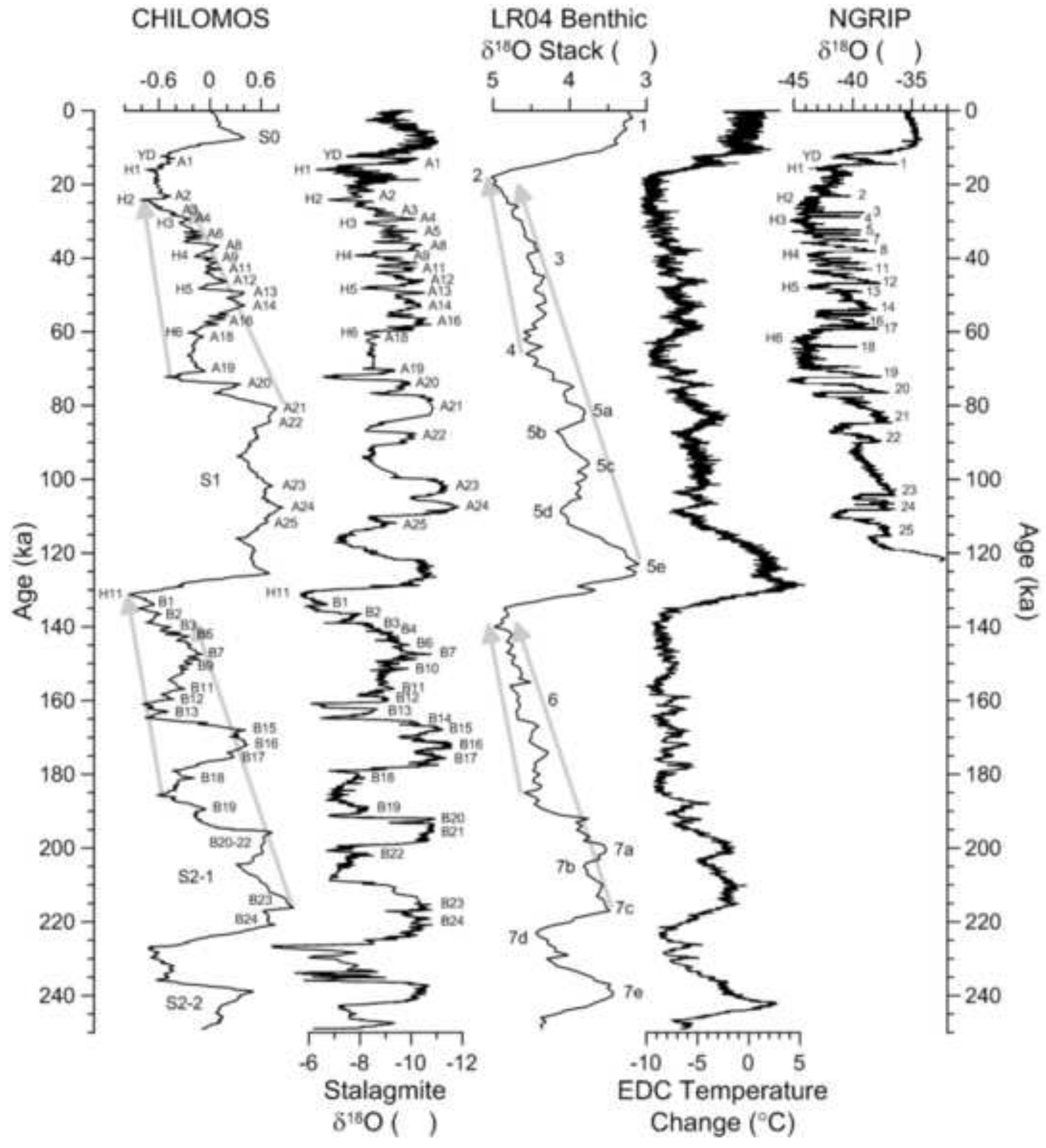


Click here to download high resolution image

\section{LOESS RECORD \\ GREENLAND ICE RECORD}

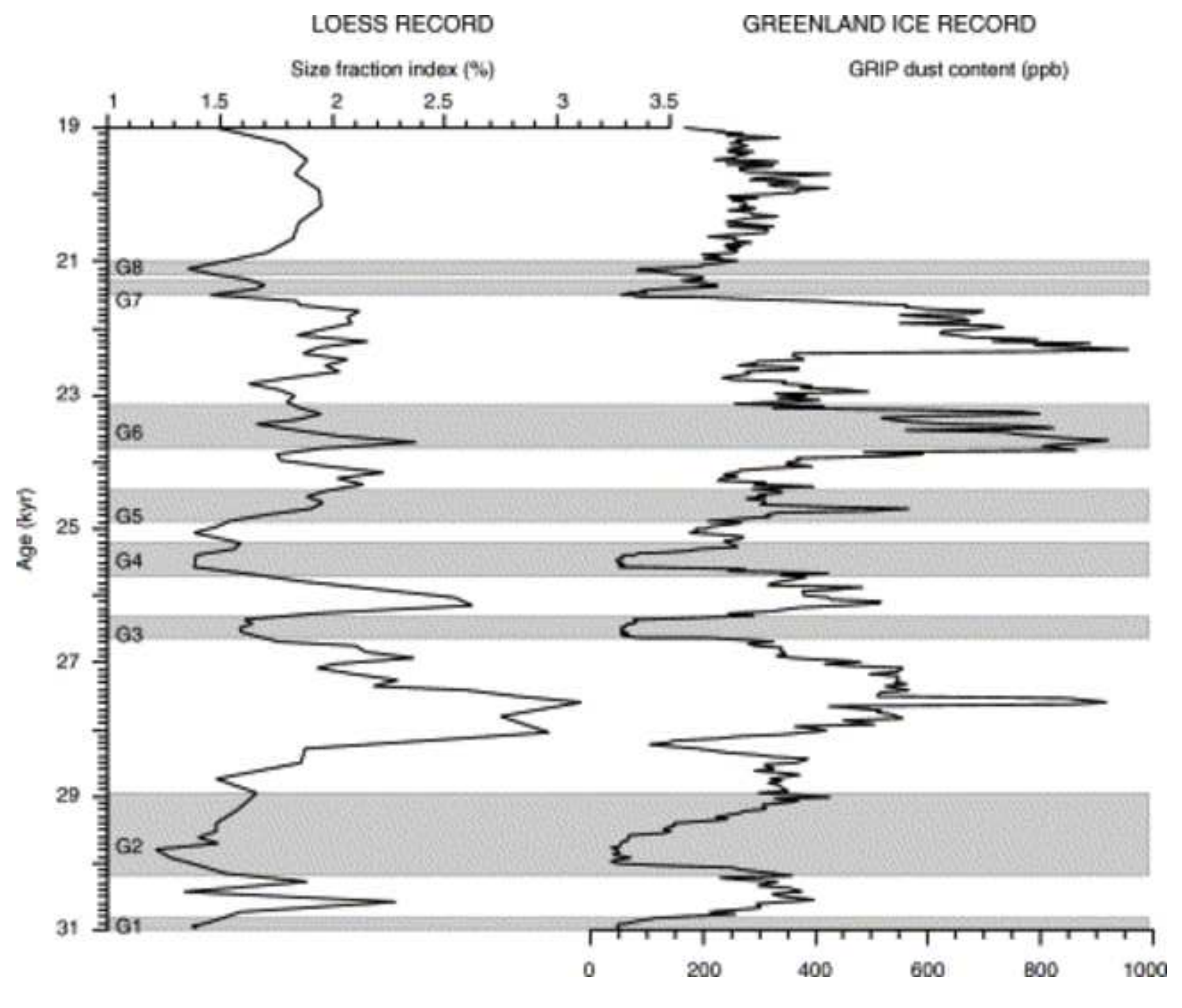

200 


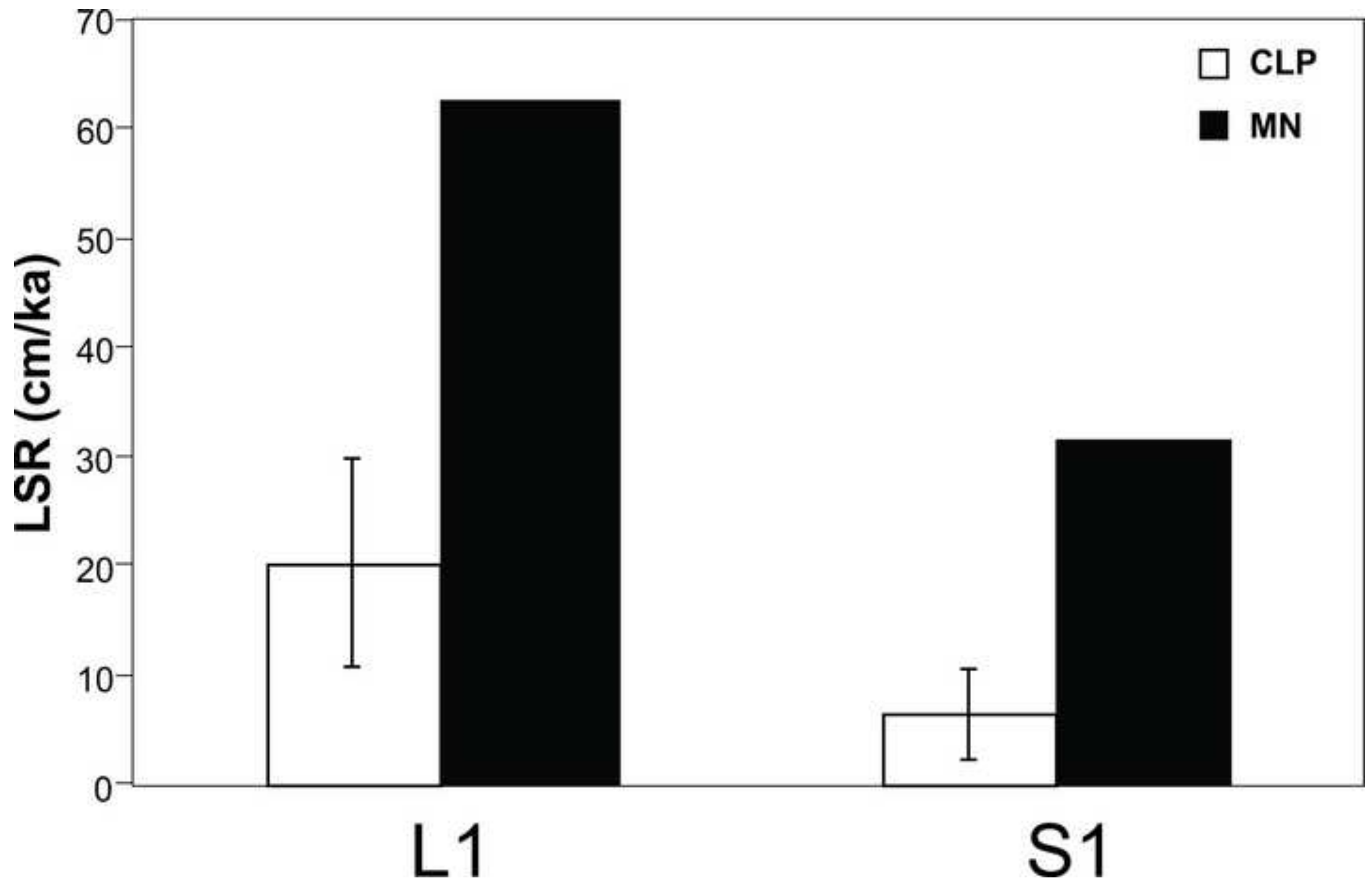




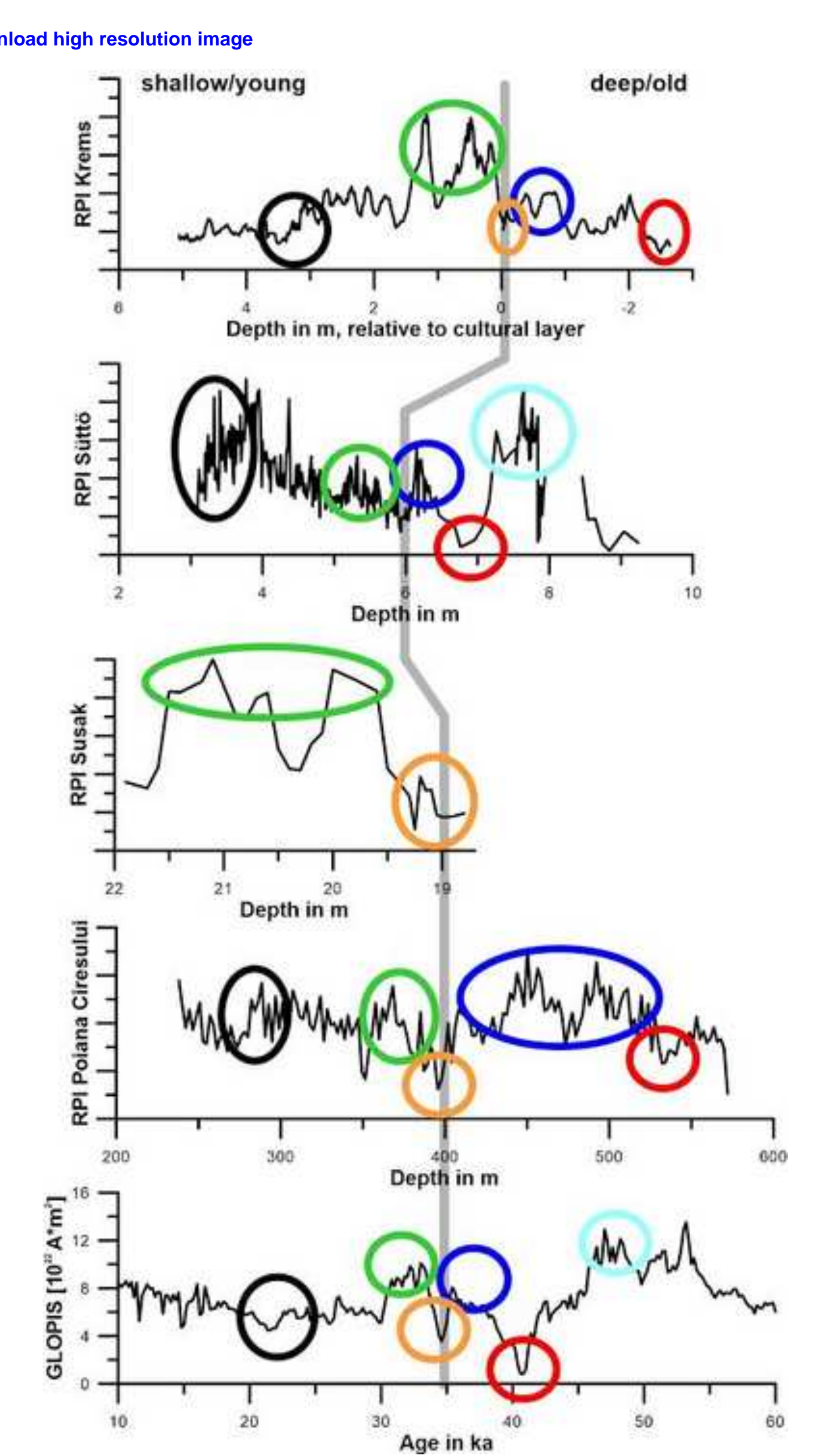

